José Eduardo Soubhia Natali

\title{
Investigação da influência de alterações associadas com a corrida no controle cardíaco
}

São Paulo

2015 

José Eduardo Soubhia Natali

\section{Investigação da influência de alterações associadas com a corrida no controle cardíaco \\ Evaluation of the influence of running in cardiac control}

Tese apresentada ao Instituto de Biociências da Universidade de São Paulo, para a obtenção de Título de Doutor em Ciências, na Área de Fisiologia.

Orientador: José Guilherme ChauíBerlinck

\section{São Paulo}

2015 
Natali, José E. S.

Investigação da influência de alterações associadas com a corrida no controle cardíaco

124 páginas

Tese (Doutorado) - Instituto de Biociências da Universidade de São Paulo. Departamento de Fisiologia.

1. Fisiologia do Exercício

2. Fisiologia Cardiovascular

3. Variabilidade Cardíaca

4. Complexidade Cardíaca

I. Universidade de São Paulo. Instituto de Biociências. Departamento de Fisiologia.

\section{Comissão Julgadora:}

Prof. Dr.

Nome
Prof. Dr.

Nome

Prof. Dr.

Nome 
Aos meus amigos 


\section{Epígrafe}

Would you kindly approve this?

Atlas 


\section{Agradecimentos}

Gostaria de agradecer a todas as pessoas que tornaram esse trabalho possível. Isso com certeza inclui você, que veio procurar seu nome nessa seção. Afinal, existe uma grande chance de já termos conversado sobre meu doutorado em algum momento ou, ainda, de você ter sido voluntário em algum dos meus experimentos. Em ambos os casos saiba que sua ajuda foi fundamental.

Caso você não faça parte desses grupos, agradeço ainda mais por se interessar em minhas produções acadêmicas. A curiosidade compartilhada é uma grande motivação para eu realizar esse tipo de estudo.

Se não tem o menor interesse nos trabalhos que produzo como um todo, mas está checando essa tese em uma biblioteca em algum momento do futuro (aproveitando, existe vida em Europa?), eu agradeço por fazer esse trabalho ainda ter relevância. Se você tiver interesse no assunto ou quiser discutir algum ponto com maior aprofundamento, não hesite em entrar em contato.

Em todos os casos, sugiro que você rompa o conforto da zona dos "agradecimentos"(ou do seu capítulo de interesse) e explore um pouco essa tese. Por exemplo, o Capítulo 3 tem uma discussão interessante sobre as minhas variáveis de interesse durante a corrida. Se você foi voluntário de algum dos meus experimentos, existe uma grande chance de seus dados estarem aqui. Se você gosta do lado aplicado da ciência, o Capítulo 4 é para você. Adicionalmente, o Capítulo 5 tem algumas figuras legais que podem atiçar sua curiosidade sobre o que acontece com os estimadores de controle cardíaco ao longo do tempo. Por outro lado, não quero criar falsas expectativas e afirmo sem peso na consciência que o Capítulo 2 só será interessante para quem utiliza a ApEn (e suas variações).

Para frustrar os que acharam que não haveria um único nome nessa seção, agradeço de maneira completamente desnecessária (afinal, uma frase nunca fará jus à importância deles) à Carol e ao ZéGui.

Finalmente, agradeço à CAPES e à FAPESP pelo apoio financeiro. 



\section{Resumo}

O estudo dos aspectos fisiológicos da corrida é importante não somente pela popularidade dessa atividade como também pelo seu papel na manutenção da saúde. Dessa maneira, é interessante identificar marcadores sensíveis aos efeitos agudos e crônicos desse exercício e capazes de, potencialmente, trazer informações sobre o estado fisiológico dos corredores. Nesse contexto, estimadores do controle cardíaco, como a variabilidade cardíaca (VC) e a complexidade cardíaca (CC) (cujos valores, quando baixos, estão associados à problemas de saúde), parecem ser particularmente importantes. No entanto, existem diversas controvérsias e lacunas no estudo da associação desses estimadores com a corrida. Para abordar esse problema, o presente estudo foi dividido em diversas etapas. Em um primeiro momento, foi necessário elaborar uma análise de complexidade cardíaca capaz de consistentemente caracterizar séries temporais. Dessa maneira, foi desenvolvida a a1ApEn, a qual é capaz de corrigir problemas identificados em outras análises não lineares; sendo robusta, consistente e com um tempo computacional adequado. Em seguida, investigou-se o efeito agudo da corrida na $\mathrm{VC}$ e na $\mathrm{CC}$ em 3 protocolos experimentais (velocidades constantes, crescentes e decrescentes). Foi possível observar que a VC e a CC se correlacionam positivamente com a frequência cardíaca (FC) e que essa relação é melhor observada no protocolo de velocidades crescentes. Nesse protocolo, foi observado, ainda, que uma correlação negativa entre a1ApEn-CC e FC está associada com sedentarismo. Essa correlação foi aprofundada sob a óptica do histórico de treinamento em maratonistas. Nesse contexto, foi possível concluir que a complexidade cardíaca obtida via a1ApEn é capaz de discernir maratonistas em função do tempo treinando para provas de longa duração. Finalmente, em experimentos realizados em velocidade constante, foi

observado um componente oscilatório nos resultados tanto de VC quanto de CC. Esse componente é mais proeminente em resultados de CC e está, potencialmente, associado 
com fatores termorregulatórios. Dessa maneira, as abordagens propostas foram capazes de não apenas trazer diversas informações novas sobre as alterações associadas com a corrida no controle cardíaco mas, também, introduzir metodologias com grande potencial em outros contextos.

Palavras Chave: Fisiologia do Exercício, Fisiologia Cardiovascular, Variabilidade Cardíaca, Complexidade Cardíaca. 


\begin{abstract}
A better understanding of the physiological aspects of running is important due to the increasing popularity of this activity and, also, for its role in maintaining health. Therefore, it is interesting to identify markers capable of detecting the acute and chronic effects of this exercise and, potentially, bring additional information about the physiological status of runners. In this context, heart rate control estimators, such as heart rate variability (HRV) and heart rate complexity (HRC) (both indexes, when low, are associated with health disorders), appears to be particularly important. Nevertheless, there are several controversies and missing information regarding the association between these estimators and running. To approach these issues, the present study was divided in four parts. First of all, it was necessary to create a HRC analysis capable of consistently characterizing time series. Thereunto, the a1ApEn was developed; a robust, consistent analytical tool with an adequate computational time that is capable of correcting problems that arose in other nonlinear analyses. Next, the acute effect of running in HRV and HRC was investigated utilizing three experimental protocols (constant, increasing and decreasing speeds). HRV and HRC are positively correlated with heart rate (HR), a relationship better observed in the protocol with increasing speeds. In this protocol, it was observed that a negative correlation between a1ApEn-HRC and HR is associated with sedentary. This correlation was further studied under the scope of the training background of marathoners. In this context, it was possible to conclude that the heart rate complexity, obtained through a1ApEn, is capable of discriminating marathoners in regard to the number of years training for long distance running. Finally, in experiments performed at constant speed, it was detected an oscillatory component in the HRV and HRC results. This component is more prominent in the HRC results and is, potentially, associated with termorregulatory factors. To conclude, the proposed approaches are capable of bringing
\end{abstract}


several new information to the study of the effects of running in heart rate control and, moreover, to introduce new methodologies of great potential in other contexts.

Keywords: Exercise Physiology, Cardiovascular Physiology, Heart Rate Variability, Heart Rate Complexity. 


\section{Sumário}

$\begin{array}{ll}\text { Lista de Figuras } & 5\end{array}$

$\begin{array}{lr}\text { Lista de Tabelas } & 6\end{array}$

1 Introdução $\quad 9$

1.1 A corrida . . . . . . . . . . . . . . . . . 9

1.2 Sistema Cardiovascular . . . . . . . . . . . . . . . . . . . . . . . 10

1.2.1 Função e Controle . . . . . . . . . . . . . . . . . . . . . 10

1.3 Controle Neural Cardíaco e a Variabilidade Cardíaca . . . . . . . . . . . . 12

1.3.1 Variabilidade entre Batimentos Cardíacos e sua Aplicação . . . . . 13

1.3.2 Análise da Variabilidade Cardíaca . . . . . . . . . . . . . . . . 14

1.3.3 Análise da Complexidade Cardíaca . . . . . . . . . . . . . 16

1.4 Variabilidade/Complexidade Cardíaca Durante o Exercício . . . . . . . . . 17

1.4.1 Variabilidade/Complexidade cardíaca e o histórico de treinamento 19

$\begin{array}{ll}\text { Referências Bibliográficas } & 22\end{array}$

2 Improvements in Approximate Entropy: area under the curve as a fast $\begin{array}{ll}\text { and robust tool to address temporal organization. } & 31\end{array}$

2.1 Introduction . . . . . . . . . . . . . . . . . . . . . . . . . 32

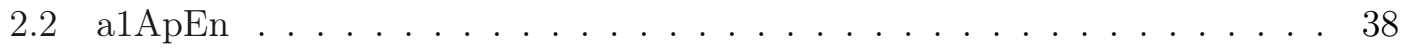


2.3 Analysis . . . . . . . . . . . . . . . . . . . . . . 4 41

2.4 Results . . . . . . . . . . . . . . . . . . . . . . . 42

2.4 .1 Positional sensitivity . . . . . . . . . . . . . . . . . . . 42

2.4 .2 pApEn inconsistencies . . . . . . . . . . . . . . . . . . 42

2.4 .3 Computational time . . . . . . . . . . . . . . . . 44

2.5 Discussion . . . . . . . . . . . . . . . . . . . . . . 45

$\begin{array}{ll}\text { Bibliography } & 46\end{array}$

3 Evaluation of Heart Rate Control Estimators in Running 48

3.1 Introduction . . . . . . . . . . . . . . . . . . . . . . . 49

3.2 Material and Methods . . . . . . . . . . . . . . . . . 53

3.2.1 Statistical Analysis . . . . . . . . . . . . . . . . . . 56

3.3 Results . . . . . . . . . . . . . . . . . . . 56

3.3.1 Exercise versus Rest . . . . . . . . . . . . . . . . 56

3.3.2 HRV and HRC as a Function of Speed and the Time of Exercise . 56

3.3.3 HRV and HRC as a Function of Heart Rate . . . . . . . . . . . . . 58

3.3.4 Relationship with Sedentary . . . . . . . . . . . . . . . 60

3.4 Discussion . . . . . . . . . . . . . . . . . . . . . 60

3.4.1 Exercise versus Rest . . . . . . . . . . . . . . . . . 60

3.4.2 Difference Between Protocols . . . . . . . . . . . . . . . . . 62

3.4.3 HRV $/ \mathrm{HRC}$ as a Function of Heart Rate . . . . . . . . . . . . . . 62

$3.4 .4 \mathrm{HRV} / \mathrm{HRC}$ in Running . . . . . . . . . . . . . . . . . . 63

3.4.5 Sedentary versus Trained . . . . . . . . . . . . . 65

3.5 Conclusion . . . . . . . . . . . . . . . . . . . . 66

$\begin{array}{ll}\text { Bibliography } & 67\end{array}$ 
4 Heart Rate Control in Amateur Marathoners with Different Training $\begin{array}{ll}\text { Backgrounds } & 73\end{array}$

4.1 Introduction . . . . . . . . . . . . . . . . . . . . 74

4.2 Material and Methods . . . . . . . . . . . . . . . . . . 78

$4.2 .1 \quad$ Statistical Analysis . . . . . . . . . . . . . . . . . . . 81

4.3 Results . . . . . . . . . . . . . . . . . . . . . . . 81

4.3.1 Differences between groups . . . . . . . . . . . . . . 81

4.3.2 HRV and HRC as a function of HR for the $1 \mathrm{M}$ group and the $3 \mathrm{M}$

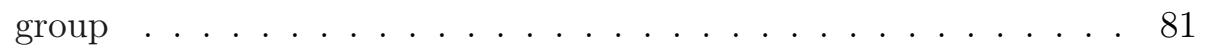

4.3.3 HRV and HRC as a function of HR for the $3 \mathrm{Y}$ group and the $10 \mathrm{Y}$

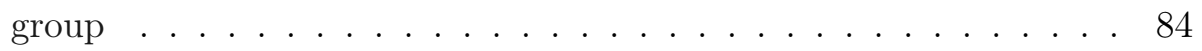

4.4 Discussion . . . . . . . . . . . . . . . . . . . . . . . 84

4.4.1 Differences between Groups . . . . . . . . . . . . . . . . 86

4.4.2 Estimators of heart rate control as a function of heart rate . . . . . 87

4.4.3 Metabolic coupling in relation to the number of completed marathons 88

4.4.4 Metabolic coupling in relation to the number years of training for endurance running . . . . . . . . . . . . . . . . . . . . . . . 89

4.5 Conclusions . . . . . . . . . . . . . . . . . . . . . . . 90 90

$\begin{array}{lr}\text { Bibliography } & 91\end{array}$

5 Oscillatory patterns in heart rate variability and complexity: a meta$\begin{array}{lr}\text { analysis } & 98\end{array}$

5.1 Introduction . . . . . . . . . . . . . . . . . . . . . . . . . . 99

5.2 Material and Methods . . . . . . . . . . . . . . . . . . . . 102

5.3 Results. . . . . . . . . . . . . . . . . . . . . . . . 104

5.3.1 Comparing the 3 models . . . . . . . . . . . . . . . . . . . . . 104

5.3.2 Sine wave fit for the three estimators . . . . . . . . . . . 106 
5.4 Discussion . . . . . . . . . . . . . . . . . . . . . . . . 109

Bibliography

6 Conclusões 116

$\begin{array}{ll}\text { A Area Apen, and pApEn for } 19 \text { time-series } & 118\end{array}$ 


\section{Lista de Figuras}

2.1 Sum of two sine waves and the corresponding moving ApEn . . . . . . . . 34

2.2 ApEn across different $r$ (tolerance) for four data-sets . . . . . . . . . . 36

2.3 Expected ApEn as a function of tolerance . . . . . . . . . . . . . . . . . 40

2.4 Comparison, with a detailed exception, of the variance of 19 data-sets with

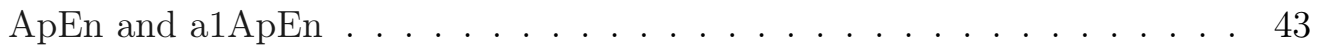

2.5 Computational time of ApEn, a1ApEn and vApEn for different vector sizes 45

3.1 Example of the methodological proceedings performed for one subject running in the protocol with increasing speeds . . . . . . . . . . . . 55

3.2 Heart rate and heart rate complexity in increasing speeds for one subject . 59

4.1 Heart rate and heart rate complexity for one subject . . . . . . . . . 83

4.2 Heart rate complexity for 11 marathoners . . . . . . . . . . . . . . . 85

5.1 Heart rate complexity and three models fitted . . . . . . . . . . . . 105

5.2 Adjusted $R^{2}$ for 3 models fitted to heart rate complexity data in 13 subjects 106

5.3 Example of a sine wave fit to heart rate variability and heart rate complexity data . . . . . . . . . . . . . . . . . . 107

5.4 Heart rate complexity and three models fitted for subject \#9 . . . . . . . 109 


\section{Lista de Tabelas}

2.1 Examples of the inconsistencies found with the use of pApEn . . . . . . 37

2.2 a1ApEn results for the time-series generated in machina . . . . . . . . . . 44

3.1 Slopes of linear regressions between heart rate complexity and heart rate variability as a function of time for the 3 speed regimes used in this study

3.2 Slopes of linear regressions between heart rate complexity and heart rate variability as a function of heart rate for the 3 speed regimes used in this study . . . . . . . . . . . . . . . . . . . . . 5 58

4.1 General information of the studied groups . . . . . . . . . . . . . . 79

4.2 Slopes of linear regressions of heart rate complexity or heart rate variability as a function of heart rate for the first marathon group and for the more than 3 marathons group of this study . . . . . . . . . . . . . . 82

4.3 Slopes of linear regressions of heart rate complexity or heart rate variability as a function of heart rate for the less than 3 years of training group and for the more than 10 years of training group of this study . . . . . . . 84

5.1 Parameters and approximate period of the sine waves fitted to a1ApEn results . . . . . . . . . . . . . . . . . . 108

A.1 pApEn $(m=1)$ for 19 time-series . . . . . . . . . . . . . 119 
A.2 pApEn $(m=2)$ for 19 time-series . . . . . . . . . . . . 120

A.3 pApEn $(m=3)$ for 19 time-series . . . . . . . . . . . . . . . 121

A.4 Area ApEn $(m=1)$ for 19 time-series . . . . . . . . . . . . 122

A.5 Area ApEn $(m=2)$ for 19 time-series . . . . . . . . . . . . . 123

A.6 Area ApEn $(m=3)$ for 19 time-series . . . . . . . . . . . . . . . 124 



\section{Capítulo 1}

\section{Introdução}

\subsection{A corrida}

A importância do estudo dos aspectos fisiológicos da corrida passa, em um primeiro momento, pela sua grande popularidade, a qual pode ser evidenciada pelo alto número de participantes em diversas competições ao redor do mundo. Tomando o exemplo extremo da maratona, provas como as de Berlim, Londres e Nova Iorque foram completadas por 28.999, 35.817 e 30.108 participantes, respectivamente, em 2015 (Berlin Marathon, 2015; Marathon Guide, 2015; New York City Marathon, 2011), números esses que só não são maiores por existir um limite máximo de inscritos. No Brasil, a Maratona Internacional de São Paulo reuniu, em 2015, cerca de 19.000 pessoas nas diferentes modalidades (maratona, 25 e 10 quilômetros e caminhada) (Maratona Internacional de São Paulo, 2015). Adicionalmente, é possível observar que a prática de corridas de rua está em franca ascensão já que, segundo os dados da Federação Paulista de Atletismo (2015), é possível constatar que o número de provas regulamentadas, somente no estado de São Paulo, subiu de 11 em 2001 para 361 em 2014, enquanto o número de participantes subiu de 146.022 em 2004 para 653.140 em 2015.

Essa forma de exercício merece uma atenção especial não só pela natureza competitiva 
mas, também, pela sua importância na evolução do gênero Homo. Isso é observável pois diversas características anatômicas e fisiológicas que surgiram nesse grupo (e estão presentes nos humanos atuais) beneficiam a prática de corridas de longa duração de forma mais marcante do que a caminhada (Bramble \& Lieberman, 2004).

A corrida possui, ainda, um papel importante no controle de massa corpórea, condicionamento físico e manutenção da saúde (McArdle et al., 1998). Estes fatores estão relacionados com o estudo dos aspectos fisiológicos do exercício, os quais, se melhores entendidos, podem levar não só a uma melhor compreensão dos sistemas envolvidos nessa atividade, como também a uma melhora na performance de praticantes.

Uma rápida análise pode identificar alterações em diversas variáveis fisiológicas, de diversos sistemas, associadas com a corrida. Porém, por uma questão de objetividade, o presente estudo focará na relação da corrida com estimadores do controle cardiovascular.

\subsection{Sistema Cardiovascular}

\subsubsection{Função e Controle}

A função do sistema cardiovascular é manter um ambiente apropriado nos diversos tecidos do corpo (Guyton \& Hall, 2006), sendo que sua importância está associada, principalmente, ao transporte de nutrientes e oxigênio para os tecidos ativos e à rápida remoção de certos produtos do metabolismo, como gás carbônico (McArdle et al., 1998).

Alterações no fluxo sanguíneo local são controladas de acordo com as necessidades (i.e., demanda) do tecido (Guyton \& Hall, 2006) e, no caso da corrida, essas alterações podem ser bem drásticas. Tomando o caso extremo do exercício na taxa metabólica máxima, $90 \%$ do fluxo sanguíneo é direcionado para o tecido muscular e $90 \%$ do consumo de $\mathrm{O}_{2}$ ocorre nos músculos locomotores (Weibel \& Hoppeler, 2005). Essas alterações, frente à alta demanda energética associada com a corrida, são moldadas por mudanças, agudas e crônicas, no sistema cardiovascular e pelo controle associado com essas mudanças. 
As alterações agudas estão associadas a mudanças na periferia do sistema vascular, como mudanças no diâmetro de vasos e a abertura de um maior número de capilares (McArdle et al., 1998), e no próprio coração. O aumento do fluxo para os tecidos locomotores também está associado a um aumento do débito cardíaco (DC), o qual é consequência de um aumento do volume sistólico e da frequência cardíaca (FC) (Guyton \& Hall, 2006). Finalmente, durante o exercício, ocorrem alterações no coração associadas com a mudança tanto no seu eixo mecânico, quanto na pressão transmural atrial relacionada à pressão intratorácica e ao retorno venoso (Casadei et al., 1996; Bernardi et al., 1990).

As alterações crônicas também resultam em uma melhor distribuição de recursos, trazendo melhorias aos processos agudos e, em última instância, à captação, transporte e utilização do oxigênio. Por exemplo, o treinamento aumenta tanto a massa do miocárdio quanto o volume sistólico, de forma que obtemos um aumento do DC (em relação a indivíduos não treinados) mesmo com FC menores (McArdle et al., 1998). É importante destacar que essas alterações na FC mostram que o treinamento é capaz de modificar o controle cardíaco. No entanto, sabendo que essa variável não é um marcador totalmente confiável do treinamento para corridas de longa duração (Lambert et al., 1998; Borresen \& Lambert, 2008), é interessante observar como outras medidas associadas com esse controle são afetadas pelo condicionamento físico.

Um adendo importante precisa ser feito em relação à frequência cardíaca. A limitação exposta acima não diminui a importância fisiológica dessa variável, uma vez que é clara a sintonia entre o controle cardíaco, frequência cardíaca e potência mecânica gerada. Temos, ao contrário, que é interessante observar a variação do controle cardíaco (nosso objeto de estudo) frente a alterações da FC, aqui propiciadas pela corrida (de maneira similar ao feito em Platisa \& Gal, 2006b,a).

Retornando às alterações crônicas, temos, ainda, outras mudanças que contribuem com o transporte de nutrientes como, por exemplo, o aumento do volume plasmático e 
um aumento do fluxo e da distribuição de sangue (McArdle et al., 1998).

Essas alterações, tanto agudas quanto crônicas, são mediadas por diferentes formas de controle, as quais podem ser divididas em mecanismos locais, hormonais e neurais (Rhoades \& Tanner, 2005). Os mecanismos locais estão associados com mudanças agudas no grau de constrição dos vasos sanguíneos em decorrência de estímulos químicos e físicos na microcirculação. Os controles hormonais, por sua vez, envolvem a ação de mensageiros químicos na regulação do sistema cardiovascular. Vale ressaltar que a secreção desses hormônios é estimulada por neurônios da via de controle neural, de forma que existe uma integração entre esses mecanismos de controle (Rhoades \& Tanner, 2005, ver adiante). Finalmente, temos o controle associado com o sistema nervoso autônomo (SNA) que age tanto no calibre dos vasos sanguíneos quanto no próprio coração (McArdle et al., 1998).

\subsection{Controle Neural Cardíaco e a Variabilidade Cardíaca}

A frequência das contrações do coração é gerada por um sistema especializado capaz de produzir e transmitir (conduzir) um impulso rítmico proporcionando a contração dos átrios e dos ventrículos (Guyton \& Hall, 2006). A ritmicidade do coração e sua força de contração são processos modulados pelas ações do sistema nervoso autônomo (Uusitalo et al., 2011). A ação do SNA parassimpático se dá pela liberação de acetilcolina, que reduz o ritmo sinusal e a excitabilidade de parte das fibras cardíacas (Task Force, 1996; Guyton \& Hall, 2006), com diminuição da frequência cardíaca e até, em casos extremos, o bloqueio atrioventricular (Guyton \& Hall, 2006). A ação do SNA simpático acarreta, através da liberação epinefrina e norepinefrina, um aumento das descargas do nodo sinusal e da excitabilidade de todas as porções do coração, além de um aumento na força de contração (Guyton \& Hall, 2006). Em condições de repouso, os efeitos parassimpáticos se sobressaem aos simpáticos (Task Force, 1996), ou seja, o nó sino atrial é mantido sob o efeito do SNA parassimpático. 
Dada a natureza dos sistemas simpático e parassimpático, é esperado que exista uma rápida modulação dos dois em resposta a mudanças das demandas ambientais (Thayer et al., 2010). Levando em conta o grande número dessas mudanças, padrões de variabilidade organizada (ou flexibilidade dinâmica) são preservados, ao invés de níveis estáticos (Thayer et al., 2010). A variabilidade decorrente desta interação, mensurada pela oscilação no intervalo entre batimentos cardíacos consecutivos (e.g., intervalos entre duas ondas R, chamados R-R, no eletrocardiograma) (Task Force, 1996), é tomada como uma medida indireta do controle cardíaco autonômico (Billman, 2009). A contrapartida da relação descrita acima é o desbalanço autonômico, que ocorre quando o SNA simpático passa a ser mais ativo que o parassimpático (Thayer et al., 2010; Billman, 2009), uma situação que acarreta um maior gasto energético (Thayer et al., 2010). Este desbalanço está associado a um enfraquecimento da flexibilidade dinâmica (uma diminuição da variabilidade) e, de maneira relacionada, da saúde (Thayer et al., 2010; Porges, 1992); e está associado com diversas doenças (Uusitalo et al., 2011; Task Force, 1996; Thayer et al., 2010).

Essa variabilidade é chamada de variabilidade cardíaca (VC) quando analisada por métodos no domínio do tempo e da frequência, e complexidade cardíaca (CC) quando estimada por via de ferramentas não lineares (ver abaixo).

\subsubsection{Variabilidade entre Batimentos Cardíacos e sua Aplicação}

Existem fortes evidências da conexão entre a redução da $\mathrm{VC} / \mathrm{CC}$ durante o repouso com morbidade/mortalidade. Um valor baixo de variabilidade cardíaca está associado com neuropatia diabética, transplante cardíaco, disfunção e infarto do miocárdio (Task Force, 1996). Adicionalmente, esse índice possui um papel importante na previsão de mortes súbitas por arritmia ventricular (Billman, 2009) e no pós infarto do miocárdio (Task Force, 1996). De maneira semelhante, um baixo valor de complexidade cardíaca está relacionado com fibrilação atrial paroxística (de maneira mais robusta do que utilizando 
métodos lineares, Shin et al., 2006), sepse neonatal (Lake et al., 2002), presença de endotoxinas (Rassias et al., 2005), mortalidade pós infarto do miocárdio (Stein et al., 2005), além de ser capaz de detectar mudanças no controle cardíaco promovida por fármacos (Kuusela et al., 2002).

É sugerido, também, que o desbalanço autonômico seja um fator anterior aos fatores de risco dessas doenças, de forma que tal desbalanço seria uma via final comum que ligaria eventuais desordens à morte e à doença (Thayer et al., 2010).

Em linhas gerais, a mensagem a ser passada é que a baixa $\mathrm{VC} / \mathrm{CC}$ resultante desse desbalanço autonômico é considerada um dos marcadores mais promissores para diagnóstico de problemas cardiovasculares (Billman, 2009).

\subsubsection{Análise da Variabilidade Cardíaca}

A variabilidade e a complexidade cardíaca são obtidas através da análise de séries temporais contendo todos períodos entre batimentos cardíacos normais consecutivos.

A variabilidade cardíaca pode ser estimada por métodos no domínio do tempo ou da frequência. Existem várias maneiras de extrair informações no domínio do tempo como, por exemplo, o desvio padrão do intervalo entre batimentos cardíacos (Task Force, 1996). No entanto, ao contrário dos estimadores que serão descritos a seguir, a informação obtida com essa metodologia está associada à dispersão dos dados e não à organização temporal do vetor de dados (é facilmente observável que o embaralhamento da série temporal altera a organização, ver abaixo, mas não a sua dispersão). Dessa maneira, o presente estudo (seguindo a tendência da literatura atual) não utilizará essa forma de análise.

A variabilidade cardíaca no domínio da frequência é estimada através da análise da densidade espectral de potência (DEP). A DEP fornece informação de como as potências se distribuem em função das diferentes frequências que compõem o sinal, sendo recomendada para o estudo de séries temporais curtas (i.e., $\cong 5$ minutos) (Task Force, 1996). 
A DEP pode ser obtida por diversos métodos (e.g. transformada rápida de Fourier TRF), sendo possível identificar, ao medir séries temporais curtas, 3 componentes (Task Force, 1996): um pico numa banda de alta frequência (HF, $0.15-0.4 H z)$; um pico numa banda de baixa frequência $(\mathrm{LF}, 0.04-0.15 \mathrm{~Hz}$ ) e um componente de frequência muito baixa $(\mathrm{VLF}, \leq 0.04 \mathrm{~Hz})$. Enquanto o componente HF estaria relacionado à atividade parassimpática, o componente LF estaria relacionado tanto à atividade simpática quanto à parassimpática (Task Force, 1996; Billman, 2009; Perini \& Veicsteinas, 2003; Aubert et al., 2003). Finalmente, a razão LF/HF é utilizada como um indicador do balanço autônomo (Task Force, 1996).

Apesar da capacidade de discriminar entre os dois ramos do controle autônomo ser considerada uma das vantagens dessa forma de análise (Aubert et al., 2003), a exata relação entre a atividade desses ramos e os componentes da DEP é alvo de controvérsia. Parte dessa discussão envolve a dubiedade do componente LF, que, por ser um marcador fraco da atividade simpática, mostra que a fisiologia por trás dessa abordagem pode ser ainda obscura (Houle \& Billman, 1999). Essa incerteza em relação ao papel da LF também afeta, dada a maneira como é calculada, a análise do balanço autônomo, outro conceito que se torna alvo de muitas críticas (Parati et al., 2006; Eckberg, 1997).

Essas críticas, e outras relacionadas a questões de nomenclatura e à confiabilidade dos estudos que usam DEP para analisar VC, estão presentes na revisão de Eckberg (1997), na qual o autor enfatiza a necessidade de um melhor entendimento dos aspectos fisiológicos associados essa forma de análise. Réplicas e tréplicas podem ser encontradas em Malik (1998). Pontos de vista opostos também são encontrados em Parati et al. (2006), com diversas respostas em Malliani (2006), mostrando a ausência de um consenso sobre o tópico.

Em linhas gerais, é possível reconhecer na relação entre VC e os dois componentes do SNA a origem das inconsistências descritas acima. Dessa maneira, é interessante procurar uma forma de análise capaz de extrair informações da DEP independentes 
dessa associação. Esse é o objetivo do Capítulo 5, onde um componente oscilatório de baixa frequência é identificado nos resultados tanto de VC como de CC (Figura 5.1), sendo mais proeminente no segundo (Figura 5.3). Sugere-se, em tal Capítulo, que esse padrão está associado a componentes termorregulatórios.

\subsubsection{Análise da Complexidade Cardíaca}

Ferramentas não-lineares (i.e., complexidade cardíaca) são consideradas promissoras no acesso às informações do controle cardíaco (Task Force, 1996), uma vez que fenômenos não lineares certamente estão envolvidos na gênese da variação entre batimentos do coração (Task Force, 1996; Jafarnia-Dabanloo et al., 2007). Uma comparação entre diversas ferramentas não lineares utilizadas no estudo da $\mathrm{CC}$ pode ser encontrada em Kuusela et al. (2002). Dentre as citadas podemos destacar métodos baseados na teoria da informação pelo seu uso mais frequente.

Segundo essa teoria, a quantidade de informação em uma mensagem está relacionada à incerteza de seu conteúdo (Shannon, 1948), sendo que a mensagem será mais informativa quanto menor for a probabilidade dela ser recebida. Essa visão pode ser adequada para análises de séries temporais considerando, ao invés da probabilidade de um novo sinal, a frequência dos símbolos (que podem ser entendidos como padrões) que a constituem. Em linhas gerais, essa é a estratégia utilizada pela $\mathrm{ApEn}^{1}$ para estimar a CC (e.g., Shin et al., 2006; Lake et al., 2002; Rassias et al., 2005; Stein et al., 2005).

Apesar de alcançar seus objetivos em diversas situações, a ApEn possui problemas de consistência (Santos et al., 2009) e esforços em melhorar essa ferramenta, como a SampEn (Richman \& Moorman, 2000), ApEn máxima (Lu et al., 2008) e vApEn (Santos et al., 2009), também possuem desvantagens (conf. Capítulo 2). Dessa maneira, para um melhor entendimento do efeito da corrida no controle cardíaco, é necessário um estimador

\footnotetext{
${ }^{1}$ ApEn (Approximate Entropy) é uma medida de complexidade desenvolvida por Pincus (1991) que compara padrões, de tamanho $m$, retirados do vetor de dados com a própria série temporal, dada uma tolerância $r$.
} 
da complexidade cardíaca consistente e que não apresente os problemas das ferramentas não lineares tipicamente utilizadas.

O presente estudo apresenta, no Capítulo 2, a a1ApEn (definida como a área sob a curva de ApEn versus a tolerância $r$, para $m=1$ ) como um estimador capaz corrigir as falhas descritas acima. No capítulo em questão, é possível observar que a a1ApEn apresenta uma consistência maior que as outras opções (conf. Tabela 2.1 e 2.2), com um tempo computacional adequado (Figura 2.5) permitindo, assim, sua ampla utilização. Dessa maneira, nos demais capítulos, o controle cardíaco foi estimado através da HF e razão $\mathrm{HF} / \mathrm{LF}$, para VC, e a1ApEn, para CC.

\subsection{Variabilidade/Complexidade Cardíaca Durante o Exer- cício}

Uma conhecida maneira de elevar o grau de controle cardíaco é o exercício físico habitual, o qual já se mostrou efetivo em aumentar a atividade do sistema parassimpático (Thayer et al., 2010; Task Force, 1996; Billman, 2009; Bernardi et al., 1996; De Meersman, 1993; Sacknoff et al., 1994; Jensen-Urstad et al., 1997), sendo, assim, um eficaz método para prevenção de doenças como fibrilação ventricular e disfunções do miocárdio (Billman, 2009).

Apesar dessa conexão ser bem estabelecida, ainda existem lacunas no seu melhor entendimento, uma vez que os experimentos que mediram a VC durante o exercício, realizados majoritariamente em bicicletas ergométricas, apresentaram resultados contraditórios. Se, por um lado, Casadei et al. (1995); Perini \& Veicsteinas (2003) observaram um aumento da VC com o tempo/intensidade de exercício, Tulppo et al. (1996); Brenner et al. (1997); Tulppo et al. (1998); Arai et al. (1989) observaram o padrão oposto.

Divergências semelhantes são encontradas nos poucos estudos relacionando CC com o exercício. Por exemplo, enquanto Lewis \& Short (2007) mostrou que a CC aumenta 
no começo do exercício e, em sequência, decresce gradativamente; Tulppo et al. (1996) obteve uma diminuição inicial de CC seguida por um aumento. Dada a semelhança entre os protocolos experimentais, é possível que essa diferença esteja relacionada aos problemas de consistência que as ferramentas analítica utilizadas (ApEn e SampEn) apresentam (conf. seção 1.3.3).

O panorama apresentado ilustra a inexistência de um consenso sobre o efeito do exercício tanto na variabilidade cardíaca quando na complexidade cardíaca. O motivo dessa inconsistência não é claro, porém é sugerido que a melhor compreensão da VC/CC é limitada pela grande diferença em protocolos experimentais (Aubert et al., 2003; Perini \& Veicsteinas, 2003; Sandercock \& Brodie, 2006; Task Force, 1996). Essa diversidade metodológica é observada, por exemplo, nos protocolos de velocidades utilizadas. Enquanto alguns estudos analisaram o controle cardíaco instantâneo em velocidades moderadas (caminhada ou 50\% de carga máxima - Dixon et al., 1992; Tulppo et al., 2001; Yoshino et al., 2004), outros utilizaram protocolos com velocidades crescentes (Arai et al., 1989; Lewis \& Short, 2007; Tulppo et al., 1996, 1998; Casadei et al., 1995; Boettger et al., 2010).

É importante ressaltar que esse último protocolo traz um problema adicional, uma vez que não é possível distinguir se eventuais alterações no controle cardíaco são provenientes da alteração da velocidade ou do tempo de experimento (representando cansaço). Dessa maneira, o melhor entendimento da $\mathrm{VC} / \mathrm{CC}$ passa por um protocolo bem definido e capaz de separar os diferentes componentes que afetam os estimadores.

O capítulo 3 aborda esses pontos para esclarecer o efeito da corrida nos estimadores de controle cardíaco. Para tanto, foi medida a complexidade cardíaca, estimada via a1ApEn, e a variabilidade cardíaca em 15 indivíduos correndo em esteiras nos seguintes protocolos: velocidade constante, velocidades crescentes e decrescentes. Foi possível observar, em todos os protocolos, e de maneira mais proeminente no de velocidades crescentes, a existência de uma correlação positiva e significativamente diferente de zero 
entre VC/CC e frequência cardíaca (Tabela 3.2). Discute-se que esse aumento de VC/CC estaria relacionado a uma reserva de componentes não neurais afetando a frequência cardíaca. Esse capítulo sugere, ainda, que a correlação entre CC e frequência cardíaca pode ser capaz de distinguir entre diferentes níveis de treinamento.

\subsubsection{Variabilidade/Complexidade cardíaca e o histórico de treina- mento}

A relação entre $\mathrm{VC} / \mathrm{CC}$ e a condição de treinamento, assim como o potencial uso das primeiras como marcadores da segunda, ainda precisam ser melhor estudadas (Borresen \& Lambert, 2008; Aubert et al., 2003). Isso ocorre pois, assim como exposto acima para o efeito agudo do exercício, a relação do controle cardíaco instantâneo com o histórico de treinamento é objeto de controvérsia. Essa falta de consenso pode ser observada mesmo em estudos que compararam as diferenças, teoricamente mais marcantes, entre indivíduos treinados e não treinados. Entre estudos nos quais os dados são adquiridos durante o repouso, de maneira longitudinal e transversal, diversos encontraram um aumento da modulação cardíaca com o treinamento (e.g., Rennie et al., 2003; Buchheit et al., 2004; Sloan et al., 2009; Schuit et al., 1999), enquanto outros não obtiveram diferenças significativas (e.g., Melo et al., 2005; Migliaro et al., 2001; Uusitalo et al., 2004; Loimaala et al., 2000).

Também existe uma falta de consenso em relação ao efeito do treinamento quando a VC ou a CC são obtidas durante o exercício, uma vez que também já foram observados tanto efeitos de aumento (Tulppo et al., 1998) quanto não significativos (Perini et al., 2002; Levy et al., 1998). Quando essa relação é expandida para a diferença no controle cardíaco instantâneo entre corredores com diferentes históricos de treinamento, existe uma completa escassez de estudos.

No contexto desses indivíduos, o estudo de maratonistas surge como alvo de alto interesse uma vez que a participação nessa prova, de grande popularidade, está associada 
com diversos problemas de saúde agudos e crônicos como: doenças cardíacas (Neilan et al., 2006; George et al., 2011; Sheppard, 2012), desordens gastrointestinais (Nicholl \& Willians, 1982; Sanchez et al., 2006), hiponatremia (Sheppard, 2012; Sanchez et al., 2006), além de lesões musculoesqueléticas (Sanchez et al., 2006; Satterthwaite et al., 1999; Nicholl \& Willians, 1982). Dessa maneira, e considerando a importância de adequar o treinamento de cada indivíduo com a sua fisiologia cardiovascular (Schmermund et al., 2008), é interessante observar se estimadores de controle cardíaco são capazes de discernir maratonistas com diferentes históricos de corridas de longa duração. Essa estratégia pode contribuir para a formulação de protocolos de treinamento mais precisos e, consequentemente, para a mitigação de problemas de saúde enfrentados por maratonistas.

Nesse cenário, a abordagem sugerida no Capítulo 3 parece ser capaz de trazer grandes contribuições. Nesse Capítulo, a correlação entre estimadores de controle cardíacos e frequência cardíaca (a qual chamaremos de acoplamento metabólico) é apontada como um fator capaz de discriminar entre indivíduos treinados e não treinados. É interessante observar que é sugerido que indivíduos não treinados possuam uma correlação negativa devido a uma incompatibilidade entre o controle cardíaco e a demanda metabólica e, dessa maneira, pode-se hipotetizar que essa incompatibilidade também seja observada em maratonistas que possuam um perfil de treinamento inadequado para um tal prova.

Esse problema é abordado no Capítulo 4 através do estudo do acoplamento metabólico como estimador do histórico de treinamento em maratonistas. Para tanto, considerou-se que um histórico de treinamento inadequado para a maratona estaria relacionado à falta de experiência nessa prova e/ou ao baixo número de anos de treinamento para provas de longa duração. Em um panorama mais específico, foi comparada a inclinação da regressão linear entre $\mathrm{VC} / \mathrm{CC}$ e frequência cardíaca entre seis indivíduos que realizaram sua primeira maratona e cinco praticantes com experiência nesse tipo de prova. Adicionalmente, os mesmo atletas foram divididos em dois grupos em relação ao tempo de treinamento para provas de longa duração (sete indivíduos com mais de dez anos e qua- 
tro indivíduos com menos de três anos). Os resultados obtidos indicam que a correlação VC/CC x FC não é capaz de discernir entre grupos com diferentes quantidades de maratonas completadas (Tabela 4.2), porém a correlação a1ApEn x FC é capaz de separar os sujeitos experimentais em relação a quantidade de anos de treinamento para provas de longa duração (Tabela 4.3). Esses resultados reafirmam o potencial da análise de acoplamento metabólico e, adicionalmente, sugerem a importância de realizar um treinamento prolongado antes da prática de uma maratona. 


\section{Referências Bibliográficas}

Arai, Y., Saul, J. P., Albrecht, P., Hartley, L. H., Lilly, L. S., Cohen, R. J., \& Colucci, W. S. (1989). Modulation of cardiac autonomic activity during and immediately after exercise. The American journal of physiology, 256(1 Pt 2):H132-H141.

Aubert, A. E., Seps, B., \& Beckers, F. (2003). Heart rate variability in athletes. Sports medicine (Auckland, N.Z.), 33(12):889-919.

Berlin Marathon (2015). Berlin Marathon. http://www.arrs.net/HP_BerMa.htm Acessado em 28/04/2015.

Bernardi, L., Salvucci, F., Suardi, R., Soldá, P. L., Calciati, A., Perlini, S., Falcone, C., \& Ricciardi, L. (1990). Evidence for an intrinsic mechanism regulating heart rate variability in the transplanted and the intact heart during submaximal dynamic exercise? Cardiovascular research, 24:969-981.

Bernardi, L., Valle, F., Coco, M., Calciati, A., \& Sleight, P. (1996). Physical activity influences heart rate variability and very-low-frequency components in Holter electrocardiograms. Cardiovascular Research, 32(2):234-237.

Billman, G. E. (2009). Cardiac autonomic neural remodeling and susceptibility to sudden cardiac death: effect of endurance exercise training. American journal of physiology. Heart and circulatory physiology, 297(4):H1171-H1193. 
Boettger, S., Puta, C., Yeragani, V. K., Donath, L., Müller, H. J., Gabriel, H. H. W., \& Bär, K. J. (2010). Heart rate variability, QT variability, and electrodermal activity during exercise. Medicine and Science in Sports and Exercise, 42(3):443-448.

Borresen, J. \& Lambert, M. I. (2008). Autonomic control of heart rate during and after exercise: Measurements and implications for monitoring training status. Sports Medicine, 38(8):633-646.

Bramble, D. M. \& Lieberman, D. E. (2004). Endurance running and the evolution of Homo. Nature, 432(7015):345-352.

Brenner, I. K., Thomas, S., \& Shephard, R. J. (1997). Spectral analysis of heart rate variability during heat exposure and repeated exercise. European journal of applied physiology and occupational physiology, 76(2):145-156.

Buchheit, M., Simon, C., Viola, A. U., Doutreleau, S., Piquard, F., \& Brandenberger, G. (2004). Heart Rate Variability in Sportive Elderly: Relationship with Daily Physical Activity. Medicine and Science in Sports and Exercise, 36(4):601-605.

Casadei, B., Cochrane, S., Johnston, J., Conway, J., \& Sleight, P. (1995). Pitfalls in the interpretation of spectral analysis of the heart rate variability during exercise in humans. Acta physiologica Scandinavica, 153(2):125-131.

Casadei, B., Moon, J., Johnston, J., Caiazza, A., \& Sleight, P. (1996). Is respiratory sinus arrhythmia a good index of cardiac vagal tone in exercise? Journal of applied physiology (Bethesda, Md. : 1985), 81:556-564.

De Meersman, R. E. (1993). Heart rate variability and aerobic fitness. American Heart Journal, 125(3):726-731.

Dixon, E. M., Kamath, M. V., McCartney, N., \& Fallen, E. L. (1992). Neural regulation 
of heart rate variability in endurance athletes and sedentary controls. Cardiovascular research, 26(7):713-719.

Eckberg, D. L. (1997). Sympathovagal balance: a critical appraisal. Circulation, 96(9):3224-32.

Federação Paulista de Atletismo (2015). Provas e organização evoluem significativamente. http://www.nosamamosatletismo.net/portals/4/netpress/NetPress_38_2011.html Acessado em 08/03/2012.

George, K., Spence, A., Naylor, L. H., Whyte, G. P., \& Green, D. J. (2011). Cardiac adaptation to acute and chronic participation in endurance sports. Heart (British Cardiac Society), 97(24):1999-2004.

Guyton, A. C. \& Hall, J. E. (2006). Textbook of Medical Physiology. Elsevier Saunders, Philadelphia, 11 edition.

Houle, M. S. \& Billman, G. E. (1999). Low-frequency component of the heart rate variability spectrum: a poor marker of sympathetic activity. The American journal of physiology, 276(1 Pt 2):H215-H223.

Jafarnia-Dabanloo, N., McLernon, D. C., Zhang, H., Ayatollahi, a., \& Johari-Majd, V. (2007). A modified Zeeman model for producing HRV signals and its application to ECG signal generation. Journal of Theoretical Biology, 244(2):180-189.

Jensen-Urstad, K., Saltin, B., Ericson, M., Storck, N., \& Jensen-Urstad, M. (1997). Pronounced resting bradycardia in male elite runners is associated with high heart rate variability. Scandinavian journal of medicine $\mathcal{E}$ science in sports, 7(5):274-278.

Kuusela, T. a., Jartti, T. T., Tahvanainen, K. U. O., \& Kaila, T. J. (2002). Nonlinear methods of biosignal analysis in assessing terbutaline-induced heart rate and blood 
pressure changes. American journal of physiology. Heart and circulatory physiology, 282(2):H773-H783.

Lake, D. E., Richman, J. S., Griffin, M. P., \& Moorman, J. R. (2002). Sample entropy analysis of neonatal heart rate variability. American journal of physiology. Regulatory, integrative and comparative physiology, 283(3):R789-R797.

Lambert, M. I., Mbambo, Z. H., \& Gibson, a. S. C. (1998). Heart rate during training and competition for longdistance running. Journal of Sports Sciences, 16(sup1):85-90.

Levy, W. C., Cerqueira, M. D., Harp, G. D., Johannessen, K.-A., Abrass, I. B., Schwartz, R. S., \& Stratton, J. R. (1998). Effect of endurance exercise training on heart rate variability at rest in healthy young and older men. The American Journal of Cardiology, 82(10):1236-1241.

Lewis, M. J. \& Short, a. L. (2007). Sample entropy of electrocardiographic RR and QT time-series data during rest and exercise. Physiological measurement, 28(6):731-744.

Loimaala, A., Huikuri, H., Oja, P., Pasanen, M., \& Vuori, I. (2000). Controlled 5mo aerobic training improves heart rate but not heart rate variability or baroreflex sensitivity. Journal of applied physiology (Bethesda, Md. : 1985), 89(5):1825-1829.

Lu, S., Chen, X., Kanters, J. r. K., Solomon, I. C., \& Chon, K. H. (2008). Automatic selection of the threshold value $\mathrm{r}$ for approximate entropy. IEEE Transactions on Biomedical Engineering, 55(8):1966-1972.

Malik, M. (1998). Sympathovagal balance: a critical appraisal. Circulation, 98(23):26432644.

Malliani, A. (2006). Cardiovascular variability is/is not an index of autonomic control of circulation. Journal of Applied Physiology, 101(2):690-691. 
Marathon Guide (2015). London Marathon - Race Results. http://www.marathonguide.com/results/browse.cfm?MIDD=16140413 Acessado em:28/04/2015.

Maratona Internacional de São Paulo (2015). Maratona Internacional de São Paulo Regulamento. http://www.yescom.com.br/maratonasp/2015/portugues/index.asp.

McArdle, W. D., Katch, F. I., \& VictorL Katch (1998). Fisiologia do exercício: energia, nutrição e desempenho humano. Editora Guanabara Koogan, Rio de Janeiro, 6 edition.

Melo, R., Santos, M., Silva, E., Quitério, R., Moreno, M., Reis, M., Verzola, I., Oliveira, L., Martins, L., Gallo-Junior, L., \& Catai, A. (2005). Effects of age and physical activity on the autonomic control of heart rate in healthy men. Brazilian Journal of Medical and Biological Research, 38(9):1331-8.

Migliaro, E., Contreras, P., Bech, S., Etxagibel, A., Castro, M., Ricca, R., \& Vicente, K. (2001). Relative influence of age, resting heart rate and sedentary life style in shortterm analysis of heart rate variability. Brazilian Journal of Medical and Biological Research, 34(4):493-500.

Neilan, T. G., Januzzi, J. L., Lee-Lewandrowski, E., Ton-Nu, T.-T., Yoerger, D. M., Jassal, D. S., Lewandrowski, K. B., Siegel, A. J., Marshall, J. E., Douglas, P. S., Lawlor, D., Picard, M. H., \& Wood, M. J. (2006). Myocardial injury and ventricular dysfunction related to training levels among nonelite participants in the Boston marathon. Circulation, 114(22):2325-33.

New York City Marathon (2011). NYC Marathon - Finisher Demographics. http://www.nycmarathon.org/Results.htm Acessado em 08/03/2012.

Nicholl, J. \& Willians, B. T. (1982). Medical problems before and after a popular marathon. British medical journal (Clinical research ed.), 285(6353):1465-1466. 
Parati, G., Mancia, G., Rienzo, M. D., Castiglioni, P., Taylor, J. a., Studinger, P., Di Rienzo, M., Malliani, A., Julien, C., Billman, G. E., Cerutti, S., Piepoli, M. F., Bernardi, L., Sleight, P., Cohen, M. a., Tan, C. O., Laude, D., Elstad, M., Toska, K., Evans, J. M., \& Eckberg, D. L. (2006). Cardiovascular variability is/is not an index of autonomic control of circulation. Journal of Applied Physiology, 101(2):690-691.

Perini, R., Fisher, N., Veicsteinas, A., \& Pendergast, D. R. (2002). Aerobic training and cardiovascular responses at rest and during exercise in older men and women. Medicine and science in sports and exercise, 34(4):700-708.

Perini, R. \& Veicsteinas, A. (2003). Heart rate variability and autonomic activity at rest and during exercise in various physiological conditions. European Journal of Applied Physiology, 90(3-4):317-325.

Pincus, S. M. (1991). Approximate entropy as a measure of system complexity. Proceedings of the National Academy of Sciences of the United States of America, 88(6):22972301.

Platisa, M. M. \& Gal, V. (2006a). Dependence of heart rate variability on heart period in disease and aging. Physiological measurement, 27(10):989-998.

Platisa, M. M. \& Gal, V. (2006b). Reflection of heart rate regulation on linear and nonlinear heart rate variability measures. Physiological measurement, 27(2):145-154.

Porges, S. W. (1992). Vagal tone: a physiologic marker of stress vulnerability. Pediatrics, 90(3 Pt 2):498-504.

Rassias, A. J., Holzberger, P. T., Givan, A. L., Fahrner, S. L., \& Yeager, M. P. (2005). Decreased physiologic variability as a generalized response to human endotoxemia. Critical care medicine, 33(3):512-519. 
Rennie, K. L., Hemingway, H., Kumari, M., Brunner, E., Malik, M., \& Marmot, M. (2003). Effects of moderate and vigorous physical activity on heart rate variability in a British study of civil servants. American Journal of Epidemiology, 158(2):135-143.

Rhoades, R. A. \& Tanner, G. A. (2005). Fisiologia Médica. Editora Guanabara Koogan, Rio de Janeiro, 2 edition.

Richman, J. S. \& Moorman, J. R. (2000). Physiological time-series analysis using approximate entropy and sample entropy. American journal of physiology. Heart and circulatory physiology, 278(6):H2039-H2049.

Sacknoff, D. M., Gleim, G. W., Stachenfeld, N., \& Coplan, N. L. (1994). Effect of athletic training on heart rate variability. American Heart Journal, 127(5):1275-1278.

Sanchez, L. D., Corwell, B., \& Berkoff, D. (2006). Medical problems of marathon runners. The American journal of emergency medicine, 24(5):608-15.

Sandercock, G. R. H. \& Brodie, D. a. (2006). The use of heart rate variability measures to assess autonomic control during exercise. Scandinavian Journal of Medicine and Science in Sports, 16(5):302-313.

Santos, B. T., Martins, R. a., Natali, J. E. S., Rodrigues, V. H., Marques, F. S., \& ChauíBerlinck, J. G. (2009). Consistency in approximate entropy given by a volumetric estimate. Chaos, Solitons and Fractals, 42(1):322-334.

Satterthwaite, P., Norton, R., Larmer, P., \& Robinson, E. (1999). Risk factors for injuries and other health problems sustained in a marathon. British journal of sports medicine, $33(1): 22-6$.

Schmermund, A., Voigtländer, T., \& Nowak, B. (2008). The risk of marathon runners-live it up, run fast, die young? European heart journal, 29(15):1800-2. 
Schuit, A. J., van Amelsvoort, L. G., Verheij, T. C., Rijneke, R. D., Maan, A. C., Swenne, C. A., \& Schouten, E. G. (1999). Exercise training and heart rate variability in older people. Medicine and science in sports and exercise, 31(6):816-821.

Shannon, C. (1948). A mathematical theory of communication. Bell System Technology Journal, 27:379:423, 623-656.

Sheppard, M. N. (2012). The fittest person in the morgue? Histopathology, 60(3):381-96.

Shin, D.-G., Yoo, C.-S., Yi, S.-H., Bae, J.-H., Kim, Y.-J., Park, J.-S., \& Hong, G.-R. (2006). Prediction of paroxysmal atrial fibrillation using nonlinear analysis of the R$\mathrm{R}$ interval dynamics before the spontaneous onset of atrial fibrillation. Circulation journal : official journal of the Japanese Circulation Society, 70(1):94-99.

Sloan, R. P., Shapiro, P. a., DeMeersman, R. E., Bagiella, E., Brondolo, E. N., McKinley, P. S., Slavov, I., Fang, Y., \& Myers, M. M. (2009). The Effect of Aerobic Training and Cardiac Autonomic Regulation in Young Adults. American Journal of Public Health, 99(5):921-928.

Stein, P. K., Domitrovich, P. P., Huikuri, H. V., \& Kleiger, R. E. (2005). Traditional and nonlinear heart rate variability are each independently associated with mortality after myocardial infarction. Journal of Cardiovascular Electrophysiology, 16(1):13-20.

Task Force of the European Society of Cardiology and the North American Society of Pacing and Electrophysiology (Task Force) (1996). Heart rate variability: standards of measurement, physiological interpretation and clinical use. Task Force of the European Society of Cardiology and the North American Society of Pacing and Electrophysiology. Circulation, 93(5):1043-1065.

Thayer, J. F., Yamamoto, S. S., \& Brosschot, J. F. (2010). The relationship of autonomic imbalance, heart rate variability and cardiovascular disease risk factors. International Journal of Cardiology, 141(2):122-131. 
Tulppo, M. P., Hughson, R. L., Mäkikallio, T. H., Airaksinen, K. E., Seppänen, T., \& Huikuri, H. V. (2001). Effects of exercise and passive head-up tilt on fractal and complexity properties of heart rate dynamics. American journal of physiology. Heart and circulatory physiology, 280(3):H1081-H1087.

Tulppo, M. P., Mäkikallio, T. H., Seppänen, T., Laukkanen, R. T., \& Huikuri, H. V. (1998). Vagal modulation of heart rate during exercise: effects of age and physical fitness. The American journal of physiology, 274(2 Pt 2):H424-H429.

Tulppo, M. P., Mäkikallio, T. H., Takala, T. E., Seppänen, T., \& Huikuri, H. V. (1996). Quantitative beat-to-beat analysis of heart rate dynamics during exercise. The American journal of physiology, 271(1 Pt 2):H244-H252.

Uusitalo, A., Mets, T., Martinmäki, K., Mauno, S., Kinnunen, U., \& Rusko, H. (2011). Heart rate variability related to effort at work. Applied Ergonomics, 42(6):830-838.

Uusitalo, A. L. T., Laitinen, T., Väisänen, S. B., Länsimies, E., \& Rauramaa, R. (2004). Physical training and heart rate and blood pressure variability: a 5-yr randomized trial. American journal of physiology. Heart and circulatory physiology, 286(5):H1821H1826.

Weibel, E. R. \& Hoppeler, H. (2005). Exercise-induced maximal metabolic rate scales with muscle aerobic capacity. The Journal of experimental biology, 208(Pt 9):16351644.

Yoshino, K., Motoshige, T., Araki, T., \& Matsuoka, K. (2004). Effect of prolonged free-walking fatigue on gait and physiological rhythm. Journal of Biomechanics, 37(8):1271-1280. 


\title{
Chapter 2
}

\section{Improvements in Approximate}

\section{Entropy: area under the curve as a} fast and robust tool to address

\section{temporal organization.}

\begin{abstract}
Approximate Entropy (ApEn) and Sample Approximate Entropy (SampEn) are widely employed tools to characterize temporal organization in time-series. These tools rely on two arbitrary choices of parameters: the window size of comparison, $m$, and the tolerance for distinguishing two vectors, $r$. The arbitrary choice of the parameters is a huge drawback in these tools since two very distinctive series may be classified differently depending on the choice of the parameters. There are two attempts to overcome such a drawback. One, pApEn, is based on the peak value of ApEn for a given $m$. The other, vApEn, is based on a double summation of ApEn values along all suitable $m$
\end{abstract}


Chapter 2. Improvements in Approximate Entropy: area under the curve as a fast and robust tool to address temporal organization.

and $r$, resulting in a pseudo-volume below the surface thus obtained. pApEn is much more robust than ApEn (and SampEn), even though the arbitrary choice of $m$ still poses subjectivity in the analysis. Moreover, recently we made a set of tests with pApEn and observed that some inconsistencies emerged for different values of $m$. vApEn, on the other hand, is extremely demanding on computational time/resources, and turns out prohibitive for series containing more than 400 points even in powerful conventional computers. Here we propose an approach based on the construction of the area under the curve of ApEn versus tolerance $r$, and it differs from the other tools: (a) from pApEn, which takes only one ApEn value and have no prescriptions for $m$; and (b) from vApEn, which takes all the areas for all possible windows size $m$. The tool, a1ApEn, consists in constructing a detailed tolerance vector and to compute the ApEn values, for the window size $m=1$. We normalize the tolerance vector and compute the area from the ApEn values relative to the normalized tolerances. The window size 1 is chosen because it can be proven that it results in the largest area compared to $m=2,3,4, \ldots N-1$; remaining then no subjectivity in the parameters' choice. We tested the consistency of the tool using a set of standard time-series. The results show that a1ApEn is an adequate approach to characterize temporal organization of time-series without the problems suffered by pApEn and vApEn.

\section{$2.1 \quad$ Introduction}

Approximate Entropy (ApEn) is a widely employed tool to characterize temporal organization in time-series. This method seeks to estimate the degree of organization by counting the number of equal events (matches) of a sub-vector $i$ of size $m$ along the original vector ( of size $N$ ), given a tolerance $(r)$. More details may be found in Pincus (1991) and Santos et al. (2009), but the central idea is to count all the matches (\#) for certain $i, m$ and $r$ as: 


$$
C_{i}^{m}(r)=\frac{\#_{i}^{m}}{N-m+1}
$$

Then, the function $\phi$ is given by the overall mean count:

$$
\phi^{m}(r)=\frac{1}{N-m+1} \sum_{1}^{N-m+1} \ln \left(C_{i}^{m}\right)
$$

Finally, ApEn is obtained through:

$$
\operatorname{ApEn}(m, r, N)=\phi^{m}(r)-\phi^{m+1}(r)
$$

ApEn is known to successfully achieve its objectives in many cases, such as: ability to test adequacy of pseudo-random numbers generators (Rukhin, 2000); prediction of survivability through body temperature regularity (Cuesta et al., 2007); estimation of machine health via analysis of vibration in rolling bearings (Yan \& Gao, 2007); characterization of motor unit activity in amyotrophic lateral sclerosis patients (Zhou et al., 2011) and prediction of paroxysmal atrial fibrillation through heart rate variability (Shin et al., 2006). Nevertheless, some drawbacks can be found and, consequently, there is room for improvement.

A minor issue regards its "positional sensitivity", i.e. two arbitrary chosen fragments of the same original data may possess very distinct ApEns. This problem holds even for highly organized series such as the sum of two sine waves (Figure $2.1 \mathrm{~A}$ ), where is possible to observe a twofold increase in the ApEn for different samples (Figure 2.1 B). This problem is usually mitigated, as shown in Figure 2.1 B, by a moving ApEn window to obtain the mean complexity of a given time series (Zhou et al., 2011; Hu et al., 2008; Chen et al., 2009).

A more important issue is that this tool rely on two arbitrary choices of parameters to obtain the estimated value, namely, the window size of comparison, $m$, and the tolerance 
Chapter 2. Improvements in Approximate Entropy: area under the curve as a fast and robust tool to address temporal organization.
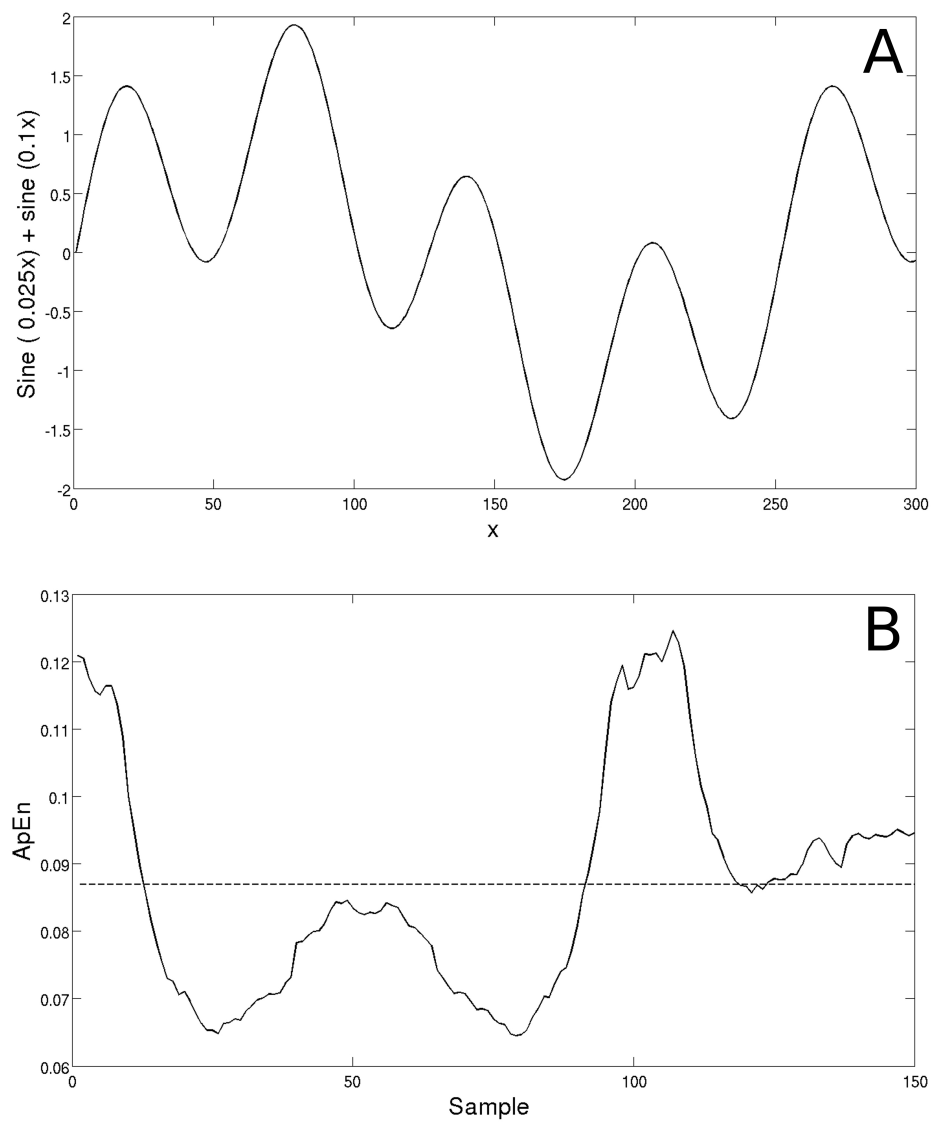

Figure 2.1: Sum of two sine waves and the corresponding moving ApEn. (A) Sum of two sine waves, one with angular frequency of 0.025 and the other with angular frequency of 0.1 , as a function of a time $\mathrm{x}$. (B) A moving ApEn of the two sine waves where each sample consists of an ApEn of a 150 points moving sub-vector from the original timeseries. The dashed line represents the mean value of complexity obtained. Notice that the higher ApEn obtained is almost two times the lower ApEn. 
for distinguishing two vectors as non-equals, $r$. This arbitrariness is a huge drawback in these tools since two very distinctive series may be classified differently depending on the choice of the parameters (Santos et al., 2009). A well known variation of ApEn, sample entropy (SampEn, developed by Richman \& Moorman (2000)), also from suffers from this disadvantage.

There are two attempts to overcome such a drawback. One is based on a collection of tolerance values constructed in order to obtain the highest (peak) ApEn for a given m (pApEn - Lu et al. (2008)). The logic behind this approach is clear when comparing this peak in different time-series (Figure 2.2). Due to the formulation of equation 2.3, small tolerances are associated with a small ApEn (i.e., the counting is as small for $m X$ as it is for $m X+1)$, which rises to a peak and then decreases as the allowed tolerance increases. Therefore, it is possible to observe that the use of a single value of $r$, as suggested by Pincus (1991) (e.g., the typically used 0.15 as illustrated in Figure 2.2) may result in different regions of the curves being used to classify the organizations of different time series.

pApEn is much more robust than ApEn (and SampEn), nevertheless, some inconsistencies are observed (exemplified in Table 2.1, check Appendix A for full tables with all simulations). Firstly, there still is a dependency on the value of $m$, since the classification of different complexities may change depending on this parameter (Table 2.1 A). Second, there is a high dependency on the size of the vector analyzed, since discrepant results are obtained with small differences in size (Table 2.1 B). Finally, well organized time series (e.g., a sine) analyzed through only one period may present a higher complexity than a more variable series (Table $2.1 \mathrm{C}$ ).

The other alternative approach is based on a double summation of ApEn values along all suitable $m$ and $r$, resulting in a pseudo-volume below the surface thus obtained (vApEn, developed by Santos et al. (2009)). vApEn is, likewise, much more robust than ApEn and SampEn, however it is extremely demanding on computational time/resources, 
Chapter 2. Improvements in Approximate Entropy: area under the curve as a fast and robust tool to address temporal organization.

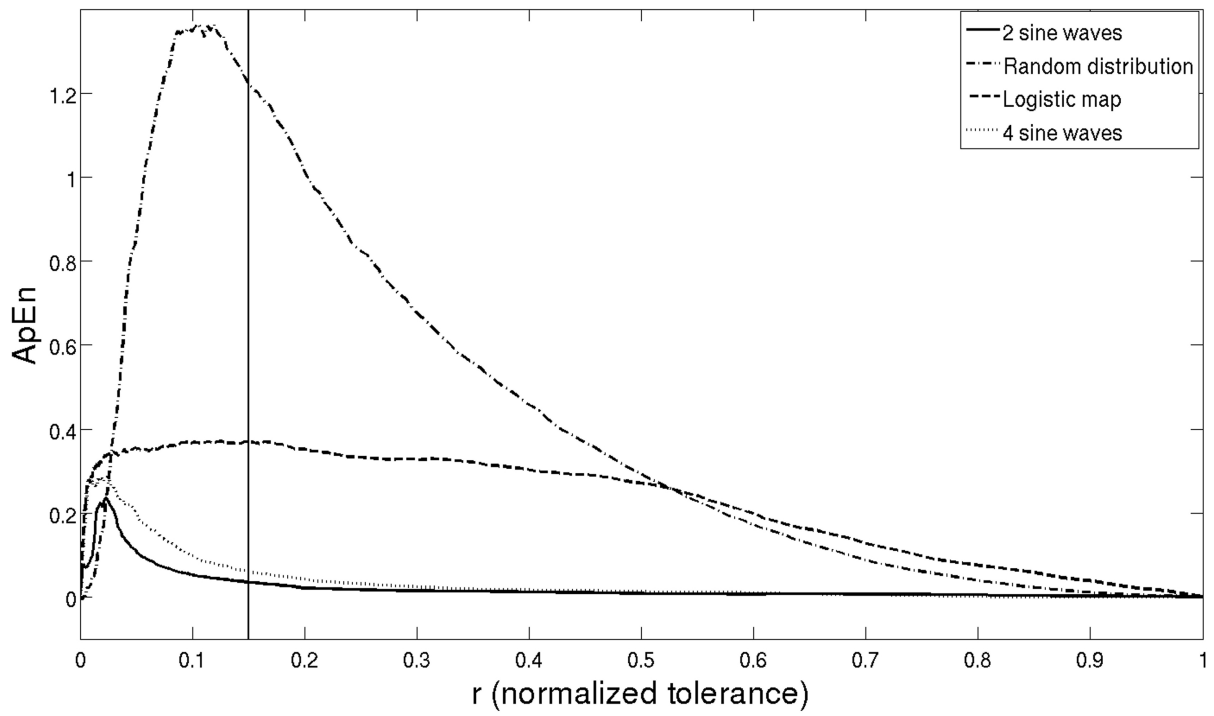

Figure 2.2: ApEn across different $r$ (tolerance) for four data-sets. ApEn with window size $m=2$ for all possible normalized tolerances $r$ (therefore, ranging from 0 to 1 ) for the following time-series: sum of 2 sine waves (parameters: angular frequency $(\omega)=0.025$ and 0.1); uniformly distributed random numbers; Logistic map (parameter $=3.7)$ and sum of 4 sine waves (parameters: $\omega=0.025,0.1,0.051$ and 0.078). The vertical line denotes the typically used $r=0.15$. 
Table 2.1: Examples of the inconsistencies found with the use of pApEn. "Size" indicates the number of points utilized in the analyses and " $m$ " is the size of the window employed to compute the pApEn. The values of pApEn are presented as the mean results (number of samples $=2$. Size) \pm standard deviation. (A) It is possible to observe that, depending on the $m$ of choice, both time-series may be classified as the most organized. (B) Vector of different sizes diverge on which signal possesses a higher complexity. (C) According to pApEn, one sine analyzed through only one period of oscillation is more complex than a logistic map in the deterministic chaos zone (Pomeau-Manneville scenario). Names are standardized for future reference, more information in section 2.1. Parameters utilized: 1 sine B: angular frequency $(\omega)=0.1 ; 4$ sines: $\omega=0.025,0.051,0.078$ and 0.1 . Tent map A: parameters $=0.2 ; 0.4$. Autoregressive models: A, second order 0.1, 0.499; B, first order parameters: 0.4499. Logistic map B: parameter $=3.7$.

\begin{tabular}{llll}
\hline A & & & \\
Size & $m$ & 4 sine waves & Tent map A \\
\hline 210 & 1 & $0.756 \pm 0.054 *$ & $0.324 \pm 0.015$ \\
210 & 3 & $0.192 \pm 0.021$ & $0.310 \pm 0.012 *$ \\
& & & \\
B & & Autoregressive A & Autoregressive B \\
Size & $m$ & $1.231 \pm 0.014 *$ & $1.198 \pm 0.018$ \\
\hline 210 & 2 & $1.269 \pm 0.023 *$ & $1.243 \pm 0.021$ \\
240 & 2 & $1.284 \pm 0.020$ \\
270 & 2 & $1.296 \pm 0.028 *$ & $1.327 \pm 0.020 *$ \\
300 & 2 & $1.317 \pm 0.032$ & \\
& & & Logistic map B \\
C & & 1 sine B & $0.488 \pm 0.006$ \\
Size & $m$ & $0.737 \pm 0.085 *$ \\
\hline 210 & 1 & $0.487 \pm 0.006$ \\
240 & 1 & $0.733 \pm 0.088 *$ & $0.487 \pm 0.007$ \\
270 & 1 & $0.761 \pm 0.067 *$ & $0.488 \pm 0.01$.
\end{tabular}


Chapter 2. Improvements in Approximate Entropy: area under the curve as a fast and robust tool to address temporal organization.

and turns out prohibitive for series containing more than 400 points even in powerful conventional computers. In short, pApEn and vApEn are much more reliable than ApEn, but the tools deserve further improvement.

\section{$2.2 \quad$ a1ApEn}

Here we propose an approach which might be considered as a step forward in relation to pApEn and a step backward in relation to vApEn. a1ApEn is based on the construction of the area under the curve of ApEn versus tolerance $r$ (Figure 2.2) and is defined for a time-series $S$ of size $N$ as:

$$
a 1 A p E n(S)=\int_{0}^{1} \operatorname{ApEn}(m=1, r, N) d r
$$

Notice, that the tolerance vector is normalized (thus, $r \in[0,1]$ ) for appropriate comparison between different time-series.

The window size 1 is chosen because it can be shown that it results in the largest area compared to $m=2,3,4, \ldots N-1$. This is performed by considering the number of matches in equation 2.1 as a function of the window size $m$, as follows:

$$
C_{i}(m, r)=\frac{\#_{i}(m)}{N-m+1}
$$

resulting in the number of total counts as:

$$
\phi(m, r)=\frac{1}{N-m+1} \sum_{1}^{N-m+1} \ln \left[C_{i}(m, r)\right]
$$

which may be rewritten as:

$$
\phi(m, r)=\frac{1}{N-m+1} \ln \left[\prod_{1}^{N-m+1} \frac{\#_{i}(m)}{N-m+1}\right]
$$


or:

$$
\phi(m, r)=\frac{\ln \left[\prod \#_{i}(m)\right]}{N-m+1}-\ln (N-m+1)
$$

Substituting $\#_{i}(m)$ for a mean value of counts $X(m)$, then:

$$
\ln \left[\prod \#_{i}(m)\right]=\ln [X(m)]^{N-m+1}
$$

which, replacing in equation 2.8 , results in:

$$
\bar{\phi}(m, r)=\ln [X(m)]-\ln (N-m+1)
$$

Notice that, now, we consider $\phi$ as a value related to the mean counting. Consequently, from equation 2.3:

$$
\operatorname{ApEn}(m, r) \cong \bar{\phi}^{m}(r)-\bar{\phi}^{m+1}(r)
$$

Replacing equation 2.10 in 2.11 results in an ApEn value related to the mean counts in each window:

$$
\overline{A p E n}(m, r)=\ln \left[\frac{X(m) \cdot(N-m)}{X(m+1) \cdot(N-m+1)}\right]
$$

Let us call this the expected ApEn value. If $N \rightarrow \infty$ is considered, then:

$$
\overline{A p E n}(m, r)=\ln \left[\frac{X(m)}{X(m+1)}\right]
$$

It is clear now that the expected ApEn depends on how $X(m)$ increases in proportion to $X(m+1)$. It is not possible to define the rule of such relation, but it is known that it must respect the following conditions: $r=0 \rightarrow X(m, 0)=1$ and $r=1 \rightarrow X(m, 1)=N$ (since $N \rightarrow \infty$ and $r$ is normalized). Nevertheless, in this framework, even an arbitrary 
Chapter 2. Improvements in Approximate Entropy: area under the curve as a fast and robust tool to address temporal organization.

rule may still give valuable information about the behavior of the curve ApEn versus tolerance.

Consider the following formulation that obeys the above conditions and is able to reproduce the curves in Figure 2.2:

$$
X(m, r)=1+(N-1) \cdot r^{q(m)}
$$

With this rule, it is possible to observe that if $q(m)$ possess a linear behavior (i.e., $q(m)=a+b m), \operatorname{ApEn}(m=1)$ encompasses the ApEn for all other windows sizes (see Figure 2.3). Furthermore, the only situation in which an area $(m=2)$ ApEn is higher than an area $(m=1)$ ApEn is when $\frac{q(3)}{q(2)} \gg \frac{q(2)}{q(1)}$.
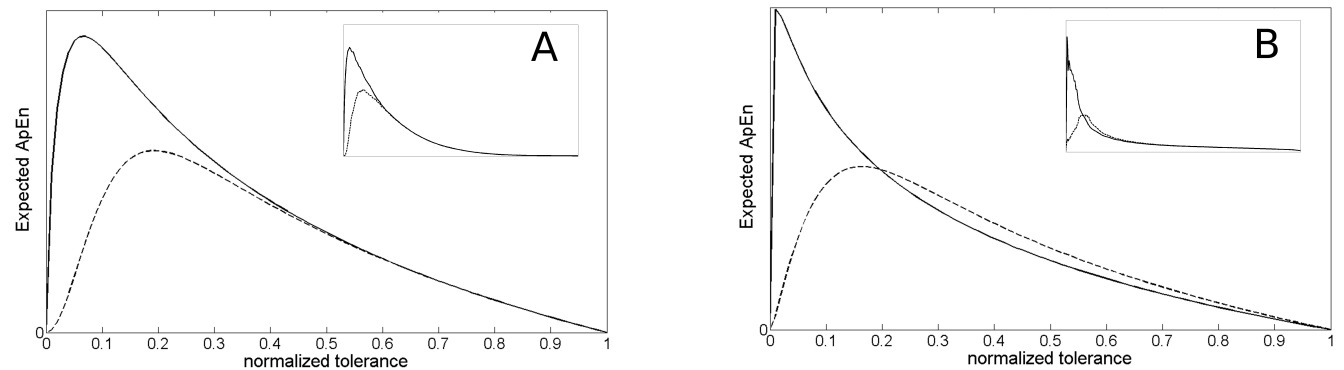

Figure 2.3: Expected ApEn as a function of tolerance (equation 2.14). Solid lines: $m=1$; dashed lines: $m=2$. (A) Factor $q(1)=1 ; q(2)=2 ; q(3)=3$. (B) Factor $q(1)=0.25$; $q(2)=1.5 ; q(3)=3$. The insets contain real ApEn values for white noise (in A) and a sine wave (in B). Notice the resemblance of the expected curves and the real ones. Expected values computed for $N=200$.

Generally, this last situation is not expected since for each inclusion of a new dimension in the state-space (i.e., $m, m+1, m+2 \ldots$ ) almost never there would be an increase in the number of counts for a suitable window size $m \ll N$ and for non straight lines series. This is particularly accurate for less organized time-series, given that the probability of increasing the number of counts remains the same with the addition of a new dimension.

Therefore, the area under the curve of ApEn versus tolerance $r$ for an $m=1$ is 
appropriate, remaining then no subjectivity in the parameters' choice.

\subsection{Analysis}

a1ApEn, ApEn, pApEn and vApEn were obtained through a set of implemented scripts in the Matlab suite (MATLAB version 7.10.0.499 Natick, Massachusetts, USA: The MathWorks Inc.). ApEn was calculated for a window size $m=2$ and tolerance $r=0.15$. Unless stated otherwise, pApEn and a1ApEn were calculated for window size $m=1$.

Sample's variances between moving ApEn, moving a1ApEn and moving pApEn of 180 points in data sets of 360 points were compared using a F-test. This was performed for the following 19 time-series: one sine $\mathbf{A}$ (parameters: amplitude $(A)=1$, angular frequency $(\omega)=0.025$ ); one sine $\mathbf{B}$ (parameters: $A=1, \omega=0.1$ ); sum of two sine waves A (parameters: $A=0.2, \omega=0.025$ and $A=1, \omega=0.1$ ); sum of two sine waves B (parameters: $A=0.1, \omega=0.025$ and $A=1, \omega=0.1$ ); sum of two sine waves $\mathbf{C}$ (parameters: $A=1, \omega=0.025$ and $A=0.2, \omega=0.1$ ); sum of four sine waves (parameters: $A=1, \omega=0.025 ; A=1, \omega=0.1 ; A=1, \omega=0.051$ and $A=1$, $\omega=0.078)$; autoregressive model A (AR A, second order, parameters: 0.1, 0.499); autoregressive model B (AR B, first order, parameters: 0.4499); moving average A (MA A, fifth order, parameters: $0.4,0.2,0.1,0.1,0.5$ ); moving average B (MA B, fifth order, parameters: $0.1,0.7,0.9,0.4,0.2)$; tent map A (TM A, parameters: $0.2,0.4$ ); tent map B (TM B, parameters: 0.6, 0.1); tent map C (TM B, parameters: 0.041, 0.9); logistic map A (LM A, parameter: 3.6); logistic map B (LM B, parameter: 3.7); normally distributed random numbers $\mathbf{A}$ (n.d.r.n A); normally distributed random numbers B (n.d.r.n B); uniformly distributed random numbers A (u.d.r.n. A); uniformly distributed random numbers B (u.d.r.n. B).

The data sets where inconsistencies were found utilizing a moving pApEn (i.e. 4 sines x TM A, AR A x AR B and 1 sine x LM B, Table 2.1) were compared with a moving 
Chapter 2. Improvements in Approximate Entropy: area under the curve as a fast and robust tool to address temporal organization.

a1ApEn, where shifting sub-vectors of size $n=210,240,270,300$ were analyzed over a data set of size $n \cdot 2$. The comparisons between each pair of time-series were performed with a Student's t-test.

Computational time differences between ApEn, vApEn and a1ApEn were compared analyzing normally distributed random numbers (n.d.r.n. A) for different vector sizes $(n=90,120,150, \ldots, 300)$ over 100 samples. The means between a1ApEn and the other two tools were compared using a using a paired Student's t-test.

\subsection{Results}

\subsubsection{Positional sensitivity}

The issue of positional sensitivity is still present in the a1ApEn, however the variance of the different samples of a moving sub-vector is significantly lower (all $p<0.01$ ) than the ones obtained using pApEn for all the 19 data sets analyzed. Regarding the ApEn, the variance of a1ApEn was significantly lower in 18 cases (all $p<0.01$, Figure $2.4 \mathrm{~A}$ ), the exception being the tent map C. Due to its bimodal composition (Figure 2.4 B), this time-series is poorly characterized for $r=0.15$ (Figure $2.4 \mathrm{C}$ ), resulting in an equally small value of ApEn for all sub-vectors sampled $\left(1.56 \cdot 10^{-5}\right)$ and, therefore, zero variance. Hence, this exception reinforces the benefits of the area approach.

\subsection{2 pApEn inconsistencies}

Utilizing the area ApEn to reanalyze the data sets from Table 2.1 it is possible to observe that those inconsistencies are no longer a problem (Table 2.2). More specifically, tent map A has a higher complexity than the sum 2 sine waves for both $m$ (Table $2.2 \mathrm{~A}$ ); for all vector sizes analyzed, autoregressive A possess a higher a1ApEn than autoregressive B (Table 2.2 B) and, finally, one sine is, as expected, more organized than the logistic map B (Table $2.2 \mathrm{C}$ ). It is important to point out that these results utilize different values of 

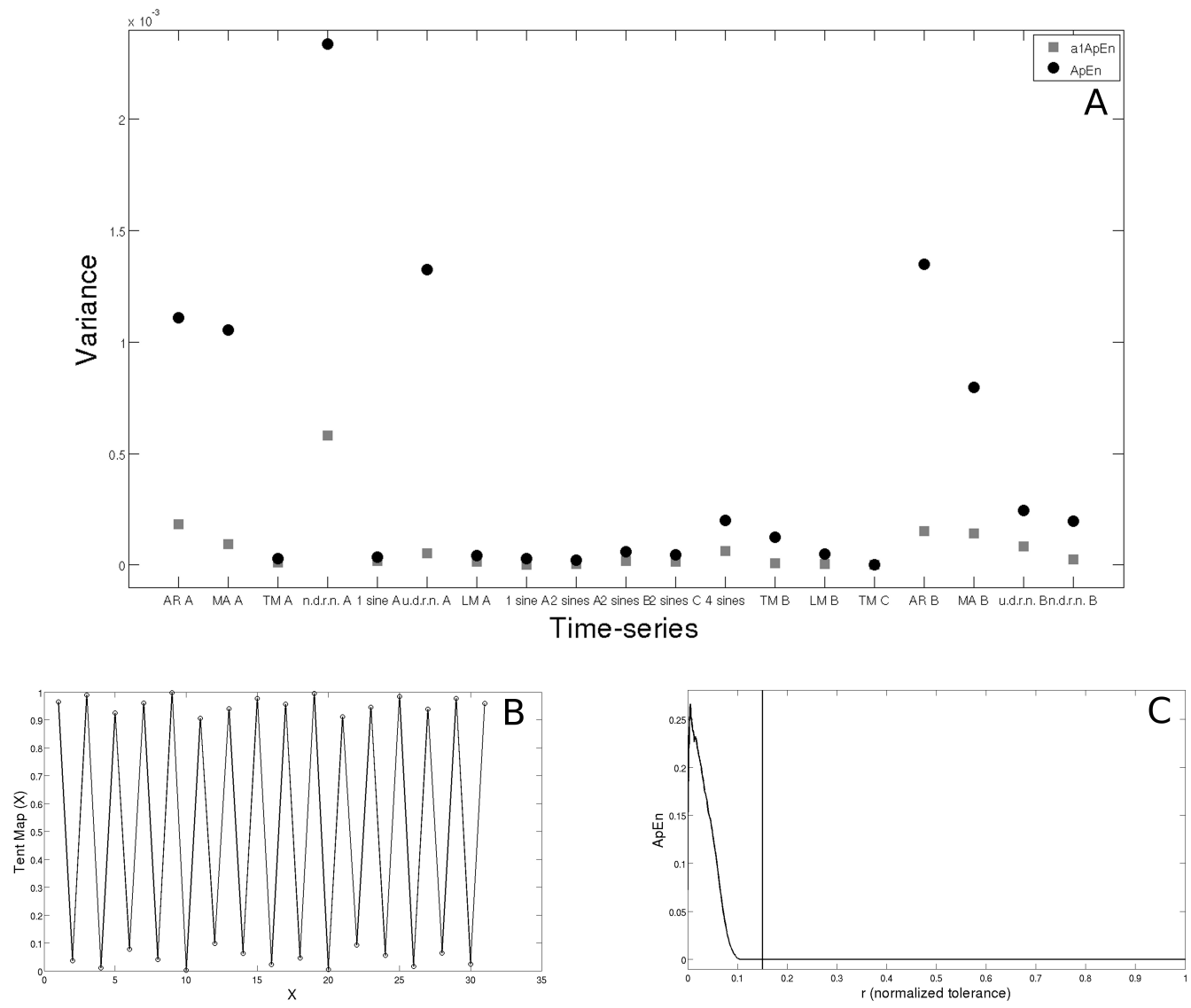

Figure 2.4: Comparison, with a detailed exception, of the variance of 19 data-sets with ApEn and a1ApEn. (A) Variance of 19 different time-series, described in section 2.3, from a moving ApEn and a moving a1ApEn of 180 points over a original data set of 360 points. Notice that the variance of a1ApEn is smaller for all time series but tent map C (B) Tent map C (parameters 0.041, 0.9) as a function of a time x. (C) ApEn of tent map $\mathrm{C}$ (shown in (B)) for window size $m=2$ for all possible normalized tolerances $r$, notice that the typically utilized $r$ (0.15, the vertical line) does not properly cover informative values of ApEn. 
Chapter 2. Improvements in Approximate Entropy: area under the curve as a fast and robust tool to address temporal organization.

$m$ for comparative purposes, however all consistencies pointed out are also detected for $m=1$ (i.e., a1ApEn).

Table 2.2: a1ApEn results for the time-series generated in machina. (A) The vector consisting of four added sine waves is more organized than the tent map A independently of the window size. (B) Auto regressive A is significantly more complex than autoregressive B for all vector sizes. (C) One sine possess a lower complexity than a logistic map (parameter $=3.7)$. Check Table 2.1 legend for further details of the data sets.

\begin{tabular}{|c|c|c|c|}
\hline $\begin{array}{l}\text { A } \\
\text { Size }\end{array}$ & $m$ & 4 sine waves & Tent map A \\
\hline 210 & 1 & $0.041 \pm 0.009$ & $0.136 \pm 0.004 *$ \\
\hline 210 & 3 & $0.030 \pm 0.007$ & $0.132 \pm 0.004 *$ \\
\hline \multicolumn{4}{|l|}{ B } \\
\hline Size & $m$ & Autoregressive A & Autoregressive B \\
\hline 210 & 2 & $0.249 \pm 0.009 *$ & $0.233 \pm 0.004$ \\
\hline 240 & 2 & $0.254 \pm 0.010 *$ & $0.236 \pm 0.005$ \\
\hline 270 & 2 & $0.254 \pm 0.012 *$ & $0.238 \pm 0.006$ \\
\hline 300 & 2 & $0.250 \pm 0.011 *$ & $0.241 \pm 0.007$ \\
\hline \multicolumn{4}{|l|}{$\mathrm{C}$} \\
\hline Size & $m$ & 1 sine $B$ & Logistic map B \\
\hline 210 & 1 & $0.080 \pm 0.001$ & $0.242 \pm 0.002 *$ \\
\hline 240 & 1 & $0.080 \pm 0.001$ & $0.242 \pm 0.002 *$ \\
\hline 270 & 1 & $0.081 \pm 0.001$ & $0.243 \pm 0.001 *$ \\
\hline
\end{tabular}

\subsubsection{Computational time}

The a1ApEn analysis is significantly slower than the ApEn $(p=0.023)$ but, in a more drastic manner, significantly faster than vApEn $(p=0.014)$; a pattern more prominent when analyzing larger vectors (Figure 2.5). 


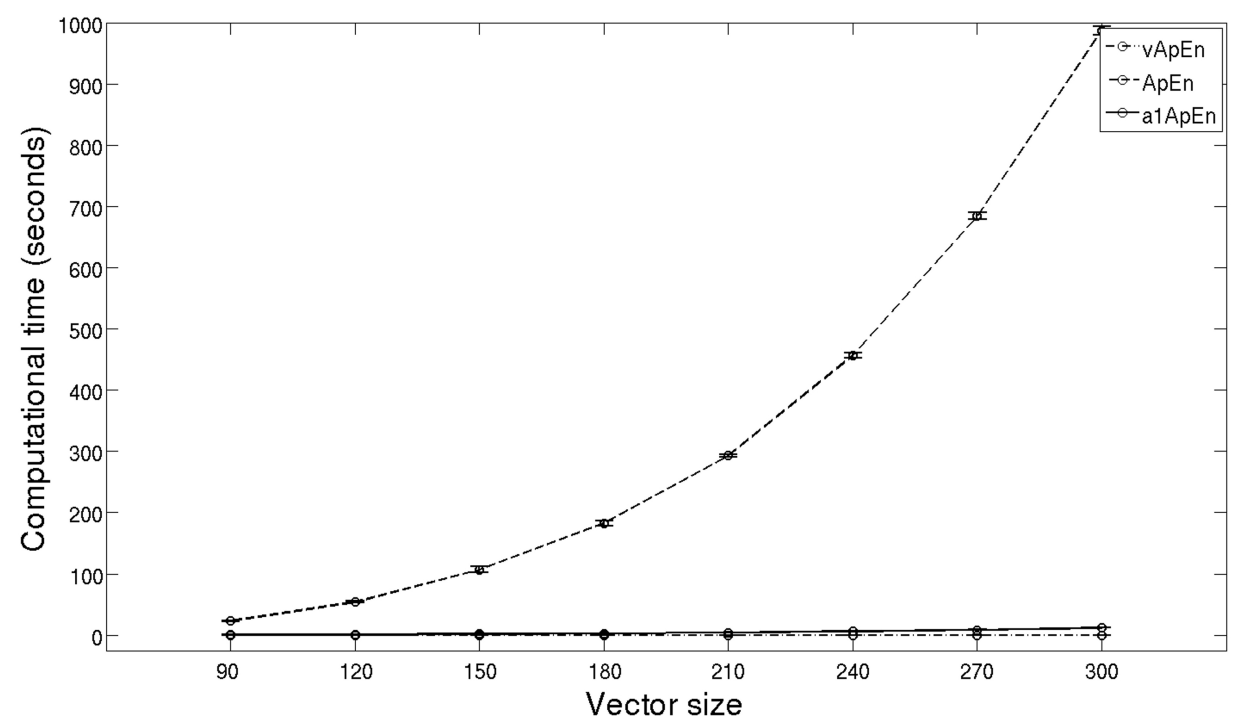

Figure 2.5: Computational time of ApEn, a1ApEn and vApEn for different vector sizes. Mean time (points) and standard deviation (error bars) of 100 analysis of ApEn, a1ApEn and vApEn for each vector size $(90,120,150,180,210,240,270$ and 300).

\subsection{Discussion}

The present work proposes a tool that considers the area beneath the curve of ApEn versus the tolerance $r$ given a $m=1$ (hence, a1ApEn) to characterize temporal organization. This is not the first attempt to improve ApEn, as observed by the already cited sampEn, pApEn and vApEn. However, a1ApEn corrects some problems that arise in those tools. Our simulations show that a1Apen is a robust, consistent tool with an appropriate computational time even for large vectors. Therefore, it is possible to conclude that a1ApEn is an adequate approach to characterize temporal organization of time-series without the problems suffered by pApEn and vApEn. 


\section{Bibliography}

Chen, L., Luo, W., Deng, Y., Wang, Z., \& Zeng, S. (2009). Characterizing the complexity of spontaneous electrical signals in cultured neuronal networks using approximate entropy. IEEE transactions on information technology in biomedicine : a publication of the IEEE Engineering in Medicine and Biology Society, 13(3):405-10.

Cuesta, D., Varela, M., Miró, P., Galdós, P., Abásolo, D., Hornero, R., \& Aboy, M. (2007). Predicting survival in critical patients by use of body temperature regularity measurement based on approximate entropy. Medical $\mathcal{E}$ biological engineering $\mathscr{E}$ computing, 45(7):671-8.

Hu, X., Miller, C., Vespa, P., \& Bergsneider, M. (2008). Adaptive computation of approximate entropy and its application in integrative analysis of irregularity of heart rate variability and intracranial pressure signals. Medical Engineering and Physics, 30(5):631-639.

Lu, S., Chen, X., Kanters, J. r. K., Solomon, I. C., \& Chon, K. H. (2008). Automatic selection of the threshold value $\mathrm{r}$ for approximate entropy. IEEE Transactions on Biomedical Engineering, 55(8):1966-1972.

Pincus, S. M. (1991). Approximate entropy as a measure of system complexity. Proceedings of the National Academy of Sciences of the United States of America, 88(6):22972301. 
Richman, J. S. \& Moorman, J. R. (2000). Physiological time-series analysis using approximate entropy and sample entropy. American journal of physiology. Heart and circulatory physiology, 278(6):H2039-H2049.

Rukhin, A. L. (2000). Approximate entropy for testing randomness. Journal of Applied Probability, 37(1):88-100.

Santos, B. T., Martins, R. a., Natali, J. E. S., Rodrigues, V. H., Marques, F. S., \& ChauíBerlinck, J. G. (2009). Consistency in approximate entropy given by a volumetric estimate. Chaos, Solitons and Fractals, 42(1):322-334.

Shin, D.-G., Yoo, C.-S., Yi, S.-H., Bae, J.-H., Kim, Y.-J., Park, J.-S., \& Hong, G.-R. (2006). Prediction of paroxysmal atrial fibrillation using nonlinear analysis of the R$\mathrm{R}$ interval dynamics before the spontaneous onset of atrial fibrillation. Circulation journal : official journal of the Japanese Circulation Society, 70(1):94-99.

Yan, R. \& Gao, R. X. (2007). Approximate Entropy as a diagnostic tool for machine health monitoring. Mechanical Systems and Signal Processing, 21(2):824-839.

Zhou, P., Barkhaus, P. E., Zhang, X., \& Rymer, W. Z. (2011). Characterizing the complexity of spontaneous motor unit patterns of amyotrophic lateral sclerosis using approximate entropy. Journal of neural engineering, 8(6):066010. 


\title{
Chapter 3
}

\section{Evaluation of Heart Rate Control Estimators in Running}

\begin{abstract}
There is not an isolated marker capable of diagnose the level of training of athletes in general and runners, in particular. The study of instantaneous heart rate frequency changes (i.e., beat-to-beat changes) as an estimator of cardiac control, obtained through heart rate variability (HRV) and heart rate complexity (HRC), may contribute to this scenario. However, there are known issues. Previous studies using these approaches provided contradictory results and, in addition, the typical tools for HRC analysis suffer from consistency problems. Moreover, there is a problem regarding the diversity of protocols in the literature, which typically merge different and even unaccounted effects in the same experiment, and consequently obscure the physiologic interpretation. The present study intends to overcome these drawbacks by assessing HRC (estimated by a1ApEn, an analytical tool of proved consistency) and HRV for 15 subjects in three different protocols of speeds (constant, increasing and decreasing) as a function of the three parametric variables: duration of experiment, speed and heart rate (for a more
\end{abstract}


physiological relationship). Our results show that, for all protocols, there is a positive correlation between $\mathrm{HRC} / \mathrm{HRC}$ and all parametric variables. This correlation is more prominent in the protocol with increasing speeds, and more specifically for the correlation with heart rate, an empirical finding seldom accounted for in the literature. Finally, in this situation, the correlation was disrupted for poorly trained subjects. We conclude that this positive relationship occurs basically in high intensity activities, and this seems to be the main source of the contradictory results cited above. Also, the results suggest that this phenomenon is associated with a reserve of non-neural cardiac adjustments, which sedentary people do not possess.

\subsection{Introduction}

The study of the physiological aspects of running is important not only due to the increasing popularity of this activity but also for its role in maintaining health. There is not, however, an isolated marker capable of diagnose training problems and/or overtraining (Armstrong \& VanHeest, 2002; Smith et al., 2011). Furthermore, typical markers, such as heart rate, are not able to discriminate the level of training in long distance runners (Borresen \& Lambert, 2008; Lambert et al., 1998).

The study of heart rate (HR) changes (i.e. beat-to-beat variation), as a result of the balance between sympathetic and parasympathetic excitation of the heart, emerges as an interesting tool to investigate this scenario. Variability between heart beats is considered to be an estimator of cardiac control (Billman, 2009) and currently is commonly obtained through frequency domain indexes (heart rate variability, HRV) and nonlinear methods (heart rate complexity, HRC). In both approaches, a low value of the estimator, during rest, is associated with health problems such as, for HRC, paroxysmal atrial fibrillation (Shin et al., 2006), neonatal sepsis (Lake et al., 2002), presence of endotoxins (Rassias et al., 2005), mortality after myocardial infarction (Stein et al., 2005) and, for HRV, 
diabetic neuropathy, heart transplant and myocardial infarction (Task Force, 1996).

Nevertheless, the acute effect of exercise in instantaneous heart rate changes is still obscure. There are some controversies regarding the association of HRV and the two facets of the cardiac autonomic control (Eckberg, 1997; Malik, 1998; Parati et al., 2006) suggesting that the physiology is not well understood under this approach (Eckberg, 1997). This is particularly important considering that HRV measured during exercise has provided contradictory results (Perini \& Veicsteinas, 2003; Tulppo et al., 1998; Aubert et al., 2003; Sandercock \& Brodie, 2006).

In this context, HRC obtained through nonlinear analysis appears as an interesting alternative to investigate this process since nonlinear phenomena are present at the very genesis of cardiac control (Task Force, 1996; Jafarnia-Dabanloo et al., 2007). Among the alternatives, it is possible to highlight Approximate Entropy (ApEn - Pincus (1991), a nonlinear method employed to quantify the degree of order in time-series. To achieve this goal, it counts the number of equal events in a sub-vector $i$ of size $m$ along the original vector, given a tolerance $r$.

ApEn is capable of achieving its goals in many cases (conf. Chapter 2); however, the effect of exercise in HRC measured through this tool, and other similar, is unclear as well. Lewis \& Short (2007) showed that HRC increased with the onset of physical activity and then continually decreased, whereas Tulppo et al. (1996) obtained a decrease at the start followed by an increase. Finally, Boettger et al. (2010) founded HRC to be not suitable to quantify autonomic cardiac control during higher exercise intensities. Nevertheless, two regards must be put forward about this approach. Firstly, the number of studies that utilize ApEn, and other nonlinear tools, to characterize HRC is considerably smaller than the ones employing frequency domain methods, hence, additional data are still necessary to test the above mentioned patterns. Second, ApEn has consistency problems by itself (Santos et al., 2009) and the attempts to improve this tool, such as SampEm (Richman \& Moorman, 2000), maximum ApEn (Lu et al., 2008) and vApEn (Santos et al., 2009), 
also suffers some drawbacks (Chapter 2). There is an alternative, the area beneath the curve of ApEn versus the tolerance $r$ given an $m=1$ (a1ApEn, Chapter 2), that corrects the problems that arose in those methodologies but it has not yet been applied to the study of beat-to-beat changes. Still, a1ApEn has the potential of shedding some light in the relationship between HRC and exercise.

In addition to the specific setbacks from each tool, there are problems shared by the frequency domain and nonlinear analyses. It is known that the diversity in protocols (analytical and experimental) impairs a better understanding of HR control in exercise (Aubert et al., 2003; Perini \& Veicsteinas, 2003; Sandercock \& Brodie, 2006) and in other situations (Task Force, 1996). One example of this methodological diversity is the protocol of speeds utilized. While some studies analyzed the instantaneous HR changes in a constant moderate speed protocol (walking or 50\% maximum workload - Dixon et al. (1992); Tulppo et al. (2001); Yoshino et al. (2004)), others employed plateaus of increasing intensity (e.g., Arai et al., 1989; Lewis \& Short, 2007; Tulppo et al., 1996, 1998; Casadei et al., 1995; Boettger et al., 2010) making, due to the diversity of approaches, even more difficult to compare the results. Moreover, with the exception of the works of Yoshino et al. (2004) and Tulppo et al. (2001), where the subjects walked on treadmills, all the above cited experiments were performed in cycle ergometers. While this apparatus provides a good control of experimental conditions as well as facilitating data acquisition, it deviates from understanding the effect of running in HRV and HRC. In this matter, Cottin et al. (2007) assessed the ventilatory threshold through HRV and obtained an increase in parasympathetic activity in faster speeds. However, this was performed in a particular experimental group (professional football players) in a 200 meters track with heart rate monitors (instead of the more accurate electrocardiogram). Therefore, it is interesting to test the generality of these results in a more controlled environment.

Finally, in the line of protocol improvements, the procedure utilizing increasing intensities (which is the most employed) brings an extra interpretative drawback, namely the 
experimental arrangement does not allow one to distinguish the effect of different speeds from the effect of the time of experiment itself (associated with weariness). There are two options to mitigate this setback. One requires multiple protocols to cover both effects separately while the other utilizes a third variable to parameterize the beat-to-beat control. Even though the former was taken into consideration in our study, the latter deserves further attention, as we explain next.

Heart rate emerges as a parameter variable of potential interest because, not surprisingly, it ties the effect of time and speed (i.e., both variables lead to an increase in metabolism mediated through HR). Moreover, it is interesting and important to note that heart rate is also a link between the studied metabolic changes associated with exercise and the system responsible for its control (estimated through HRV and HRC). The relationship between HR control and HR was already explored during resting conditions (Platisa \& Gal, 2006b; Migliaro et al., 2001; Tsuji et al., 1996) and further studies showed that the absence of this connection is associated with cardiovascular illness (Platisa \& Gal, 2006a). Similarly, previous experiments in our laboratory, with 5 subjects running on a treadmill, obtained a positive HRV/HRC x HR relationship in normal conditions, whereas deviations were associated with a lower fitness level. However, proper experimentation still was necessary to test this pattern.

To clarify all these issues, our experiment measured HRC, estimated through a1ApEn, and HRV for 15 individuals running in treadmills in three protocols: constant speed, increasing speeds and decreasing speeds. The subjects took part in all three protocols. In all cases, the relationship between these variables and the time of the experiment or HR were analyzed. We hypothesize that HRV and HRC will be positively correlated to HR in all three protocols, and in all subjects except in those poorly trained ones. 


\subsection{Material and Methods}

The experiments were conducted in 15 healthy male voluntaries (mean age: 29 years, range 20 - 35; mean body mass index: 23.86, range $19.58-32.95)$ with different degrees of fitness, from completely sedentary (no weekly exercise, one subject) to highly trained amateurs (ironman and ultra marathons finishers, three subjects). All subjects were instructed to be hydrated and not drink coffee and alcohol in the day of the experiment and to avoid extreme physical activity in the day before. The experiments were conducted at the Biosciences Institute of the University of São Paulo and the experimental protocol was approved by the local ethics committee (Comissão de Ética no Uso de AnimaisInstituto de Biociências (CEUA-IB)). All electrocardiogram (ECG) data were collected at ambient temperatures of $21-24{ }^{\circ} \mathrm{C}$ and always at the same preferential time of the day for physical activity for each individual.

During the first part of the experiment, ECG data were recorded for 5 minutes during rest, and afterwards each participant had its preferential speed $(u)$ estimated. Then, the experimental procedures described below were executed, one in each day in a randomized order. Each session consisted in a warm-up of 5 minutes at $0.9 u$, followed by ECG recording during 25 minutes of running in the following protocols: constant speed $(u)$, increasing speeds $(0.8 u, 0.9 u, u, 1.1 u, 1.2 u$; during 5 minutes at each speed) and decreasing speeds $(1.2 u, 1.1 u, u, 0.9 u, 0.8 u$, during 5 minutes at each speed). Data from one individual at constant speed were discarded due to signal noise.

ECG data were acquired by means of three superficial electrodes (Unilect Electrodes, Maersk Medical LTD, Copenhagen, Denmark) in the CM5 configuration. ECG was recorded and digitalized using a sampling rate of $1000 \mathrm{~Hz}$ by a MP30 interface and the Biopac Student Lab Pro software (Biopac Systems Inc., Goleta, CA, USA). The following procedures are exemplified in Figure 1. From the raw data obtained (Figure 3.1 A), R-R intervals (period between two consecutive R waves in an ECG) were extracted (Figure 
$3.1 \mathrm{~B})$. For the exercise segment, the intervals obtained were separated in five blocks, each one representing five minutes of experiment (associated with different speeds in the "increasing" or "decreasing" protocols). In each block, the first 2 minutes of data were discarded to avoid non stationary behavior resulting from the transition between speeds. From each block (and for the resting data), excerpts of 300 uninterrupted points were taken for analysis (Figure 3.1 C). To obtain a more clear temporal relationship and to increase the robustness of the analysis (as discussed for complexity analysis in Chapter 2 ), all procedures were performed in a moving window of 256 points along the original 300 vectors, resulting in 44 values of HRC (Figure 3.1 D), HRV (Figure 3.1 E-F) and mean HR for each block.

For each segment of the moving window, the mean HR was obtained. To obtain heart rate variability, a fast Fourier transform was carried out in the vector of R-R intervals. The obtained spectral components were separated in $\leq 0.04 \mathrm{~Hz}$ for very low frequencies range, $0.04-0.15 \mathrm{~Hz}$ for low frequencies range ( $\mathrm{LF}$, related to both sympathetic and parasympathetic activity) and $0.15-0.4 \mathrm{~Hz}$ for high frequencies range (HF, associated with the parasympathetic activity) (Task Force, 1996). Variability was estimated via the normalized HF (nuHF, in the present study calculated by $\left.n u H F=\frac{H F}{(V L F+L F+H F)}\right)$ and the ratio between HF and LF (from now on simply referred as to "ratio"). Heart rate complexity was obtained by means of a1ApEn (Chapter 2). Notice that we chose to express the ratio as $\frac{H F}{L F}$, instead of the typical $\frac{L F}{H F}$ (Task Force, 1996), so a higher value of all three estimators studied was related to a higher level heart rate variability/complexity. Both R-R extraction and subsequent analysis were performed through a set of implemented scripts in Matlab (MATLAB version 7.10.0.499 Natick, Massachusetts, USA: The MathWorks Inc.). 

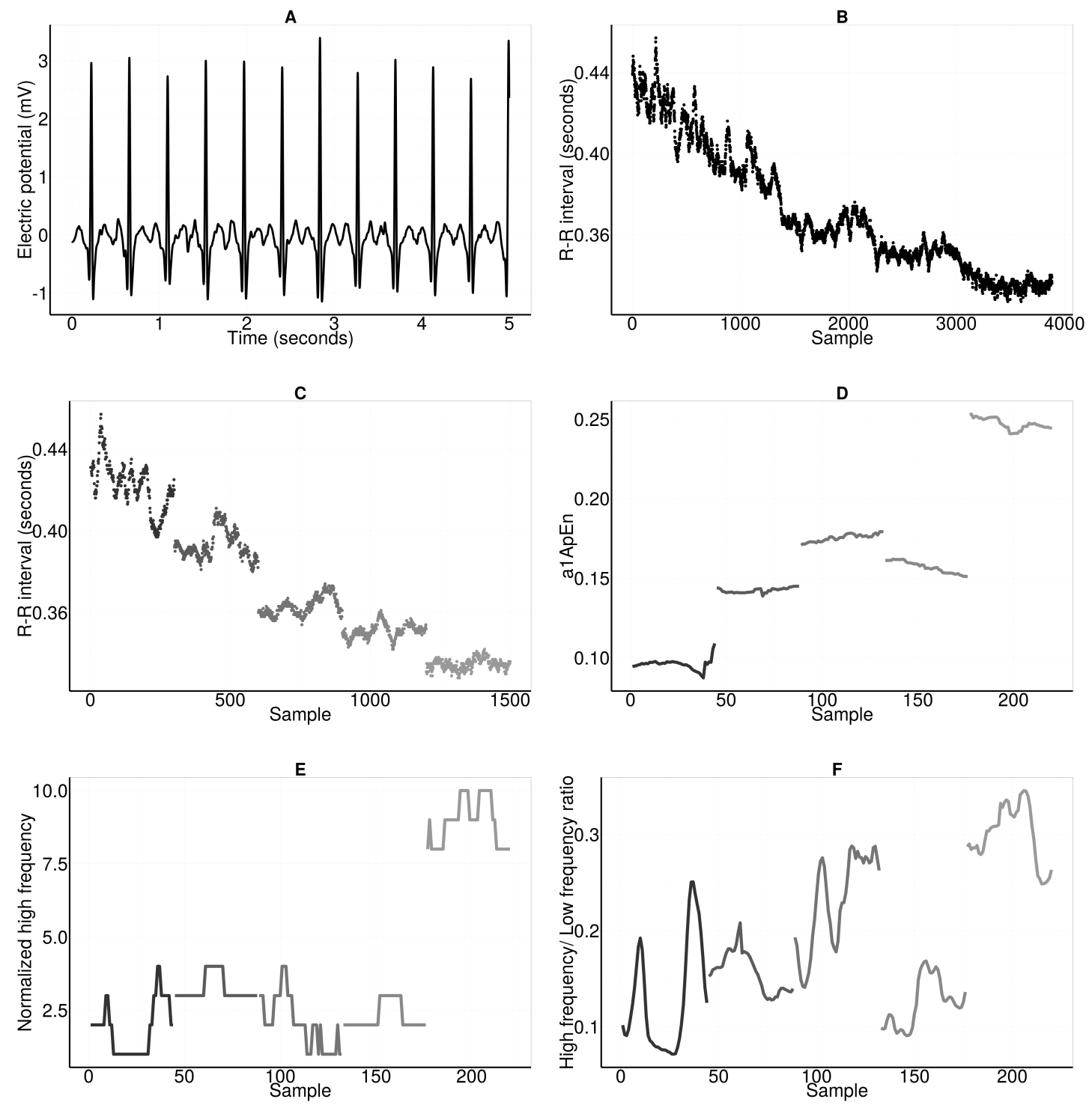

Figure 3.1: Example of the methodological proceedings performed for one subject running in the protocol with increasing speeds. (A) Electrocardiogram record. (B) Period between two consecutive R waves in the ECG (R-R intervals - seconds) versus the sample number (i.e. order) of the R-R intervals. (C) R-R intervals divided in 5 blocks (one for each speed) of 300 points, which were utilized for analysis. (D) Heart rate complexity, estimated through a1ApEn. (E) Normalized high frequency component of the heart rate variability spectral analysis. (F) Ratio between high frequency and low frequency components of the heart rate variability spectral analysis. Heart rate variability and complexity were calculated for a moving window of 256 points (44 ordered samples) for each of the 5 blocks; see text for more details. In panels $(C)$ to $(F)$, the different shades of grey are related to speeds, the darker the slower. 


\subsubsection{Statistical Analysis}

HRC, nuHF and ratio were compared between rest and the first five minutes of exercise using Student's t-test and differences were considered significant for $p \leq 0.05$. To test the relationship between each estimator and the moment of experiment (sample ordering as a representative of time), a linear regression was performed. The same procedure was executed for the estimators versus mean HR. The relationships were considered significant if the confidence interval did not cross zero $($ C.I. $=95 \%)$. All statistical tests were performed using Matlab built in scripts. Figures were produced in the $\mathrm{R}$ environment (R Core Team, 2013).

\subsection{Results}

\subsubsection{Exercise versus Rest}

The HRC, measured through a1ApEn, and the nuHF component of the HRV were significantly lower during exercise for all 15 subjects (all $p<0.001$ ). On the other hand, the HRV ratio was significantly higher at rest for 8 individuals whereas it was significantly higher during exercise for the remaining 7 (all $p<0.001$ ).

\subsubsection{HRV and HRC as a Function of Speed and the Time of Exercise}

The results, summarized in Table 3.1, show that it is neither possible to associate $\mathrm{HRV} / \mathrm{HRC}$ only to speed (since these variables change even during the constant speed protocol) nor to duration of the exercise (given that different patterns are obtained in the protocols with increasing and decreasing speeds).

Even though speed and time do not independently explain the changes in HRC/HRV, they, however, appear to contribute to them. This may observed by the predominantly positive relationship found in the constant protocol (i.e., HRV/HRC increase with time of experiment) and the predominantly negative relationship obtained with decreasing 
Table 3.1: Slopes of linear regressions between heart rate complexity (HRC) and heart rate variability (HRV) as a function of time for the 3 speed regimes used in this study. The cells contain for the 15 subjects (14 in the protocol with constant speed) the number of events in which the slope of the linear regression of HRV and HRC as a function of time was positive and significantly different from zero, negative and significantly different from zero and non significantly different from zero. HRV was estimated utilizing the spectral components of the fast Fourier transform (normalized high frequency, nuHF, and the ratio between high and low frequencies) and HRC was estimated employing a1ApEn.

\begin{tabular}{cccc}
\hline Speed & $\begin{array}{c}\text { Qualitative behavior of the slope of the linear } \\
\text { regression as a function of time }\end{array}$ \\
\hline Constant & Positive & Negative & Not different from 0 \\
\hline a1ApEn & 7 & 3 & 4 \\
nuHF & 9 & 1 & 4 \\
Ratio & 8 & 2 & 4 \\
& & & \\
\hline Increasing & Positive & Negative & Not different from 0 \\
\hline a1ApEn & 13 & 2 & 0 \\
nuHF & 11 & 2 & 2 \\
Ratio & 12 & 2 & \\
& & & Not different from 0 \\
\hline Decreasing & Positive & Negative & 4 \\
a1ApEn & 3 & 8 & 2 \\
nuHF & 7 & 6 & 2 \\
Ratio & 6 & 7 &
\end{tabular}


speeds (i.e., HRV/HRC decreases with lower speeds). Finally, the regime with increasing speeds appears to combine these two effects (i.e., time and speed), given the observation that the positive relationship is more frequent than in the other protocols tested.

\subsubsection{HRV and HRC as a Function of Heart Rate}

The results are summarized in Table 3.2. Differently from what was observed in the previous section, the relationship obtained for a1ApEn, nuHF and HF/LF ratio is predominantly positive regardless of the protocol utilized (an example of the positive slope obtained is found in Figure $3.2 \mathrm{~B}$ ). Once again this pattern is more conspicuous with increasing speeds (exemplified for a1ApEn in Figure 3.2).

Table 3.2: Slopes of linear regressions between heart rate complexity (HRC) and heart rate variability (HRV) as a function of heart rate (HR) for the 3 speed regimes used in this study. The cells contain for the 15 subjects (14 in the protocol with constant speed) the number of events in which the slope of the linear regression of HRV and $\mathrm{HRC}$ as a function of HR were positive and significantly different from zero, negative and significantly different from zero and non significantly different from zero. HRV was estimated utilizing the spectral components of the fast Fourier transform (normalized high frequency, nuHF, and the ratio between high and low frequencies) and HRC was estimated employing a1ApEn.

\begin{tabular}{cccc}
\hline Speed & \multicolumn{3}{c}{$\begin{array}{c}\text { Qualitative behavior of the slope of the linear } \\
\text { regression as a function of heart rate }\end{array}$} \\
\hline Constant & Positive & Negative & Not different from 0 \\
\hline a1ApEn & 9 & 3 & 2 \\
nuHF & 8 & 3 & 3 \\
Ratio & 8 & 4 & 2 \\
& & & \\
\hline Increasing & Positive & Negative & Not different from 0 \\
\hline a1ApEn & 13 & 2 & 0 \\
nuHF & 11 & 2 & 0 \\
Ratio & 12 & 3 & \\
& & & Not different from 0 \\
\hline Decreasing & Positive & Negative & 3 \\
\hline a1ApEn & 9 & 3 & 1 \\
nuHF & 8 & 6 & 3 \\
Ratio & 7 & 5 &
\end{tabular}




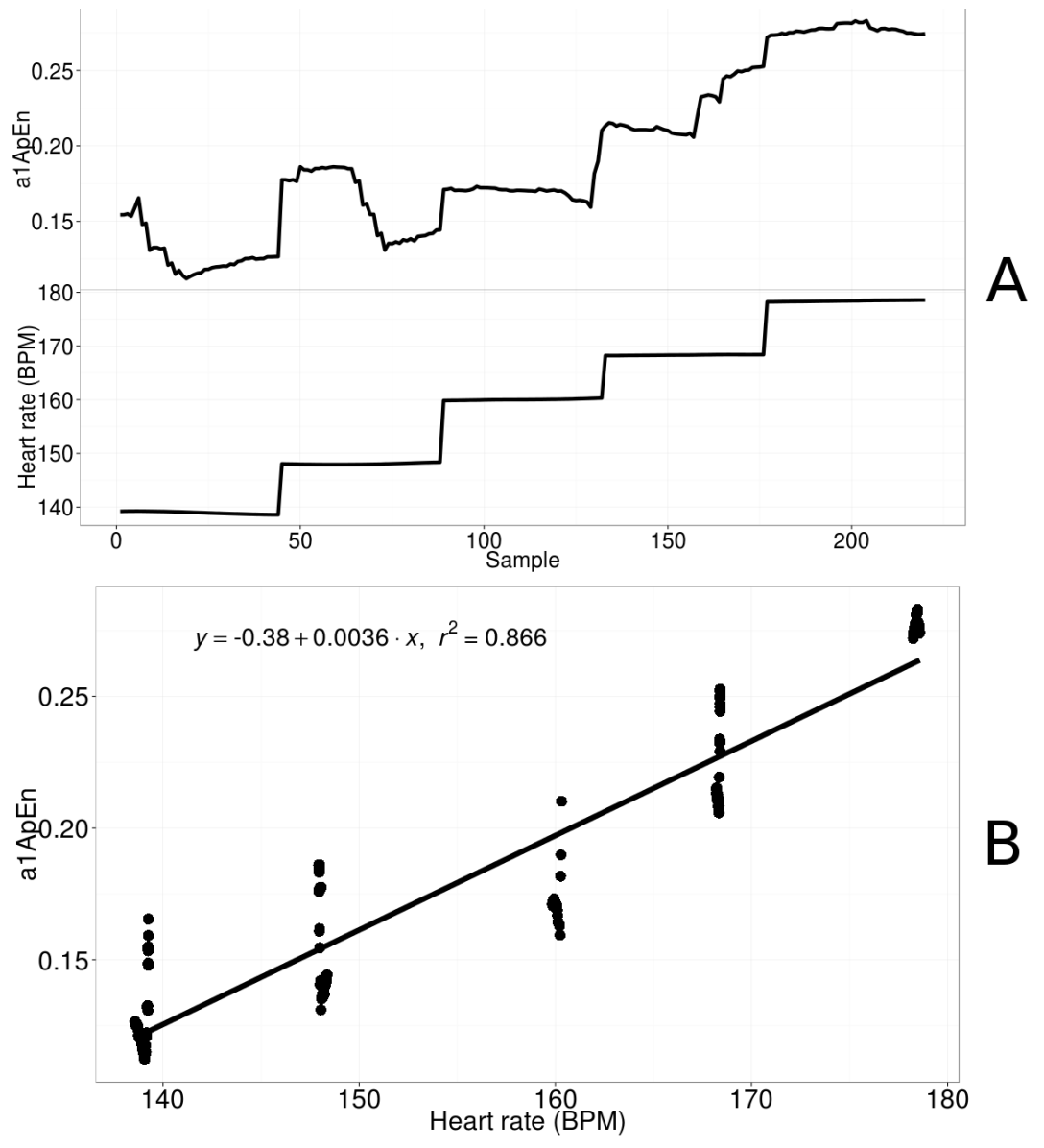

Figure 3.2: Heart rate (HR) and heart rate complexity (HRC) in increasing speeds for one subject. (A) HRC, estimated through a1ApEn, and mean heart rate (in beats per minute) calculated for a moving window of 256 points (ordered samples) in a subject running in increasing speeds. (B) For the same dataset, the linear regression of HRC as a function of heart rate. The obtained equation and the coefficient of determination $r^{2}$ are present in the Figure. 


\subsubsection{Relationship with Sedentary}

Among the three protocols, only the one with increasing speeds was able to discriminate the level of training of the subjects. This is particularly true for a1ApEn: there are two subjects in which we observe a negative correlation between HRC and HR (see Table 3.2 ; one of them is the completely sedentary individual whereas the other is relatively sedentary (some exercise but without regularity) and this subject also shows the highest body mass index $(B M I=32.95)$ among our sample. HRV, measured through nuHF and ratio, does not completely discriminate the training level of the subjects since it included these two sedentary individuals as well as non-sedentary ones in the group with non-positive correlation.

\subsection{Discussion}

The experiments were conducted to investigate the effect of running on heart rate changes. For short, our results show that the onset of exercise is associated with a decrease in nuHF and a1ApEn, but with an inconsistent pattern in HRV ratio analysis. During exercise, HRV/HRC appear to have a positive correlation with the duration (time) and the speed of running. These independent variables are combined in the protocol with increasing speeds, where the positive correlation is even more prominent. Moreover, it is possible to interpret these changes through the increase in HR they generate. Finally, it was observed that, in the protocol with increasing speeds, deviation from this positive pattern was found in poorly trained individuals.

\subsubsection{Exercise versus Rest}

Running led to a decrease in HRV measured through nuHF and in HRC. The nuHF decrease was expected since there is an withdraw of parasympathetic activity during exercise, resulting in a higher HR (Aubert et al., 2003; Perini \& Veicsteinas, 2003; Arai 
et al., 1989; Boettger et al., 2010; Tulppo et al., 1996). Given that HRC does not possess a theoretical direct relationship with any branch of the autonomous nervous system (Tulppo et al., 1996), its interpretation is not as straightforward as HRV in such a realm. HRC tends to decrease as a result of cardiovascular perturbations (conf. section 3.1); therefore, our results suggest that the beginning of exercise may be considered as a disturbance in basal heart rate control, i.e., changes associated with acute effects.

To compare our HRC results with others is not a straightforward task. This is because of the small number of previous studies, different protocols and different types of analyses. Tulppo et al. (1996) and Lewis \& Short (2007) obtained in similar experiments, using a cycle ergometer, patterns different from each other. These rest x exercise differences may be associated with the choice of the nonlinear tool of analysis, since the former utilized ApEn whereas the latter employed SampEn. Additionally, Lewis \& Short (2007) concluded that SampEn is a worse discriminator of resting and exercise conditions than linear tools. In another experiment where subjects walked on a treadmill and data were analyzed with ApEn, Tulppo et al. (2001) obtained a higher HRC during exercise. However, the authors analyzed the last $500 \mathrm{R}-\mathrm{R}$ intervals from a 30 minutes experiment, a time when the subjects have higher and increasing HRC as presently shown.

The analysis of HRV ratio produced inconsistent results. This ratio is considered to be associated with sympathovagal balance (Task Force, 1996; Goldberger, 1999). However, there are known problems in linking the LF and HF power with the sympathetic and the parasympathetic nervous systems, respectively (Eckberg, 1997), and even supporters of the HRV analysis consider the LF component to be associated with both the sympathetic and parasympathetic nervous systems, limiting the interpretation of the ratio (Task Force, 1996). In exercise, the ratio is considered not adequate to estimate sympathovagal balance (Goldberger, 1999; Perini \& Veicsteinas, 2003). Therefore, in the following sections we will focus on the nuHF component of HRV. 


\subsubsection{Difference Between Protocols}

The results regarding the relationship between $\mathrm{HRV} / \mathrm{HRC}$ and $\mathrm{HR} /$ time of experiment demonstrate that the increasing speeds protocol produced more consistent results. In this protocol, the cumulative effect of speed and duration of exercise showed that, as expected (see below), HR is an important determiner of HRV/HRC. Moreover, regarding the effect of HR, the presence of inconsistencies in the protocol of decreasing and constant speeds suggests that unaccounted effects may still be influencing these regimes. One parameter that could possibly explain these differences is the preferential speed. Considering that there is some subjectivity in its choice, an inadequacy between the speed and the cardiovascular physiology of a subject may lead to discrepant results. This is particularly true for the constant protocol, where the beat-to-beat changes could be too low or too high, and for the protocol with decreasing speeds, where the beginning of the experiment is at the highest speed. This could result in different cardiovascular responses depending on the subject's relationship to this particular speed which may, as a consequence, disrupt the among subjects homogeneity of the protocol.

More studies are necessary to understand what do exactly influence these protocols, but, nevertheless, the regime with increasing speeds seems to overcome such problems. This in turn suggests that the heart rate control is able to deal more regularly with steady increases in the metabolic rate. This is, indeed, the most utilized protocol (see section 3.1) and our data attest this to be the most appropriate one.

\subsubsection{HRV/HRC as a Function of Heart Rate}

Considering that the results and the discussion regarding the more consistent relationship between $\mathrm{HRV} / \mathrm{HRC}$ and heart rate may be easily extrapolated to the relationship between $\mathrm{HRV} / \mathrm{HRC}$ and time of experiment, this and the following sections will focus on the heart rate.

The tight relationship between HRV/HRC and HR should be no mystery since in 
exercise the cardiac control is constantly adjusted to the metabolic changes deriving from the mechanical output variation. Even if not explicitly, such a relationship is present in studies measuring heart rate control for different oxygen consumption levels (e.g., Tulppo et al., 1996; Perini et al., 1990), and also as an indicator of the intensity of exercise (Lewis \& Short, 2007).

During rest, Platisa \& Gal (2006b) obtained a quadratic relationship between these variables (i.e., $H R V \approx H R^{2}$ ). On the other hand, Migliaro et al. (2001) e Tsuji et al. (1996) obtained, similarly to the present study, a linear relationship. This difference may be associated with the data acquisition, given that Platisa \& Gal (2006b) utilized 24 hour ECG Holter monitoring (and therefore different ranges of HR) whereas the other studies, including ours, acquired the ECG during shorter controlled periods of time.

Finally, the above cited authors obtained a lower HRV/HRC at higher HR. Considering the paradigm of nuHF as a representation of the parasympathetic activity such a result shows that, as expected at rest, this facet of the autonomous nervous system is associated with lower heart rates.

\subsubsection{HRV/HRC in Running}

Contrary to what was described in the last section for rest, the results of our experiments showed a positive relationship between the HRV/HRC and heart rate. For nuHF-HRV, this kind of relationship was also obtained in some studies (e.g., Perini \& Veicsteinas, 2003; Casadei et al., 1995), although others show the opposite (e.g., Tulppo et al., 1996; Brenner et al., 1997; Tulppo et al., 1998; Arai et al., 1989; Aubert et al., 2003). As discussed in section 3.4.2, it is possible that this difference in the results might be associated with the intensity at the onset of exercise. Even though all subjects reached exhaustion, Tulppo et al. (1996) and Tulppo et al. (1998) started the cycling experiment at 50W and $25 \mathrm{~W}$, respectively, whereas Casadei et al. (1995) started at $100 \mathrm{~W}$. Another possibility is that the positive relationship between HRV and HR is associated with a higher 
total power output of the exercise since it is suggested that the relationship between nuHF and the parasympathetic system holds true only for low intensities (Sandercock \& Brodie, 2006). For instance, Brenner et al. (1997) obtained a negative relationship in experiments performed at $50 \% \dot{\mathrm{V}} \mathrm{O}_{2}$ max whereas Perini et al. (1998) and Perini \& Veicsteinas (2003) only obtained an increase in nuHF when the $\dot{V} O_{2}$ max was higher than $60 \%$ and $70 \%$, respectively. Moreover, with regards to running experiments, Cottin et al. (2007) obtained a positive relationship between nuHF and speed, but only beyond the first anaerobic threshold.

Once again, due to the similarity of protocols of Tulppo et al. (1996) and Lewis \& Short (2007), the obtained increase and the obtained decrease, respectively, of heart rate complexity at high intensities are not easily associated with differences in the experimental design, hence, they could be related to the analytical tool (ApEn x SampEn). In addition, further comparisons, regarding HRV and HRC, are problematic since there exists a great variety of protocols, many of which are poorly described. Also, most of the works cited above were executed in cycle ergometers.

Despite all these relevant considerations, it is possible to affirm that running constitutes a high intensity activity in which there is an increase in the heart rate variability and heart rate complexity with higher heart rates unrelated with the expected changes in the sympathovagal balance. A plausible explanation is that at higher magnitudes of exercise the non-neural components (e.g., changes in the mechanical cardiac axis, atrial transmural pressure associated with intratoraxic pressure and venous return - Casadei et al. (1996); Bernardi et al. (1990)) of heart rate adjustments becomes significant and, therefore, the parasympathetic component of HRV becomes less detectable (Sandercock \& Brodie, 2006) or even less relevant. Casadei et al. (1996), for example, compared the non-neural contribution in HF power during mild exercise and obtained a $32 \%$ increase (range from $17 \%$ to $75 \%$ ) in comparison to rest and, furthermore, they suggested that these non-neural components could explain the behavior of LF and HF during severe 
exercise. In addition, Bernardi et al. (1990) compared HRV between normal and heart transplanted subjects and concluded that a non-autonomic mechanism is superimposed on the autonomic modulation of heart rate during peak exercise.

Therefore, considering that the conditions attained by the subjects in the present study are importantly related to non-neural components of cardiac control, our experiments show that HRV and a1ApEn-HRC are able to identify the same patterns at different levels of physiological activity. Moreover, the detected increase in cardiac control, despite its decrease at the onset of exercise, advocates toward a reserve of non-neural control to which the cardiovascular system may resort in situations with a higher metabolic demand.

\subsubsection{Sedentary versus Trained}

An important and interesting result of our study is the possibility to discriminate between different fitness degrees utilizing the relationship between heart rate control and HR via a1ApEn. A similar result was obtained by Perini \& Veicsteinas (2003). The authors gathered data from different studies and observed that professional cyclists possessed a higher tendency to increase the HF component at elevated $\dot{V} O_{2} \max$. This pattern corroborates our suggestion the existence of a non-neural reserve, which is utilized at high effort intensities. Apparently, sedentary individuals fail to have such a reserve and therefore suffer from an impaired cardiac control at higher metabolic demands.

Regarding the individual with a higher BMI, Rennie et al. (2003) observed that trained men in such conditions $\left(B M I>\frac{25 \mathrm{~kg}}{\mathrm{~m}^{2}}\right)$ possessed HRV levels similar to normalweight sedentary man. Therefore, it is possible to infer that our experimental subject with a high body mass might not have, likewise, the above mentioned non-neural reserve.

A limitation of our experiment is that the subjects were not separated in clear categorical groups (i.e., sedentary versus trained). Therefore, apart from the clear extreme conditions described in the Material and Methods, many individuals could be classified 
in the midrange fitness level, obscuring the depth of our results.

Hence, further experiments are necessary to ensure the comprehensiveness of our study. For the same reason, even though the pattern discussed above was not as consistent in HRV measurements as it is in HRC, it is not possible to discard frequency domains analyses for detecting such a pattern without more tests.

\subsection{Conclusion}

The present study has shown that both heart rate complexity and heart rate variability varies positively with heart rate and that the protocol with increasing speeds is more suited to detect such a relationship. Furthermore, we observed that a deviation from this pattern is associated with a poor fitness degree. Finally, we may suggest that previous contradictory results were due to diversity of methodologies (particularly regarding the intensity of exercise) and inconsistencies in the analytical tools of choice (especially with the nonlinear tools). 


\section{Bibliography}

Arai, Y., Saul, J. P., Albrecht, P., Hartley, L. H., Lilly, L. S., Cohen, R. J., \& Colucci, W. S. (1989). Modulation of cardiac autonomic activity during and immediately after exercise. The American journal of physiology, 256(1 Pt 2):H132-H141.

Armstrong, L. E. \& VanHeest, J. L. (2002). The unknown mechanism of the overtraining syndrome: clues from depression and psychoneuroimmunology. Sports medicine (Auckland, N.Z.), 32(3):185-209.

Aubert, A. E., Seps, B., \& Beckers, F. (2003). Heart rate variability in athletes. Sports medicine (Auckland, N.Z.), 33(12):889-919.

Bernardi, L., Salvucci, F., Suardi, R., Soldá, P. L., Calciati, A., Perlini, S., Falcone, C., \& Ricciardi, L. (1990). Evidence for an intrinsic mechanism regulating heart rate variability in the transplanted and the intact heart during submaximal dynamic exercise? Cardiovascular research, 24:969-981.

Billman, G. E. (2009). Cardiac autonomic neural remodeling and susceptibility to sudden cardiac death: effect of endurance exercise training. American journal of physiology. Heart and circulatory physiology, 297(4):H1171-H1193.

Boettger, S., Puta, C., Yeragani, V. K., Donath, L., Müller, H. J., Gabriel, H. H. W., \& Bär, K. J. (2010). Heart rate variability, QT variability, and electrodermal activity during exercise. Medicine and Science in Sports and Exercise, 42(3):443-448. 
Borresen, J. \& Lambert, M. I. (2008). Autonomic control of heart rate during and after exercise: Measurements and implications for monitoring training status. Sports Medicine, 38(8):633-646.

Brenner, I. K., Thomas, S., \& Shephard, R. J. (1997). Spectral analysis of heart rate variability during heat exposure and repeated exercise. European journal of applied physiology and occupational physiology, 76(2):145-156.

Casadei, B., Cochrane, S., Johnston, J., Conway, J., \& Sleight, P. (1995). Pitfalls in the interpretation of spectral analysis of the heart rate variability during exercise in humans. Acta physiologica Scandinavica, 153(2):125-131.

Casadei, B., Moon, J., Johnston, J., Caiazza, A., \& Sleight, P. (1996). Is respiratory sinus arrhythmia a good index of cardiac vagal tone in exercise? Journal of applied physiology (Bethesda, Md. : 1985), 81:556-564.

Cottin, F., Médigue, C., Lopes, P., Leprêtre, P. M., Heubert, R., \& Billat, V. (2007). Ventilatory thresholds assessment from heart rate variability during an incremental exhaustive running test. International Journal of Sports Medicine, 28:287-294.

Dixon, E. M., Kamath, M. V., McCartney, N., \& Fallen, E. L. (1992). Neural regulation of heart rate variability in endurance athletes and sedentary controls. Cardiovascular research, 26(7):713-719.

Eckberg, D. L. (1997). Sympathovagal balance: a critical appraisal. Circulation, 96(9):3224-32.

Goldberger, J. J. (1999). Sympathovagal balance: how should we measure it? The American journal of physiology, 276(24):H1273-H1280.

Jafarnia-Dabanloo, N., McLernon, D. C., Zhang, H., Ayatollahi, a., \& Johari-Majd, V. 
(2007). A modified Zeeman model for producing HRV signals and its application to ECG signal generation. Journal of Theoretical Biology, 244(2):180-189.

Lake, D. E., Richman, J. S., Griffin, M. P., \& Moorman, J. R. (2002). Sample entropy analysis of neonatal heart rate variability. American journal of physiology. Regulatory, integrative and comparative physiology, 283(3):R789-R797.

Lambert, M. I., Mbambo, Z. H., \& Gibson, a. S. C. (1998). Heart rate during training and competition for longdistance running. Journal of Sports Sciences, 16(sup1):85-90.

Lewis, M. J. \& Short, a. L. (2007). Sample entropy of electrocardiographic RR and QT time-series data during rest and exercise. Physiological measurement, 28(6):731-744.

Lu, S., Chen, X., Kanters, J. r. K., Solomon, I. C., \& Chon, K. H. (2008). Automatic selection of the threshold value $\mathrm{r}$ for approximate entropy. IEEE Transactions on Biomedical Engineering, 55(8):1966-1972.

Malik, M. (1998). Sympathovagal balance: a critical appraisal. Circulation, 98(23):26432644 .

Migliaro, E., Contreras, P., Bech, S., Etxagibel, A., Castro, M., Ricca, R., \& Vicente, K. (2001). Relative influence of age, resting heart rate and sedentary life style in shortterm analysis of heart rate variability. Brazilian Journal of Medical and Biological Research, 34(4):493-500.

Parati, G., Mancia, G., Rienzo, M. D., Castiglioni, P., Taylor, J. a., Studinger, P., Di Rienzo, M., Malliani, A., Julien, C., Billman, G. E., Cerutti, S., Piepoli, M. F., Bernardi, L., Sleight, P., Cohen, M. a., Tan, C. O., Laude, D., Elstad, M., Toska, K., Evans, J. M., \& Eckberg, D. L. (2006). Cardiovascular variability is/is not an index of autonomic control of circulation. Journal of Applied Physiology, 101(2):690-691. 
Perini, R., Milesi, S., Biancardi, L., Pendergast, D. R., \& Veicsteinas, A. (1998). Heart rate variability in exercising humans: effect of water immersion. European journal of applied physiology and occupational physiology, 77:326-332.

Perini, R., Orizio, C., Baselli, G., Cerutti, S., \& Veicsteinas, A. (1990). The influence of exercise intensity on the power spectrum of heart rate variability.

Perini, R. \& Veicsteinas, A. (2003). Heart rate variability and autonomic activity at rest and during exercise in various physiological conditions. European Journal of Applied Physiology, 90(3-4):317-325.

Pincus, S. M. (1991). Approximate entropy as a measure of system complexity. Proceedings of the National Academy of Sciences of the United States of America, 88(6):22972301.

Platisa, M. M. \& Gal, V. (2006a). Dependence of heart rate variability on heart period in disease and aging. Physiological measurement, 27(10):989-998.

Platisa, M. M. \& Gal, V. (2006b). Reflection of heart rate regulation on linear and nonlinear heart rate variability measures. Physiological measurement, 27(2):145-154.

R Core Team (2013). R: A Language and Environment for Statistical Computing.

Rassias, A. J., Holzberger, P. T., Givan, A. L., Fahrner, S. L., \& Yeager, M. P. (2005). Decreased physiologic variability as a generalized response to human endotoxemia. Critical care medicine, 33(3):512-519.

Rennie, K. L., Hemingway, H., Kumari, M., Brunner, E., Malik, M., \& Marmot, M. (2003). Effects of moderate and vigorous physical activity on heart rate variability in a British study of civil servants. American Journal of Epidemiology, 158(2):135-143. 
Richman, J. S. \& Moorman, J. R. (2000). Physiological time-series analysis using approximate entropy and sample entropy. American journal of physiology. Heart and circulatory physiology, 278(6):H2039-H2049.

Sandercock, G. R. H. \& Brodie, D. a. (2006). The use of heart rate variability measures to assess autonomic control during exercise. Scandinavian Journal of Medicine and Science in Sports, 16(5):302-313.

Santos, B. T., Martins, R. a., Natali, J. E. S., Rodrigues, V. H., Marques, F. S., \& ChauíBerlinck, J. G. (2009). Consistency in approximate entropy given by a volumetric estimate. Chaos, Solitons and Fractals, 42(1):322-334.

Shin, D.-G., Yoo, C.-S., Yi, S.-H., Bae, J.-H., Kim, Y.-J., Park, J.-S., \& Hong, G.-R. (2006). Prediction of paroxysmal atrial fibrillation using nonlinear analysis of the R$\mathrm{R}$ interval dynamics before the spontaneous onset of atrial fibrillation. Circulation journal : official journal of the Japanese Circulation Society, 70(1):94-99.

Smith, T. B., Hopkins, W. G., \& Lowe, T. E. (2011). Are there useful physiological or psychological markers for monitoring overload training in elite rowers? International journal of sports physiology and performance, 6(4):469-84.

Stein, P. K., Domitrovich, P. P., Huikuri, H. V., \& Kleiger, R. E. (2005). Traditional and nonlinear heart rate variability are each independently associated with mortality after myocardial infarction. Journal of Cardiovascular Electrophysiology, 16(1):13-20.

Task Force of the European Society of Cardiology and the North American Society of Pacing and Electrophysiology (Task Force) (1996). Heart rate variability: standards of measurement, physiological interpretation and clinical use. Task Force of the European Society of Cardiology and the North American Society of Pacing and Electrophysiology. Circulation, 93(5):1043-1065. 
Tsuji, H., Venditti, F. J., Manders, E. S., Evans, J. C., Larson, M. G., Feldman, C. L., \& Levy, D. (1996). Determinants of heart rate variability. Journal of the American College of Cardiology, 28(6):1539-1546.

Tulppo, M. P., Hughson, R. L., Mäkikallio, T. H., Airaksinen, K. E., Seppänen, T., \& Huikuri, H. V. (2001). Effects of exercise and passive head-up tilt on fractal and complexity properties of heart rate dynamics. American journal of physiology. Heart and circulatory physiology, 280(3):H1081-H1087.

Tulppo, M. P., Mäkikallio, T. H., Seppänen, T., Laukkanen, R. T., \& Huikuri, H. V. (1998). Vagal modulation of heart rate during exercise: effects of age and physical fitness. The American journal of physiology, 274(2 Pt 2):H424-H429.

Tulppo, M. P., Mäkikallio, T. H., Takala, T. E., Seppänen, T., \& Huikuri, H. V. (1996). Quantitative beat-to-beat analysis of heart rate dynamics during exercise. The American journal of physiology, 271(1 Pt 2):H244-H252.

Yoshino, K., Motoshige, T., Araki, T., \& Matsuoka, K. (2004). Effect of prolonged free-walking fatigue on gait and physiological rhythm. Journal of Biomechanics, 37(8):1271-1280. 


\title{
Chapter 4
}

\section{Heart Rate Control in Amateur}

\section{Marathoners with Different Training}

\section{Backgrounds}

\begin{abstract}
Marathon running is a popular activity associated with several health adversities. There is not, however, a single marker capable of describing the level of training in long distance runners. Such marker may provide training guidelines and, potentially, mitigate the health issues. Heart rate control estimators (heart rate variability, HRV, and heart rate complexity, HRC) may contribute to this scenario. Previous studies suggested that the sign of the slope of the linear regression between HRC and heart rate (HR) is associated with the amount of training. The present study intends to test this pattern in regards to the training background in marathoners. For this objective, HRV/HRC were obtained for eleven amateur marathoners running on treadmills. The subjects were separated by the number of marathons completed (one and more than three) and by the number of years training for long distance running (less than three, 3Y, and more than ten, 10Y).
\end{abstract}


Chapter 4. Heart Rate Control in Amateur Marathoners with Different Training Backgrounds

Independently of the estimator, the utilized approach was not able to classify the groups according to the number of marathons. On the other hand, the slopes between HRC and HR of all subjects of the $10 \mathrm{Y}$ group were significantly positive whereas the same slopes were non-positive for the $3 \mathrm{Y}$ group. This confirms that the current analysis is capable of assessing differences in training backgrounds and cardiovascular physiological status.

\subsection{Introduction}

A better understanding of the physiological aspects of exercise is important not only because it allows for a better comprehension of the physiological systems involved in such activity, but also, due to the role of this activity in maintaining health. For instance, exercise is considered an effective way to prevent ventricular fibrillation and myocardial dysfunction (Billman, 2009). Nevertheless, it is known that excessive physical activity might cause health problems (Kim et al., 2014; Möhlenkamp et al., 2008).

This is particularly true for marathon running, which is associated with several adversities such as, acutely, cardiac diseases (George et al., 2011; Neilan et al., 2006; Sheppard, 2012), gastrointestinal disorders (Nicholl \& Willians, 1982; Sanchez et al., 2006), hyponatremia (Sanchez et al., 2006; Sheppard, 2012) and musculoskeletal injuries (Nicholl \& Willians, 1982; Sanchez et al., 2006; Satterthwaite et al., 1999); and chronically, high blood pressure (Kim et al., 2014) and cardiac damage (Breuckmann et al., 2009). This is utterly important considering the current popularity of marathon races among amateur athletes, a group not as medically supervised and, generally, healthy as professional athletes (Predel, 2014).

Still, there is not an isolated marker capable of diagnose training problems and/or overtraining (Armstrong \& VanHeest, 2002; Borresen \& Lambert, 2008; Smith et al., 2011). As a consequence, further studies are necessary to identify the optimal individual dose and intensity of long-term endurance exercise (Predel, 2014). 
Cardiovascular dysfunctions are the main cause of exercise-related sudden death (Kim et al., 2014), but it is known that typical markers, for instance heart rate, are not able to discriminate the level of training of long distance runners (Borresen \& Lambert, 2008; Lambert et al., 1998).

The analysis of instantaneous heart rate changes may greatly contribute to this scenario. The study of the variation of sequential heart beats (obtained in a electrocardiogram, ECG) is considered an estimator of cardiac control (Billman, 2009) and may be, more commonly, measured by a frequency domain index (denominated heart rate variability, HRV) and nonlinear tools (termed heart rate complexity, HRC). In both cases, a low value of those estimators is associated with several cardiovascular problems (Lake et al., 2002; Shin et al., 2006; Stein et al., 2005; Task Force, 1996).

In this context, $\mathrm{HRV} / \mathrm{HRC}$ have the potential to bring new information regarding the cardiac control response to the extended high metabolic demand endured by long distance runners (an issue better explained below), possibly allowing for the discrimination, for instance, among different running backgrounds. This is important considering the necessity to adequate the training of each individual to his/her cardiovascular fitness and risk factor (Schmermund et al., 2008). Therefore, this approach may contribute to more precise training protocols formulations and, consequently, to the mitigation of marathon runners' health issues. However, there are no studies relating HRV/HRC to the individual historical of training. In addition, studies comparing the, more explicit, differences between instantaneous heart rate changes in trained and untrained individuals are controversial, as it will be exposed shortly.

Typically, regular physical activity increases the cardiac control, estimated though HRV/HRC, by augmenting the parasympathetic nervous system activity (Billman, 2009; Task Force, 1996). This is more prominently observed in cross-sectional studies comparing HRV in groups of trained and untrained individuals (conf. Aubert et al., 2003, for a review). For example, in an experiment with 3,328 participants, Rennie et al. (2003) 
Chapter 4. Heart Rate Control in Amateur Marathoners with Different Training Backgrounds

found a higher HRV in men experiencing a routine of vigorous physical activity (it is interesting to point out that this pattern was not observed in women). A higher instantaneous cardiac control was also obtained in many other studies (e.g., Bonaduce et al., 1998; Buchheit et al., 2004; De Meersman, 1993; Jensen-Urstad et al., 1997). Nevertheless, situations where no differences in frequency domain indexes are observed do exist (e.g., Lazoglu et al., 1996; Melo et al., 2005; Migliaro et al., 2001) and even a study where trained subjects possessed a lower HRV is reported (Sacknoff et al., 1994).

Even though the longitudinal approach possess benefits (e.g., it is less sensitive to intra group variation), inconsistent results are also found. While some studies obtained an increase in instantaneous heart rate control with training (Al-Ani et al., 1996; Melanson \& Freedson, 2001; Schuit et al., 1999; Sloan et al., 2009) other studies did not find a significant trend (Bonaduce et al., 1998; Boutcher \& Stein, 1995; Loimaala et al., 2000; Perini et al., 2002; Uusitalo et al., 2004). It has been suggested that the lack of correlation is associated with training protocols of short duration and low intensity (Boutcher \& Stein, 1995; Levy et al., 1998; Loimaala et al., 2000; Melanson \& Freedson, 2001). However, there is an intrinsic difficulty to compare these studies since they utilize a high diversity of training protocols and different experimental subjects.

An additional problem is that the majority of studies that compared trained and untrained individuals measured HRV/HRC during rest (e.g., De Meersman, 1993; JensenUrstad et al., 1997; Sacknoff et al., 1994) or post-exercise (conf. Borresen \& Lambert, 2008; Du et al., 2005, for examples). Therefore, these studies did not take into consideration the acute effect of exercise (related to the high metabolic demand) in the heart rate control of the subjects. A possible consequence of not considering this acute effect is found in the work of Tulppo et al. (1998), in which differences in the modulation of heart rate were found when the estimators were measured during exercise, but not during rest. In this context, Uusitalo et al. (2004) suggest that a correlation between training and high instantaneous heart rate control is more commonly found when data is acquired 
during physical activity.

Nonetheless, other studies that acquired data during exercise did not find such relationship (e.g., Dixon et al., 1992; Gregoire et al., 1996; Levy et al., 1998; Perini et al., 2002). Moreover, Sandercock \& Brodie (2006) consider that the few studies which analyzed the instantaneous cardiac control measured during exercise are, at best, equivocal. Therefore, independently of the moment of data acquisition, the above presented scenario illustrates that the relationship between HRV/HRC and the level of training, as well as the potential use of the first as a marker of the second, still needs to be better studied (Aubert et al., 2003; Borresen \& Lambert, 2008). Finally, it is worth pointing out that, since there is a shortage of HRC studies in this area, most of the above cited studies utilized frequency domain HRV (Tulppo et al., 1998, is the exception).

The work presented in Chapter 3 has the potential of shedding some light in this matter. We measured the heart rate variability and complexity in subjects running during 25 minutes in 3 different speed protocols. We observed a significant correlation between beat-to-beat control and heart rate (HR) in the protocol with increasing speeds, and such a correlation is able to discriminate between fitness degrees.

The ability to distinguish between trained and untrained individuals was only observable with HRC obtained through a1ApEn (a variation of ApEn (Pincus, 1991) developed in Chapter 2) but not by HRV estimators. Hence, this analytical tool can, by itself, contribute to the scenario established in this manuscript. Moreover, it is worth pointing out that we suggested that a significantly positive correlation is related to an adequacy between cardiac control and metabolic demand (to what we shall refer, from now on, as metabolic coupling) obtained at high intensity exercises, a situation disrupted in untrained individuals (conf. Chapter 3).

The present work aims for a step forward to the study of Chapter 3 and utilizes the correlation between cardiac control estimators and heart rate in the context of our initial problem: the discrimination between different running backgrounds. For this 
Chapter 4. Heart Rate Control in Amateur Marathoners with Different Training Backgrounds

objective, we assume that the lack of metabolic coupling may be found even in highly trained individuals (such as marathon finishers). Thereunto, this study hypothesize that amateur athletes who have recently ran their first marathon should have a mechanicalcardiovascular relationship less well-matched than runners who finished more marathons and, therefore, a non-positive correlation between HRC and heart rate.

Even though there are not, to our knowledge, other studies comparing first-time with experienced marathoners, the hypothesis above is made considering that the high metabolic demand of this event has not yet been experienced by the first-marathon group (Coyle, 2007). Furthermore, similarly to what was obtained by in Chapter 3, we expect that this pattern will not be observable with the HRV estimators.

To test this hypothesis, heart rate variability and complexity were analyzed in 11 marathon finishers divided in the two groups described above. Experiments were performed a few weeks after a marathon and consisted in HRV/HRC analyses of the ECG data acquired during a treadmill run in variations of the last marathon mean speed of the given individual.

\subsection{Material and Methods}

The experiments were conducted in 13 male subjects; however, two datasets were discarded after cardiovascular disorders were detected. The remaining 11 individuals were divided in the following groups. The first marathon group (1M) included 4 individuals who have recently completed their first marathons and 2 who have completed their second marathon but reported problems in one of them (i.e., careless training and inability to run the whole marathon). The experienced group (3M) included 5 individuals who have completed at least 3 marathons in the last 5 years.

At the same time, for a broader categorization of the different running backgrounds, the same subjects were also separated in relation to the number of years of training 
for long distance running: less than 3 years (3Y) and more than 10 years (10Y). This configuration resulted in 4 subjects in the $3 \mathrm{Y}$ group and 7 individuals in the $10 \mathrm{Y}$ group. General information of all groups is shown in Table 4.1.

Table 4.1: General information of the studied groups. Age (in years), body mass index (BMI, in $\frac{\mathrm{kg}}{\mathrm{m}^{2}}$ ), time between the marathon and the experiment (in days) and marathon conclusion time (in hours:minutes) for the following four groups: subjects that completed one marathon, more than 3 marathons, subjects that trained for endurance running for less than 3 years and subjects that trained for long distance running for more than 10 years. Data is shown in mean (range).

\begin{tabular}{|c|c|c|c|c|}
\hline & First Marathon & $\begin{array}{l}\text { More than } 3 \\
\text { Marathons }\end{array}$ & $\begin{array}{l}\text { Less than } 3 \\
\text { years of training }\end{array}$ & $\begin{array}{l}\text { More than } 10 \\
\text { years of training }\end{array}$ \\
\hline Age (years) & $39(32-55)$ & $43(32-59)$ & $42(33-55)$ & $40(32-59)$ \\
\hline BMI $\left(\frac{\mathrm{kg}}{\mathrm{m}^{2}}\right)$ & $23.1(20.3-25.6)$ & $23.2(20.8-25.7)$ & $22.5(20.3-24.0)$ & $23.5(20.8-25.7)$ \\
\hline $\begin{array}{c}\text { Time to experiment } \\
\text { (days) }\end{array}$ & $34(15-62)$ & $53(42-99)$ & $38(15-62)$ & $45(26-99)$ \\
\hline $\begin{array}{l}\text { Marathon time } \\
\text { (hours:minutes) }\end{array}$ & $3: 30(3: 10-4: 40)$ & $3: 50(3: 30-4: 07)$ & $3: 37(3: 12-4: 40)$ & $3: 40(3: 10-4: 07)$ \\
\hline
\end{tabular}

Experiments were performed between 2 and 14 weeks after the completion of the marathon. All subjects were non-smokers and were instructed to be hydrated and not drink coffee and alcohol in the day of the experiment and to avoid extreme physical activity in the day before. The experiments were conducted at the Biosciences Institute of the University of São Paulo and the experimental protocol was approved by the local ethics committee (Comissão de Ética no Uso de Animais-Instituto de Biociências (CEUAIB)). All electrocardiogram (ECG) data were collected at ambient temperatures of 21 $24^{\circ} \mathrm{C}$ during the morning (8 a.m. to $11: 30$ a.m.).

ECG data was recorded for 10 minutes during rest and, afterwards, the participants warmed up at $90 \%$ of each individual's mean marathon speed $(u)$ for 5 minutes. Subsequently, ECG was recorded in the following speeds: $0.85 u, 0.9 u, u$ and $1.1 u$; during 5 minutes at each speed. At 19 minutes of experiment the subjects were inquired if they would proceed to the last speed, $1.15 \mathrm{u}$, for more 5 minutes. Therefore, the total time of 
Chapter 4. Heart Rate Control in Amateur Marathoners with Different Training Backgrounds

running was between 20 and 25 minutes. Only one subject (from the $3 \mathrm{M} / 10 \mathrm{Y}$ groups) has chosen to stop at the 20 minutes mark and no other volunteer reached exhaustion during the experiment.

ECG data was acquired by means of three superficial electrodes (Unilect Electrodes, Maersk Medical LTD, Copenhagen, Denmark) in the CM5 configuration. ECG was recorded and digitalized using a sampling rate of $1000 \mathrm{~Hz}$ by a MP30 interface and the Biopac Student Lab Pro software (Biopac Systems Inc., Goleta, CA, USA). From the raw data, $R-R$ intervals (period between two consecutive $R$ waves in an ECG) were extracted. The first minute of data were discarded to avoid transient behaviors. The following analyses were performed in a moving window of 256 points along the R-R vector.

For each segment of the moving window, the mean HR was obtained. To obtain heart rate variability, a fast Fourier transform was carried out in the vector of R-R intervals. The obtained spectral components were separated in $\leq 0.04 \mathrm{~Hz}$ for very low frequencies range, $0.04-0.15 \mathrm{~Hz}$ for low frequencies range ( $\mathrm{LF}$, related to both sympathetic and parasympathetic activity) and $0.15-0.4 \mathrm{~Hz}$ for high frequencies range (HF, associated with the parasympathetic activity) (Task Force, 1996). HRV was estimated via the normalized HF (nuHF, in the present study calculated by $\left.n u H F=\frac{H F}{(V L F+L F+H F)}\right)$ and the ratio between HF and LF (from now on simply referred as to "ratio"). Finally, HRC was obtained by means of a1ApEn. Notice that we chose to express the ratio as $\frac{H F}{L F}$, instead of the typical $\frac{L F}{H F}$ (Task Force, 1996), so a higher value of all three estimators studied was related to a higher level of heart rate variability/complexity. Both R-R extraction and subsequent analysis were performed through a set of implemented scripts in Matlab (MATLAB version 7.10.0.499 Natick, Massachusetts, USA: The MathWorks Inc.). 


\subsubsection{Statistical Analysis}

The time between the marathon and the experiment, marathon conclusion time, age and BMI were compared between groups using Student's t-test and differences were considered significant for $p \leq 0.05$. To test the relationship between each estimator and the heart rate, a linear regression was performed. The relationships were considered significant if the confidence interval did not cross zero $($ C.I. $=95 \%)$. All statistical tests were performed using Matlab built-in scripts. Figures were produced in the $\mathrm{R}$ environment (R Core Team, 2013).

\subsection{Results}

\subsubsection{Differences between groups}

The 1M group was not significantly different from the 3M group in relation to age $(p=$ $0.59)$, body mass index (BMI, $p=0.91)$, marathon time $(p=0.08)$ and time between marathon and the experiment $(p=0.20)$. Similarly, the 3Y group was not significantly different from the $10 \mathrm{Y}$ group in relation to age $(p=0.70)$, BMI $(p=0.41)$, marathon time $(p=0.52)$ and time between marathon and the experiment $(p=0.64)$.

\subsubsection{HRV and HRC as a function of $\mathrm{HR}$ for the $1 \mathrm{M}$ group and the $3 \mathrm{M}$ group}

The behavior of the slopes of the linear regressions between HRV/HRC and heart rate for the $1 \mathrm{M}$ and $3 \mathrm{M}$ groups are shown in Table 4.2. Even though a significantly positive slope is consistently found among subjects with more than 3 marathons (exemplified for a1ApEn in Figure 4.1), there is not, regardless of the analytical tool of choice, a clear pattern in the first-marathon group. Nevertheless, it is possible to observe a majority of non-positive slopes when utilizing a1ApEn. 
Chapter 4. Heart Rate Control in Amateur Marathoners with Different Training Backgrounds

Table 4.2: Slopes of linear regressions of heart rate complexity (HRC) or heart rate variability (HRV) as a function of heart rate for the first marathon group (1M) and for the more than 3 marathons group (3M) of this study. The cells contain, for a total of 11 subjects ( 6 for the $1 \mathrm{M}$ group and 5 for the $3 \mathrm{M}$ group), the number of events in which the slope of the linear regression was positive and significantly different from zero, negative and significantly different from zero and non significantly different from zero. HRV was estimated utilizing the spectral components of the fast Fourier transform (normalized high frequency, nuHF, and the ratio between high and low frequencies) and HRC was estimated employing a1ApEn.

\begin{tabular}{cccc}
\hline Groups & $\begin{array}{c}\text { Qualitative behavior of the slope of the linear } \\
\text { regression as a function of heart rate }\end{array}$ \\
\hline 1M & Positive & Negative & Not different from 0 \\
\hline a1ApEn & 2 & 3 & 1 \\
nuHF & 3 & 1 & 2 \\
Ratio & 4 & 0 & 2 \\
& & & \\
\hline 3M & Positive & Negative & Not different from 0 \\
\hline a1ApEn & 5 & 0 & 0 \\
nuHF & 5 & 0 & 0 \\
Ratio & 5 & 0 & \\
& & &
\end{tabular}




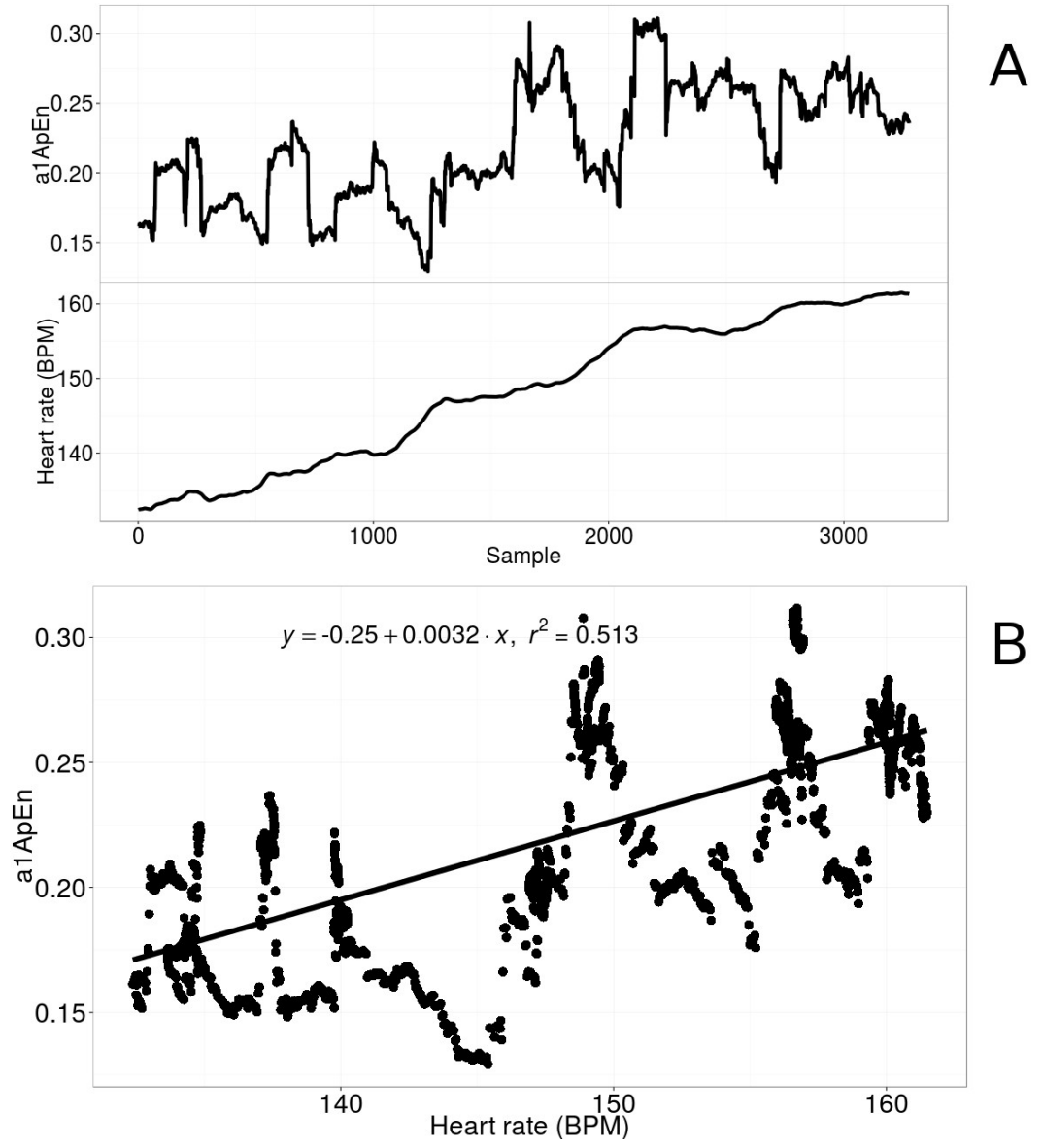

Figure 4.1: Heart rate (HR) and heart rate complexity (HRC) for one subject. (A) HRC, estimated through a1ApEn, and mean heart rate (in beats per minute) calculated for a moving window of 256 points (ordered samples) in a subject running in increasing speeds. (B) For the same dataset, the linear regression of $\mathrm{HRC}$ as a function of heart rate. The obtained equation and the coefficient of determination $r^{2}$ are present in the Figure. 
Chapter 4. Heart Rate Control in Amateur Marathoners with Different Training Backgrounds

\subsubsection{HRV and HRC as a function of $\mathrm{HR}$ for the $3 \mathrm{Y}$ group and the $10 \mathrm{Y}$ group}

The results are summarized in Table 4.3. It is possible to observe that the a1ApEn results show a positive trend in all subjects in the 10Y group (Figure 4.2 A) and a non-positive trend in all subjects in the 3Y group (Figure 4.2 B). Therefore, this analytical tool is able to discriminate between the $3 \mathrm{Y}$ and $10 \mathrm{Y}$ groups. On the other hand, both HRV analyses show a positive trend between the estimators and heart rate regardless of the group (Table 4.3) and, therefore, are unable to discriminate between them.

Table 4.3: Slopes of linear regressions of heart rate complexity (HRC) or heart rate variability (HRV) as a function of heart rate for the less than 3 years of training group (3Y) and for the more than 10 years of training group (10Y) of this study. The cells contain, for a total of 11 subjects ( 4 for the $3 \mathrm{Y}$ group and 7 for the $10 \mathrm{Y}$ group), the number of events in which the slope of the linear regression was positive and significantly different from zero, negative and significantly different from zero and non significantly different from zero. HRV was estimated utilizing the spectral components of the fast Fourier transform (normalized high frequency, nuHF, and the ratio between high and low frequencies) and HRC was estimated employing a1ApEn.

\begin{tabular}{cccc}
\hline Groups & $\begin{array}{c}\text { Qualitative behavior of the slope of the linear } \\
\text { regression as a function of heart rate }\end{array}$ \\
\hline 3Y & Positive & Negative & Not different from 0 \\
\hline a1ApEn & 0 & 3 & 1 \\
nuHF & 3 & 1 & 0 \\
Ratio & 3 & 0 & 1 \\
& & & \\
\hline 10Y & Positive & Negative & Not different from 0 \\
\hline a1ApEn & 7 & 0 & 0 \\
nuHF & 5 & 0 & 1 \\
Ratio & 6 & 0 & \\
& & & \\
\hline
\end{tabular}

\subsection{Discussion}

The cardiovascular risk factor related to excessive exercise habits are, currently, an area of research of increased interest (Kim et al., 2014). In such a broad context, the present 

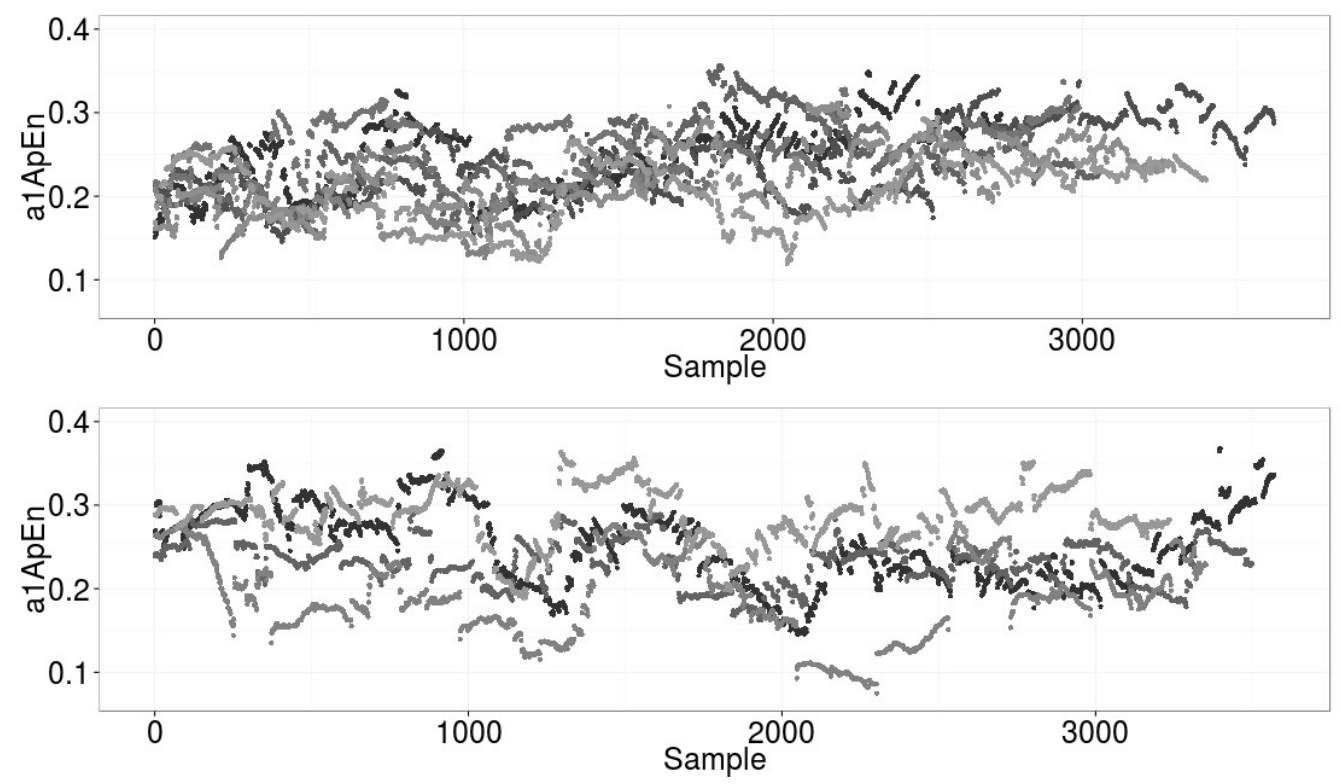

B

Figure 4.2: Heart rate complexity (HRC) for 11 marathoners. HRC, estimated through a1ApEn, calculated for a moving window of 256 points (ordered samples) for: (A) 7 subjects who have trained for endurance running for more than 10 years; (B) 4 subjects who have trained for endurance running for less than 3 years. Different shades of gray represent individuals. 
Chapter 4. Heart Rate Control in Amateur Marathoners with Different Training Backgrounds

manuscript approached this issue by studying how the metabolic coupling behaves in marathoners with different running backgrounds. Our results show that the slope of the linear regression between heart rate complexity and heart rate successfully classified the subjects by the number of years training for long distance running. On the other hand, the slope of the linear regression between $\mathrm{HRV} / \mathrm{HRC}$ and heart rate is not able to discriminate between individuals in regard to the number of finished marathons.

\subsubsection{Differences between Groups}

Within-groups, the subjects of this study were not homogeneous; however, the groups were similar in their heterogeneity. Therefore, it is possible to affirm that the results were not a consequence of differences in age, BMI, marathon conclusion time or period between the marathon and the experiment. Nevertheless, some considerations must be put forward.

On the matter of the age of the subjects, it is important to point out that this variable is considered one of the major determinants of instantaneous heart rate control information (Tsuji et al., 1996) and different results are expected for young versus middleaged/older adults (Melanson \& Freedson, 2001). Therefore, further studies with a wider range of ages are necessary to test the generality of the patterns obtained here.

Another important point is that, even though the number of days between the marathon and the experiment diverged considerably among subjects, it is known that biomarkers indicating potential myocardial damage regress to normal values between 24 to 48 hours after a marathon (Oxborough et al., 2010; Predel, 2014). Moreover, impairments in the systolic and/or diastolic function after long distance running (i.e., exercise-induced cardiac fatigue) appear to be, in general, transient (less than 48 hours, Oxborough et al., 2010). Hence, it is not likely that the period between the marathon and the experiment influenced our analyses. 


\subsubsection{Estimators of heart rate control as a function of heart rate}

The acute effect of the current protocol in the correlation between of heart rate control and heart rate is discussed in Chapter 3. Nevertheless, the nature of the present study allows some speculations about the chronic effect of exercise in the interaction of these variables. In the context of training for long distance running, the majority of studies associate the decrease of HR during rest to an increase in HRV via changes in the parasympathetic tone (e.g., Rennie et al., 2003; Sloan et al., 2009). However, other studies observed, with training, a decrease in the heart rate without changes in HRV (Bonaduce et al., 1998; Gregoire et al., 1996), while another observed changes in HRV but not in heart rate (Melanson \& Freedson, 2001).

Our results show that HRV/HRC indexes during exercise could increase or even decrease with higher heart rates, and also this relationship is dependent of the training background. Therefore, to expect a fixed negative correlation, acutely and/or chronically, between $\mathrm{HRV} / \mathrm{HRC}$ and $\mathrm{HR}$ may be misleading. Hence, it is important that future studies consider that different training regimes might change the HRV/HRC versus HR relationship and, moreover, that these changes may be better observable during the exercise section itself.

Another interesting benefit of our approach is that it proposes a clear threshold between different groups (i.e., the positive/non-positive slope). This advantage is easily recognized considering that typical beat-to-beat heart rate control studies suffer the drawback of lacking a formal definition of normal measurements (Migliaro et al., 2001) and, as a consequence, an intrinsic difficulty to compare different individuals (Al-Ani et al., 1996). On the other hand, utilizing the present methodology it is possible to categorize an individual regardless of his/her absolute values of HRV/HRC or any additional standardization.

The non-positive slopes bring an interesting new perspective as well. The study of Chapter 3 obtained such non-positive slopes for sedentary individuals and, therefore, 
Chapter 4. Heart Rate Control in Amateur Marathoners with Different Training Backgrounds

it is possible that these slopes may be a marker of an impairing effect of completing a marathon in some highly trained individuals. This suggests that, even though basic cardiac functions are restored shortly after a marathon (see section 4.4.1), the effect of a high metabolic demand on cardiac control could last longer.

\subsubsection{Metabolic coupling in relation to the number of completed marathons}

On the contrary of our initial hypothesis, the slope of the linear regression of HRV/HRC versus heart rate is not adequate to discriminate individuals who have completed their first marathon from subjects who have completed more than 3 marathons in the last 5 years. However, it is interesting to observe that, regardless of the cardiac control estimator, all individuals who have completed more marathons possessed the behavior expected for trained individuals (i.e., a significantly positive correlation, see Chapter 3).

This is, to our knowledge, the first study that compares HRV/HRC in individuals separated by the number of completed marathons. However, some studies have shown that the number of marathons appears to be related to cardiac disorders. For instance, there is a positive correlation between the number of marathons and coronary artery calcification (Möhlenkamp et al., 2008) or myocardial fibrosis assessed through late gadolinium enhancement (Wilson et al., 2011). It is important to point out that those studies were performed in individuals with more than 50 years (mean 57 years, in both), indicating a possible effect of age, and, more importantly, all subjects passed an inclusion criterion more stringent than ours, as described below.

The work of Möhlenkamp et al. (2008) included subjects that had completed 5 marathons in the previous 3 years, i.e., more than one per year. The volunteers of the study of Wilson et al. (2011), that included professional athletes, completed a mean number of 178 marathons (range 20-650). Therefore, it is possible to propose the existence of an upper limit on the number of marathons above which it may affect negatively the cardiovascular system. Even though these studies are, as a whole, different from ours, 
such scenario allows us to hypothesize that the correlation between heart rate control estimators and heart rate should be negative in individuals that participated in a high number of marathons over a short period of time, a matter that deserves further studies.

Finally, the absence of a defined pattern in the individuals who completed their first marathon suggests that the first marathon by itself does not influence the metabolic coupling as we expected. It is possible that this absence of pattern is associated with the internal differences in training background of the group, an issue better discussed below.

\subsubsection{Metabolic coupling in relation to the number years of training for endurance running}

The results show that differences in the slope of the linear regression between heart rate complexity and heart rate were able to discriminate individuals by years of training for endurance running. Therefore, in our analyses and in the range of number of marathons studied, the amount of years training for long distance running is more influential than the number of marathons completed.

The importance of a prolonged period of endurance training has already been suggested by other authors. Loimaala et al. (2000) obtained no significant differences in HRV with training and, consequently, suggested that such intervention needs to be performed for many years before changes in the studied variables become detectable. Moreover, Bonaduce et al. (1998) obtained higher values of HRV in detrained subjects than in controls, illustrating that HRV is affected by the training background.

Another interesting point is that the positive correlation is more consistently obtained though a1ApEn-HRC. This was also the case in Chapter 3 and corroborates the proposal that nonlinear heart rate analyses show different information from HRV analyses (Heffernan et al., 2007; Tulppo et al., 2001). Hence, the use of a1ApEn-HRC may contribute to a better understanding of the effect of training in instantaneous cardiac control, the conflictive scenario presented in the section 4.1. 
Chapter 4. Heart Rate Control in Amateur Marathoners with Different Training Backgrounds

Our original hypothesis did not include the number of years training for long distance running as a classification criterion. This pattern was observed during the analysis and additional data may confirm such trend. Nevertheless, within the paradigm of $\mathrm{HRC} / \mathrm{HRC}$ as an estimator of cardiac control, our results bring up a strong suggestion: endurance runners should train for more than three years before running their first marathon. Moreover, the present study successfully confirms the potential of the study of the linear regression between $\mathrm{HRC}$ and heart rate as an index of physiological status.

\subsection{Conclusions}

In summary, our results demonstrated that the slope of the linear regression between heart rate complexity and heart rate is capable of discriminating between the number of years of training for endurance running. This may contribute to the discussion of heart rate control in the context of exercise physiology and, potentially, supply criteria for training protocols. 


\section{Bibliography}

Al-Ani, M., Munir, S. M., White, M., Townend, J., \& Coote, J. H. (1996). Changes

in $\mathrm{R}-\mathrm{R}$ variability before and after endurance training measured by power spectral analysis and by the effect of isometric muscle contraction. European Journal of Applied Physiology and Occupational Physiology, 74(5):397-403.

Armstrong, L. E. \& VanHeest, J. L. (2002). The unknown mechanism of the overtraining syndrome: clues from depression and psychoneuroimmunology. Sports medicine (Auckland, N.Z.), 32(3):185-209.

Aubert, A. E., Seps, B., \& Beckers, F. (2003). Heart rate variability in athletes. Sports medicine (Auckland, N.Z.), 33(12):889-919.

Billman, G. E. (2009). Cardiac autonomic neural remodeling and susceptibility to sudden cardiac death: effect of endurance exercise training. American journal of physiology. Heart and circulatory physiology, 297(4):H1171-H1193.

Bonaduce, D., Petretta, M., Cavallaro, V., Apicella, C., Ianniciello, A., Romano, M., Breglio, R., \& Marciano, F. (1998). Intensive training and cardiac autonomic control in high level athletes. Medicine and science in sports and exercise, 30(5):691-696.

Borresen, J. \& Lambert, M. I. (2008). Autonomic control of heart rate during and after exercise: Measurements and implications for monitoring training status. Sports Medicine, 38(8):633-646. 
Boutcher, S. H. \& Stein, P. (1995). Association between heart rate variability and training response in sedentary middle-aged men. European Journal of Applied Physiology and Occupational Physiology, 70(1):75-80.

Breuckmann, F., Möhlenkamp, S., Nassenstein, K., Lehmann, N., Ladd, S., Schmermund, A., Sievers, B., Schlosser, T., Jöckel, K.-H., Heusch, G., Erbel, R., \& Barkhausen, J. (2009). Myocardial Late Gadolinium Enhancement: Prevalence, Pattern, and Prognostic Relevance in Marathon Runners 1. Radiology, 251(1):50-57.

Buchheit, M., Simon, C., Viola, A. U., Doutreleau, S., Piquard, F., \& Brandenberger, G. (2004). Heart Rate Variability in Sportive Elderly: Relationship with Daily Physical Activity. Medicine and Science in Sports and Exercise, 36(4):601-605.

Coyle, E. F. (2007). Physiological Regulation of Marathon Performance. Sports Medicine, 37(4):306-311.

De Meersman, R. E. (1993). Heart rate variability and aerobic fitness. American Heart Journal, 125(3):726-731.

Dixon, E. M., Kamath, M. V., McCartney, N., \& Fallen, E. L. (1992). Neural regulation of heart rate variability in endurance athletes and sedentary controls. Cardiovascular research, 26(7):713-719.

Du, N., Bai, S., Oguri, K., Kato, Y., Matsumoto, I., Kawase, H., ., \& Matsuoka, T. (2005). Heart Rate Recovery After Exercise and Neural Regulation of Heart Rate Variability in 30-40 Year Old Female Marathon Runners. Journal of Sports Science and Medicine, 4(1):9-17.

George, K., Spence, A., Naylor, L. H., Whyte, G. P., \& Green, D. J. (2011). Cardiac adaptation to acute and chronic participation in endurance sports. Heart (British Cardiac Society), 97(24):1999-2004. 
Gregoire, J., Tuck, S., Hughson, R. L., \& Yamamoto, Y. (1996). Heart Rate Variability at Rest and Exercise: Influence of Age, Gender, and Physical Training. Canadian Journal of Applied Physiology, 21(6):455-470.

Heffernan, K. S., Fahs, C. a., Shinsako, K. K., Jae, S. Y., \& Fernhall, B. (2007). Heart rate recovery and heart rate complexity following resistance exercise training and detraining in young men. American journal of physiology. Heart and circulatory physiology, 293(5):H3180-6.

Jensen-Urstad, K., Saltin, B., Ericson, M., Storck, N., \& Jensen-Urstad, M. (1997). Pronounced resting bradycardia in male elite runners is associated with high heart rate variability. Scandinavian journal of medicine 83 science in sports, 7(5):274-278.

Kim, Y.-J., Lee, Y.-H., Park, Y., \& Jee, H. (2014). Relationship of exercise habits and cardiac events to resting blood pressure in middle-aged amateur marathoners. Gazzetta Medica Italiana, 173(5):273-81.

Lake, D. E., Richman, J. S., Griffin, M. P., \& Moorman, J. R. (2002). Sample entropy analysis of neonatal heart rate variability. American journal of physiology. Regulatory, integrative and comparative physiology, 283(3):R789-R797.

Lambert, M. I., Mbambo, Z. H., \& Gibson, a. S. C. (1998). Heart rate during training and competition for longdistance running. Journal of Sports Sciences, 16(sup1):85-90.

Lazoglu, A. H., Glace, B., Gleim, G. W., \& Coplan, N. L. (1996). Exercise and heart rate variability. American Heart Journal, 131(4):825-827.

Levy, W. C., Cerqueira, M. D., Harp, G. D., Johannessen, K.-A., Abrass, I. B., Schwartz, R. S., \& Stratton, J. R. (1998). Effect of endurance exercise training on heart rate variability at rest in healthy young and older men. The American Journal of Cardiology, 82(10):1236-1241. 
Loimaala, A., Huikuri, H., Oja, P., Pasanen, M., \& Vuori, I. (2000). Controlled 5mo aerobic training improves heart rate but not heart rate variability or baroreflex sensitivity. Journal of applied physiology (Bethesda, Md. : 1985), 89(5):1825-1829.

Melanson, E. L. \& Freedson, P. S. (2001). The effect of endurance training on resting heart rate variability in sedentary adult males. European Journal of Applied Physiology, 85(5):442-449.

Melo, R., Santos, M., Silva, E., Quitério, R., Moreno, M., Reis, M., Verzola, I., Oliveira, L., Martins, L., Gallo-Junior, L., \& Catai, A. (2005). Effects of age and physical activity on the autonomic control of heart rate in healthy men. Brazilian Journal of Medical and Biological Research, 38(9):1331-8.

Migliaro, E., Contreras, P., Bech, S., Etxagibel, A., Castro, M., Ricca, R., \& Vicente, K. (2001). Relative influence of age, resting heart rate and sedentary life style in shortterm analysis of heart rate variability. Brazilian Journal of Medical and Biological Research, 34(4):493-500.

Möhlenkamp, S., Lehmann, N., Breuckmann, F., Bröcker-Preuss, M., Nassenstein, K., Halle, M., Budde, T., Mann, K., Barkhausen, J., Heusch, G., Jöckel, K.-H., \& Erbel, R. (2008). Running: the risk of coronary events : Prevalence and prognostic relevance of coronary atherosclerosis in marathon runners. European heart journal, 29(15):1903-10.

Neilan, T. G., Januzzi, J. L., Lee-Lewandrowski, E., Ton-Nu, T.-T., Yoerger, D. M., Jassal, D. S., Lewandrowski, K. B., Siegel, A. J., Marshall, J. E., Douglas, P. S., Lawlor, D., Picard, M. H., \& Wood, M. J. (2006). Myocardial injury and ventricular dysfunction related to training levels among nonelite participants in the Boston marathon. Circulation, 114(22):2325-33.

Nicholl, J. \& Willians, B. T. (1982). Medical problems before and after a popular marathon. British medical journal (Clinical research ed.), 285(6353):1465-1466. 
Oxborough, D., Birch, K., Shave, R., \& George, K. (2010). "Exercise-Induced Cardiac Fatigue"-A Review of the Echocardiographic Literature. Echocardiography, 27(9):11301140.

Perini, R., Fisher, N., Veicsteinas, A., \& Pendergast, D. R. (2002). Aerobic training and cardiovascular responses at rest and during exercise in older men and women. Medicine and science in sports and exercise, 34(4):700-708.

Pincus, S. M. (1991). Approximate entropy as a measure of system complexity. Proceedings of the National Academy of Sciences of the United States of America, 88(6):22972301.

Predel, H.-G. (2014). Marathon run: cardiovascular adaptation and cardiovascular risk. European Heart Journal, 35(44):3091-3098.

R Core Team (2013). R: A Language and Environment for Statistical Computing.

Rennie, K. L., Hemingway, H., Kumari, M., Brunner, E., Malik, M., \& Marmot, M. (2003). Effects of moderate and vigorous physical activity on heart rate variability in a British study of civil servants. American Journal of Epidemiology, 158(2):135-143.

Sacknoff, D. M., Gleim, G. W., Stachenfeld, N., \& Coplan, N. L. (1994). Effect of athletic training on heart rate variability. American Heart Journal, 127(5):1275-1278.

Sanchez, L. D., Corwell, B., \& Berkoff, D. (2006). Medical problems of marathon runners. The American journal of emergency medicine, 24(5):608-15.

Sandercock, G. R. H. \& Brodie, D. a. (2006). The use of heart rate variability measures to assess autonomic control during exercise. Scandinavian Journal of Medicine and Science in Sports, 16(5):302-313.

Satterthwaite, P., Norton, R., Larmer, P., \& Robinson, E. (1999). Risk factors for injuries 
and other health problems sustained in a marathon. British journal of sports medicine, $33(1): 22-6$.

Schmermund, A., Voigtländer, T., \& Nowak, B. (2008). The risk of marathon runners-live it up, run fast, die young? European heart journal, 29(15):1800-2.

Schuit, A. J., van Amelsvoort, L. G., Verheij, T. C., Rijneke, R. D., Maan, A. C., Swenne, C. A., \& Schouten, E. G. (1999). Exercise training and heart rate variability in older people. Medicine and science in sports and exercise, 31(6):816-821.

Sheppard, M. N. (2012). The fittest person in the morgue? Histopathology, 60(3):381-96.

Shin, D.-G., Yoo, C.-S., Yi, S.-H., Bae, J.-H., Kim, Y.-J., Park, J.-S., \& Hong, G.-R. (2006). Prediction of paroxysmal atrial fibrillation using nonlinear analysis of the R$\mathrm{R}$ interval dynamics before the spontaneous onset of atrial fibrillation. Circulation journal : official journal of the Japanese Circulation Society, 70(1):94-99.

Sloan, R. P., Shapiro, P. a., DeMeersman, R. E., Bagiella, E., Brondolo, E. N., McKinley, P. S., Slavov, I., Fang, Y., \& Myers, M. M. (2009). The Effect of Aerobic Training and Cardiac Autonomic Regulation in Young Adults. American Journal of Public Health, 99(5):921-928.

Smith, T. B., Hopkins, W. G., \& Lowe, T. E. (2011). Are there useful physiological or psychological markers for monitoring overload training in elite rowers? International journal of sports physiology and performance, 6(4):469-84.

Stein, P. K., Domitrovich, P. P., Huikuri, H. V., \& Kleiger, R. E. (2005). Traditional and nonlinear heart rate variability are each independently associated with mortality after myocardial infarction. Journal of Cardiovascular Electrophysiology, 16(1):13-20.

Task Force of the European Society of Cardiology and the North American Society of Pacing and Electrophysiology (Task Force) (1996). Heart rate variability: standards of 
measurement, physiological interpretation and clinical use. Task Force of the European Society of Cardiology and the North American Society of Pacing and Electrophysiology. Circulation, 93(5):1043-1065.

Tsuji, H., Venditti, F. J., Manders, E. S., Evans, J. C., Larson, M. G., Feldman, C. L., \& Levy, D. (1996). Determinants of heart rate variability. Journal of the American College of Cardiology, 28(6):1539-1546.

Tulppo, M. P., Hughson, R. L., Mäkikallio, T. H., Airaksinen, K. E., Seppänen, T., \& Huikuri, H. V. (2001). Effects of exercise and passive head-up tilt on fractal and complexity properties of heart rate dynamics. American journal of physiology. Heart and circulatory physiology, 280(3):H1081-H1087.

Tulppo, M. P., Mäkikallio, T. H., Seppänen, T., Laukkanen, R. T., \& Huikuri, H. V. (1998). Vagal modulation of heart rate during exercise: effects of age and physical fitness. The American journal of physiology, 274(2 Pt 2):H424-H429.

Uusitalo, A. L. T., Laitinen, T., Väisänen, S. B., Länsimies, E., \& Rauramaa, R. (2004). Physical training and heart rate and blood pressure variability: a 5-yr randomized trial. American journal of physiology. Heart and circulatory physiology, 286(5):H1821H1826.

Wilson, M., O'Hanlon, R., Prasad, S., Deighan, A., MacMillan, P., Oxborough, D., Godfrey, R., Smith, G., Maceira, A., Sharma, S., George, K., \& Whyte, G. (2011). Diverse patterns of myocardial fibrosis in lifelong, veteran endurance athletes. Journal of Applied Physiology, 110(6):1622-1626. 


\title{
Chapter 5
}

\section{Oscillatory patterns in heart rate variability and complexity: a}

\section{meta-analysis}

\begin{abstract}
The study instantaneous heart rate changes is a non invasive form to obtain indirect information about heart rate control. This beat-to-beat variation is denominated heart rate variability (HRV) and when estimated through frequency domain methods provides information about the sympathetic (SNS) or parasympathetic (PNS) nervous system. Beat-to-beat variation can also be estimated by nonlinear methods, then termed heart rate complexity (HRC). Even though HRC does not possess a straightforward relationship with the SNS or PNS, these estimators are also utilized to infer changes in the autonomous nervous system (ANS). In many situations, a low value of both indexes (HRV/HRC) is associated with several cardiovascular diseases. On the other hand, there are scenarios (such as, exercise and temperature challenges) in which those indexes appear to be less informative, mainly because the association between HRV/HRC and the
\end{abstract}


ANS ceases to hold tight. Therefore, it is interesting to extract additional information from HRV/HRC analyses that could lead to a broader understanding of cardiac control. Previous experiments in our laboratory suggested the existence of an oscillatory component in $\mathrm{HRV} / \mathrm{HRC}$ results along the time of experiment. The present study tested the existence of this pattern in HRV/HRC of 13 subjects running at constant speed. For this purpose, sine wave, linear and quadratic models were fitted to the results of these estimators. The sine wave model significantly, and more adequately than the other models, fitted the results obtained. Furthermore, the correlation obtained was significantly higher for the HRC data. As far as we know, this is the first time a meta-analysis of this kind is applied to HRV/HRC data and it reveals a new way to approach cardiac control. We suggest that the observed oscillatory pattern is associated with thermoregulation.

\subsection{Introduction}

The variation in sequential heart rate beats arises from the dynamical interaction between sympathetic and parasympathetic nervous systems and is considered an estimator of heart rate control (Billman, 2009). These instantaneous heart rate (HR) changes are studied through variations in R-R intervals (period between two consecutive $\mathrm{R}$ waves in an electrocardiogram - ECG) and may be, more commonly, measured by a frequency domain index (heart rate variability, HRV) and nonlinear methods (heart rate complexity, HRC). HRV employs a fast Fourier transform and the different ranges of the obtained spectrum (low frequencies, LF, and high frequencies, HF) are associated with the sympathetic (LF) or parasympathetic nervous system (LF and HF) (Task Force, 1996). Typically, a high value of HRV is associated with an increase in the parasympathetic activation (Task Force, 1996). On the other hand, HRC employs, among other options, methods deriving from the informational theory (such as a1ApEn, Chapter 2) to quantify the degree of disorder in time series. Even though the relationship is not as straightforward 
Chapter 5. Oscillatory patterns in heart rate variability and complexity: a meta-analysis

as in HRV, many studies utilized nonlinear methods to infer alterations the branches of the autonomic nervous system (e.g., Boettger et al., 2010; Flouris et al., 2014; Heffernan et al., 2007; Kuusela et al., 2002; Platisa \& Gal, 2006).

In both cases, a low value of such estimators is associated with several cardiovascular diseases (Lake et al., 2002; Rassias et al., 2005; Stein et al., 2005; Task Force, 1996). Nevertheless, the physiology behind these analyses is considered obscure (Eckberg, 1997). The main problem is that HRV/HRC data does not match what is expected for the branches of the autonomous nervous system (ANS) in many situations (Eckberg, 1997; Malik, 1998; Parati et al., 2006). This issue can be illustrated in the context of HRV/HRC during exercise and also as response to temperature changes. Even though our study focuses on the former process, some discussions shall be extrapolated to the latter.

It is well known that the relationship between beat-to-beat and ANS is particularly problematic when studied during exercise at higher intensities. This is because the increase in HRV/HRC obtained may not be explained by the decrease in parasympathetic activation typically expected for these conditions (conf. Casadei et al. (1995); Perini \& Veicsteinas (2003) and Chapter 3). A plausible rationalization is that at higher magnitudes of exercise, non-neural regulation (e.g., changes in the mechanical cardiac axis due to changes in the ventilatory pattern, and/or atrial transmural pressure associated with intratoraxic pressure and venous return (Bernardi et al., 1990; Casadei et al., 1996)) becomes more relevant (Sandercock \& Brodie, 2006). This suggestion is corroborated by data that include experiments with ganglion blockage (Casadei et al., 1996) and heart transplanted subjects (Bernardi et al., 1990). However, since beat-to-beat analyses (especially HRV) are limited to inferences regarding the sympathetic and the parasympathetic autonomous nervous systems, there is not a clear way to extract this non-neural information in normal subjects.

The constraints imposed by the HRV/HRC versus sympathovagal modulation paradigm are also reflected in other parameters influencing the heart rate control, leading to the 
conclusion that the relationship between cardiac control and specific ranges of a spectral power analysis is too simplistic (Parati et al., 1995). This is observable, for example, in the few existing studies regarding the effect of high temperatures in HRV/HRC. Brenner et al. (1997) obtained, during $50 \% \dot{V} \mathrm{O}_{2}$ max exercise at high temperatures, a non significant decrease in the parasympathetic activity estimated through the HF component and, moreover, a significant increase in the LF/HF ratio (representing sympathovagal balance). Furthermore, Flouris et al. (2014) studied the instantaneous heart rate control, during exercise, and obtained an increase in the parasympathetic activity in 75 of the 102 variables measured (including linear, frequency domain and nonlinear methods) in a protocol along 14 days of high temperature acclimation. It is possible to identify, therefore, a variety of protocols (from a simple exposure to acclimation) designed to better understand the relationship between instantaneous heart rate control and temperature. However, this interpretation is, once again, only related to changes in the branches of the autonomous nervous system. This restraint is highlighted in the work of Flouris et al. (2014), where 102 heart rate control estimators were utilized to reach a single conclusion.

This is of great relevance considering that thermoregulation affects very low frequency components of heart rate control (Aubert et al., 2003; Parati et al., 1995), which are not typically covered by heart rate analysis. Moreover, it is suggested that hot-induced alterations are associated with the necessity to sustain venous return (Brenner et al., 1997) which provoke, in the first instance, cardiac changes unrelated to the ANS (Bernardi et al., 1990).

In this context, even though the HRV/HRC versus sympathovagal modulation contributes to many fields of physiology, it is interesting to extract additional information from HRV/HRC analyses that could lead to a broader understanding of cardiac control and, more specifically, to a better comprehension of the beat-to-beat changes during, as exemplified, exercise or temperature challenges.

Previous experiments in our laboratory measuring HRC and HRV in 7 subjects walk- 
Chapter 5. Oscillatory patterns in heart rate variability and complexity: a meta-analysis

ing in treadmills suggested that the estimators exhibit an oscillatory pattern along the time of experiment. Despite the potential to extract new information from this pattern, it is required, first and foremost, additional analysis with a new set of data to test if this pattern is ubiquitous. For this objective, 13 new subjects were studied. We analyzed HRV and HRC, measured through a1ApEn, during 25 minutes of running; a situation when the autonomous neural components of cardiac control become less detectable (conf. Chapter 3 and Sandercock \& Brodie (2006). Moreover, it was suggested that, for same data utilized in this study, that the HRV/HRC obtained possess non-neural origin (Chapter 3$)$.

\subsection{Material and Methods}

The present study utilized part of the data of Chapter 3. However, from the original 15 subjects, 2 were discarded due to noise, resulting in 13 healthy male voluntaries (mean age: 29 years, range $20-35$; mean body mass index: 24.88, range $19.58-32.95)$ with different degrees of fitness. All subjects were instructed to be hydrated and not to drink coffee and alcohol in the day of the experiment and to avoid extreme physical activity in the day before. The experiments were conducted at the Biosciences Institute of the University of São Paulo and the experimental protocol was approved by the local ethics committee (Comissão de Ética no Uso de Animais-Instituto de Biociências (CEUA-IB)). All ECG data were collected at ambient temperatures of $21-24{ }^{\circ} \mathrm{C}$ and always at the preferential time of the day for physical activity for each individual.

For control purposes, electrocardiogram data was recorded for 5 minutes during resting conditions, and afterwards each participant had its preferential speed $(u)$ estimated and warmed-up during 5 minutes at $0.9 u$. Subsequently, ECG was recorded during 25 minutes of running at constant speed $u$.

ECG data was acquired by means of three superficial electrodes (Unilect Electrodes, 
Maersk Medical LTD, Copenhagen, Denmark) in the CM5 configuration. ECG was recorded and digitalized using a sampling rate of $1000 \mathrm{~Hz}$ by a MP30 interface and the Biopac Student Lab Pro software (Biopac Systems Inc., Goleta, CA, USA). From the raw data, $\mathrm{R}-\mathrm{R}$ intervals were extracted. The first minute of data were discarded to avoid transient behaviors. All of the following procedures were performed in sequential (timeordered) series of 256 points sub-vectors, with 231 points of overlap between each pair of sub-vectors, along the original data set.

For each sub-vector, the heart rate variability and heart rate complexity were analyzed. Heart rate variability, via fast Fourier transform (FFT) was carried out and the spectral components were separated in $\leq 0.04 \mathrm{~Hz}$ for very low frequencies range, $0.04-0.15 \mathrm{~Hz}$ for low frequencies range (LF, related to both sympathetic and parasympathetic activity) and $0.15-0.4 \mathrm{~Hz}$ for high frequencies range (HF, associated with the parasympathetic activity) (Task Force, 1996). Variability was estimated via the normalized HF (nuHF, in the present study calculated by nuHF $\left.=\frac{H F}{(V L F+L F+H F)}\right)$ and the ratio between HF and LF (from now on simply referred as to "ratio"). Heart rate complexity was obtained by means of a1ApEn (Chapter 3). Notice that we chose to express the ratio as $\frac{H F}{L F}$, instead of the typical $\frac{L F}{H F}$ (Task Force, 1996), so a higher value of all three estimators studied was related to a higher level heart rate variability/complexity.

Both R-R extraction and subsequent analyses were performed through a set of implemented scripts in Matlab (MATLAB version 7.10.0.499 Natick, Massachusetts, USA: The MathWorks Inc.). Since the original dataset is sequentially analyzed, we obtain sequential results, i.e., time-ordered resulting vectors.

The resulting vectors were DC corrected (i.e., shifted along the y axis) in order to have zero mean. These resulting data were fitted through a single sine wave (nonlinear least squares method: Trust-Region algorithm), a linear polynomial and a quadratic polynomial (linear least squares). To verify the correlation that each model provided, the HRV/HRC vectors and the 3 models were compared utilizing a Pearson's correlation 
Chapter 5. Oscillatory patterns in heart rate variability and complexity: a meta-analysis

test. To infer the best adequacy of the models, the correlation value obtained and the adjusted $R^{2}$ were compared between models utilizing a paired Student's t-test. Similarly, we also investigated which of the 3 estimators is better described by the most adequate model. All differences were considered significant for $p \leq 0.05$. All statistical tests were performed using Matlab built in scripts. Figures were produced in the $\mathrm{R}$ environment (R Core Team, 2013).

\subsection{Results}

\subsubsection{Comparing the 3 models}

An example of the three fits obtained for an a1ApEn vector is found in Figure 5.1. The sine wave model was significantly correlated to a1ApEn, nuHF and HF/LF ratio data in all 13 subjects. On the other hand, the linear polynomial was significantly correlated to a1ApEn and nuHF in 8 individuals and to $\mathrm{HF} / \mathrm{LF}$ ratio in 10 subjects. Finally, the quadratic polynomial was significantly correlated to a1ApEn and HF/LF ratio in 12 cases and to nuHF in 8 subjects.

The correlation coefficient and adjusted $R^{2}$ were significantly higher in the sine wave model than in the linear and quadratic polynomial for a1ApEn (all $p<0.001$ ) and for nuHF (all $p<0.01$ ). Figure 5.2 shows such results for adjusted $R^{2}$ for a1ApEn data. On the other hand, the sine wave model for the HF/LF ratio possessed a correlation coefficient and adjusted $R^{2}$ higher than the linear polynomial (both $p<0.01$ ) but not significantly different from the quadratic polynomial $(p=0.33$ for the correlation coefficient and $p=0.12$ for adjusted $R^{2}$ ).

These results imply that the sine wave model explains significantly the HRC/HRV data and, moreover, better than the linear and quadratic polynomial for a1ApEn and nuHF. 

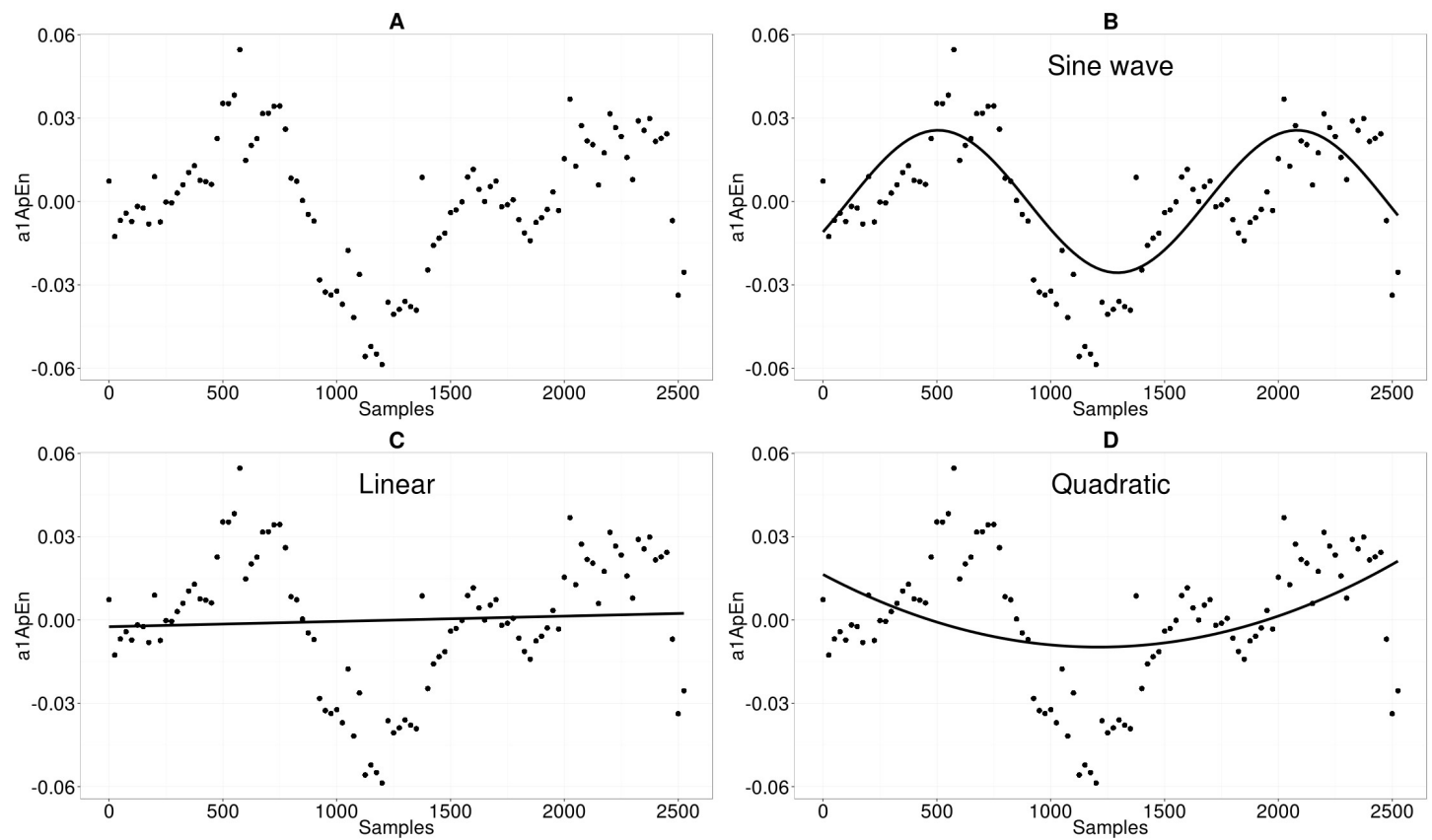

Figure 5.1: Heart rate complexity (HRC) and three models fitted. (A) HRC, estimated through a1ApEn, calculated for sub-vectors of 256 points (ordered samples) for one subject running. To this data, it was fitted: (B) a sine wave, (C) a linear polynomial and (D) a quadratic polynomial. 
Chapter 5. Oscillatory patterns in heart rate variability and complexity: a meta-analysis

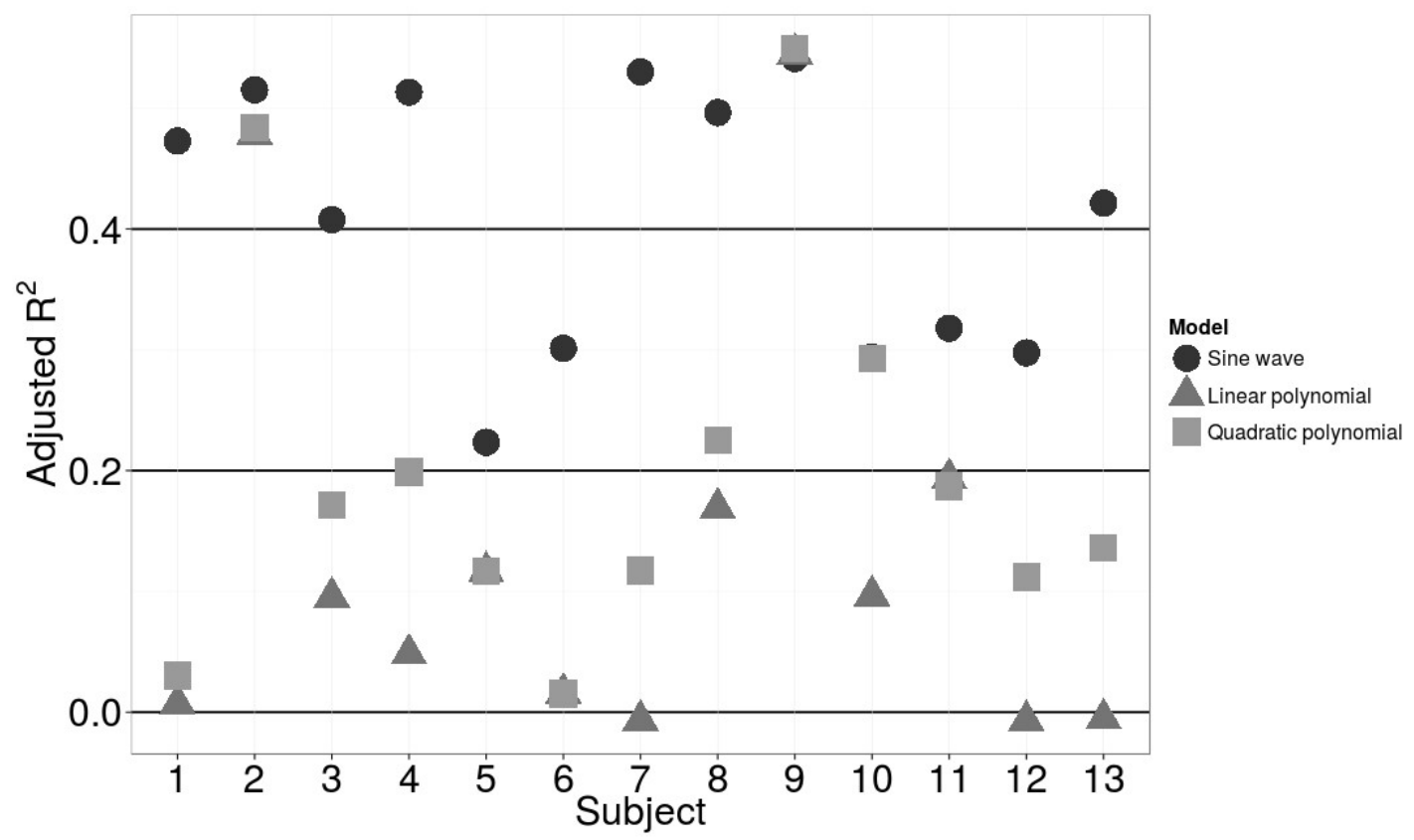

Figure 5.2: Adjusted $R^{2}$ for 3 models (sine wave - black circles; linear polynomial - grey triangles; quadratic polynomial - grey squares) fitted to HRC data in 13 subjects. See text for discussion.

\subsubsection{Sine wave fit for the three estimators}

A sine wave fit for the three estimators in one subject is exemplified in Figure 5.3. The sine wave model correlation coefficient and adjusted $R^{2}$ were significantly higher for a1ApEn than for nuHF $(p<0.05)$ and HF/LF ratio $(p<0.01)$.

Furthermore, it is important to point out that the a1ApEn data had only one subject (\#9 in Figure 5.2) in which the sine wave fit was poorer than the other models. This is particularly interesting because, differently from what was observed for nuHF in 2 subjects and $\mathrm{HF} / \mathrm{LF}$ ratio in 3 subjects, the a1ApEn vector for subject \#9 possessed a positive trend summed upon the oscillatory component (Figure 5.4). Finally, the sine wave parameters and the approximate period obtained are shown in Table 5.1. 

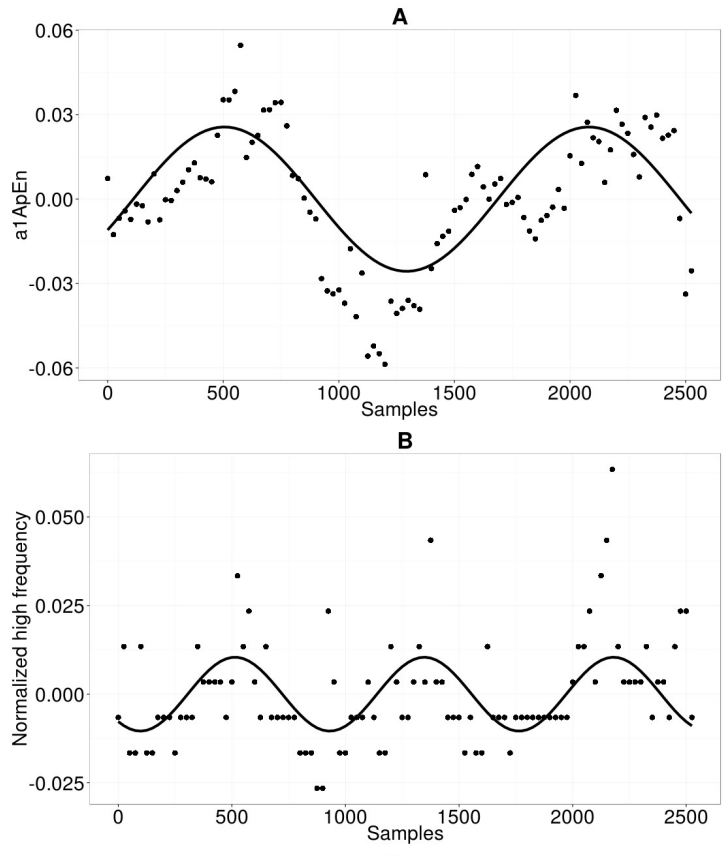

C

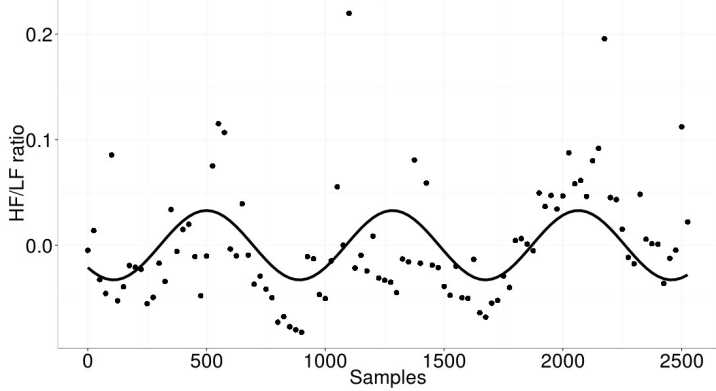

Figure 5.3: Example of a sine wave fit to heart rate variability (HRV) and heart rate complexity (HRC) data (ordered samples in the x-axis). (A) HRC estimated through ApEn. (B) Normalized high frequency component of the heart rate variability spectral analysis (C) Ratio between high frequency and low frequency components of the heart rate variability spectral analysis. 
Chapter 5. Oscillatory patterns in heart rate variability and complexity: a meta-analysis

Table 5.1: Parameters and approximate period of the sine waves fitted to a1ApEn results. The cells contain the parameters of the sine waves $(A, \omega$ and $\theta$ in $y=A(\sin x(\omega x+$ $\theta)$ )) where $x$ is the ordered samples (representing time) adjusted to the a1Apen results obtained for the 13 subjects running. Moreover, the approximate period (in minutes) for the same sine waves are reported. Finally, the subject \#9 data (shown in Figure 5.4) provided a poor fit and, therefore, it was not possible to estimate the approximate period.

\begin{tabular}{|c|c|c|c|c|}
\hline \multirow[b]{2}{*}{ Subject } & \multicolumn{3}{|c|}{$\begin{array}{l}\text { Parameters obtained for the sine wave fit: } \\
\qquad y=A(\sin x(\omega x+\theta))\end{array}$} & \multirow[t]{2}{*}{$\begin{array}{c}\text { Approximate period } \\
\text { (minutes) }\end{array}$} \\
\hline & $\mathrm{A}$ & $\omega$ & $\theta$ & \\
\hline 1 & 0.0369 & 0.1597 & -0.1857 & 10 \\
\hline 2 & 0.0314 & 0.0368 & -2.1782 & 25 \\
\hline 3 & 0.0268 & 0.0608 & -3.1166 & 20 \\
\hline 4 & 0.0371 & 0.2309 & 0.6964 & 8 \\
\hline 5 & 0.0245 & 0.0913 & -2.5731 & 15 \\
\hline 6 & 0.0299 & 0.1625 & 3.2285 & 9 \\
\hline 7 & 0.0256 & 0.0996 & -0.5413 & 17 \\
\hline 8 & 0.0299 & 0.0870 & 0.6085 & 14 \\
\hline 9 & 0.3424 & 0.0021 & -0.1361 & - \\
\hline 10 & 0.0243 & 0.1677 & -0.0210 & 8 \\
\hline 11 & 0.0243 & 0.0496 & -2.9991 & 25 \\
\hline 12 & 0.0254 & 0.0719 & -2.2586 & 19 \\
\hline 13 & 0.0279 & 0.0736 & 0.5641 & 19 \\
\hline
\end{tabular}



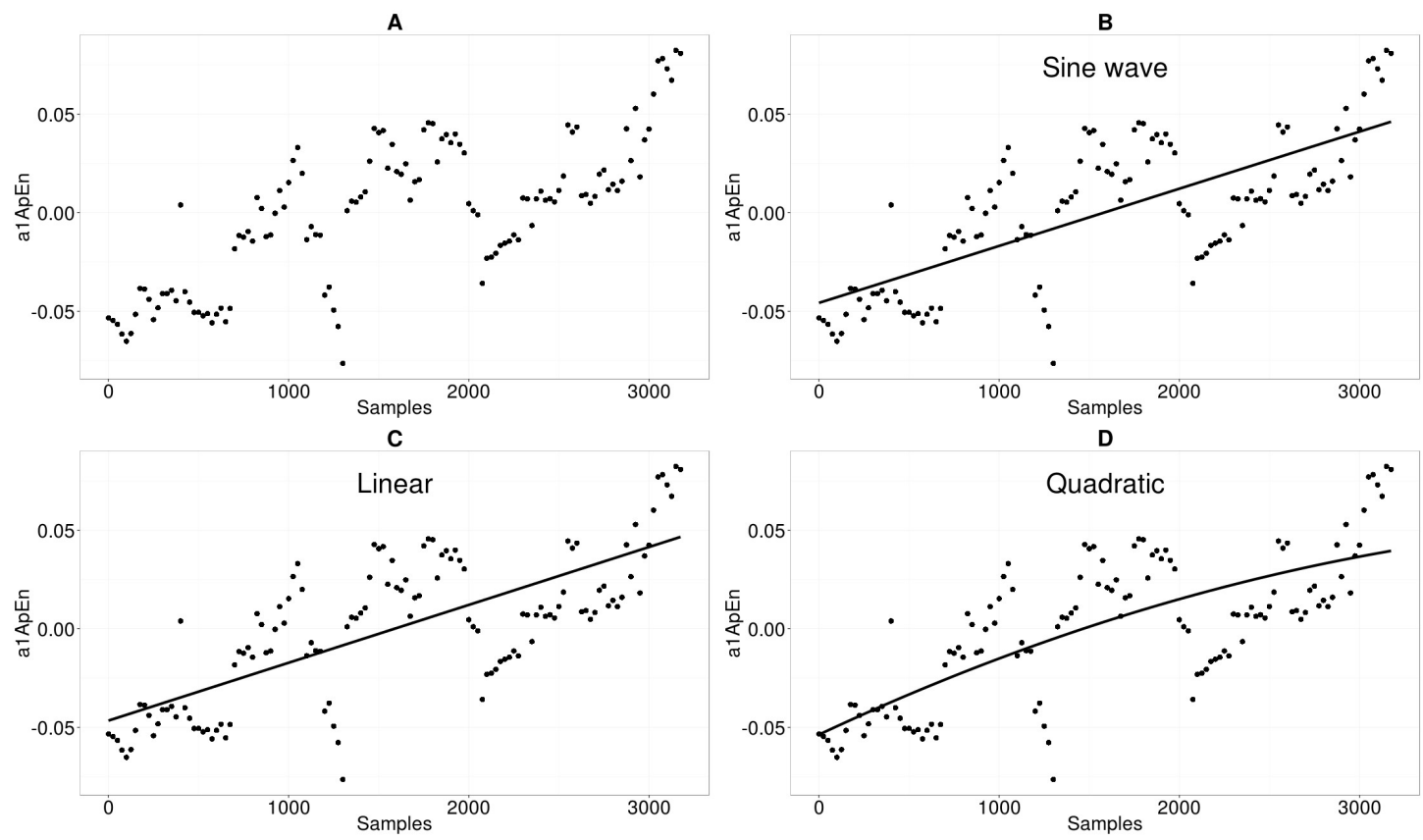

Figure 5.4: Heart rate complexity (HRC) and three models fitted for subject \#9. (A) Raw HRC data, estimated through a1ApEn, calculated for sub-vectors of 256 points (ordered samples). Fits: (B) Sine wave, (C) Linear polynomial; (D) Quadratic polynomial.

\subsection{Discussion}

The present study aimed to identify unaccounted information in the results from typical instantaneous heart rate control estimators. To this end, 3 different models (sine wave, linear and quadratic polynomials) were adjusted to HRV and HRC results obtained from 13 subjects during 25-minutes treadmill exercise. This meta-analysis demonstrated that the sine wave model significantly, and more adequately than the other models, explains the results obtained with a1ApEn (the highest correlation) and nuHF, but not with the $\mathrm{HF} / \mathrm{LF}$ ratio.

The discordant results obtained for $\mathrm{HF} / \mathrm{LF}$ ratio were not a surprise since this estimator is highly dependent on the capacity of LF to describe the sympathetic nervous system activity, a highly questioned relationship (Eckberg, 1997). Moreover, another study from our group that included the same R-R data from the present one also found 
Chapter 5. Oscillatory patterns in heart rate variability and complexity: a meta-analysis

that $\mathrm{HF} / \mathrm{LF}$ ratio shows different and less consistent results in comparison to the other estimators (Chapter 3). Thus, the HF/LF ratio will not be further taken into account.

On the other hand, for a1ApEn and nuHF, it is shown, therefore, that cardiac variability/complexity are phenomena possessing oscillatory components. In other words, the cardiac control itself shows an organized variation in time. Moreover, the consistency of these results for all the subjects strongly suggests a physiological basis underlying the process. Next, we put forward a hypothesis for that.

Since thermoregulation is associated with very low frequency components of heart rate control and, potentially, non-neural aspects of cardiac control (conf. section 5.1), we suggest that at least part of the obtained cardiac control oscillatory pattern may be related to this process. Nevertheless, proper experimentation with protocols including different thermal stresses are still necessary to test this hypothesis. An interesting suggestion is that temperature differences may be associated not only to the existence of the oscillatory pattern but, also, to the frequency of the oscillations. Some efforts of our group are now directed to approach such an issue.

This is not the first time that, with a focus on slower oscillatory patterns, an alternative to the emblematic LF and HF components is proposed. There are attempts to extract information from the very low frequency component of the spectral analysis $(\mathrm{VLF}, \mathrm{FFT}$ range $\leq 0.04 \mathrm{~Hz})$. The study of VLF produces interesting results: for example it is known that this estimator increases with physical activity (Aubert et al., 2003; Sandercock \& Brodie, 2006). Nevertheless, the physiological processes behind it are questioned, even among supporters of LF and HF analyses (Aubert et al., 2003; Task Force, 1996). In this sense, its use is discouraged for short term ECGs, i.e., of the order of minutes (Aubert et al., 2003; Task Force, 1996). It is important to point out that short term ECGs are usually contrasted with long term 24 hours ECGs, in which is suggested that VLF gains relevance (Task Force, 1996). Therefore, in addition to the dubious theoretical background, there are no clear methodological guidelines to the use 
this estimator in situations of intermediary data set size.

The present study shows a number of relevant points to cardiac control analysis. Firstly, our approach by-passes the above mentioned problems because it is a metaanalysis of the estimators themselves, and their potential oscillatory behavior. This allows the HRV and HRC analyses to be performed in 256 points vectors, within the range recommended by Task Force (1996). In addition, instead of dealing with the debatable use of VLF from ECG recordings, we extract direct information in regard to low frequency oscillations of the cardiac control itself; and such information comes from better understood estimators: nuHF-HRV and, specially, a1ApEn-HRC.

It is important to emphasize that we are not suggesting that the pattern detected in this meta-analysis is associated with the sympathetic or parasympathetic nervous system. As already cited, our results from a parallel study concluded that this association does not stand and, moreover, suggested that these estimators are, indeed, detecting non-neural aspects of the cardiac control (Chapter 3).

It is interesting to note that both the putative non-neural and the oscillatory components of cardiac control were better detected by the use of a1ApEn. This tool is, therefore, able to characterize the dominant aspect of cardiac control regardless of its origin.

In conclusion, we propose an innovative approach to extract additional information from heart rate control analyses by studying the time-variation of its estimators themselves. Particularly in the present case, our meta-analysis was able to detect an oscillatory pattern in typical $\mathrm{HRV} / \mathrm{HRC}$ and we suggest that, maybe, it is associated with thermoregulation. Nevertheless, future studies are required to reveal the full potential of this approach. 


\section{Bibliography}

Aubert, A. E., Seps, B., \& Beckers, F. (2003). Heart rate variability in athletes. Sports medicine (Auckland, N.Z.), 33(12):889-919.

Bernardi, L., Salvucci, F., Suardi, R., Soldá, P. L., Calciati, A., Perlini, S., Falcone, C., \& Ricciardi, L. (1990). Evidence for an intrinsic mechanism regulating heart rate variability in the transplanted and the intact heart during submaximal dynamic exercise? Cardiovascular research, 24:969-981.

Billman, G. E. (2009). Cardiac autonomic neural remodeling and susceptibility to sudden cardiac death: effect of endurance exercise training. American journal of physiology. Heart and circulatory physiology, 297(4):H1171-H1193.

Boettger, S., Puta, C., Yeragani, V. K., Donath, L., Müller, H. J., Gabriel, H. H. W., \& Bär, K. J. (2010). Heart rate variability, QT variability, and electrodermal activity during exercise. Medicine and Science in Sports and Exercise, 42(3):443-448.

Brenner, I. K., Thomas, S., \& Shephard, R. J. (1997). Spectral analysis of heart rate variability during heat exposure and repeated exercise. European journal of applied physiology and occupational physiology, 76(2):145-156.

Casadei, B., Cochrane, S., Johnston, J., Conway, J., \& Sleight, P. (1995). Pitfalls in the interpretation of spectral analysis of the heart rate variability during exercise in humans. Acta physiologica Scandinavica, 153(2):125-131. 
Casadei, B., Moon, J., Johnston, J., Caiazza, A., \& Sleight, P. (1996). Is respiratory sinus arrhythmia a good index of cardiac vagal tone in exercise? Journal of applied physiology (Bethesda, Md. : 1985), 81:556-564.

Eckberg, D. L. (1997). Sympathovagal balance: a critical appraisal. Circulation, 96(9):3224-32.

Flouris, A. D., Poirier, M. P., Bravi, A., Wright-Beatty, H. E., Herry, C., Seely, A. J., \& Kenny, G. P. (2014). Changes in heart rate variability during the induction and decay of heat acclimation. European Journal of Applied Physiology, 114:2119-2128.

Heffernan, K. S., Fahs, C. a., Shinsako, K. K., Jae, S. Y., \& Fernhall, B. (2007). Heart rate recovery and heart rate complexity following resistance exercise training and detraining in young men. American journal of physiology. Heart and circulatory physiology, 293(5):H3180-6.

Kuusela, T. a., Jartti, T. T., Tahvanainen, K. U. O., \& Kaila, T. J. (2002). Nonlinear methods of biosignal analysis in assessing terbutaline-induced heart rate and blood pressure changes. American journal of physiology. Heart and circulatory physiology, 282(2):H773-H783.

Lake, D. E., Richman, J. S., Griffin, M. P., \& Moorman, J. R. (2002). Sample entropy analysis of neonatal heart rate variability. American journal of physiology. Regulatory, integrative and comparative physiology, 283(3):R789-R797.

Malik, M. (1998). Sympathovagal balance: a critical appraisal. Circulation, 98(23):26432644.

Parati, G., Mancia, G., Rienzo, M. D., Castiglioni, P., Taylor, J. a., Studinger, P., Di Rienzo, M., Malliani, A., Julien, C., Billman, G. E., Cerutti, S., Piepoli, M. F., Bernardi, L., Sleight, P., Cohen, M. a., Tan, C. O., Laude, D., Elstad, M., Toska, K., 
Evans, J. M., \& Eckberg, D. L. (2006). Cardiovascular variability is/is not an index of autonomic control of circulation. Journal of Applied Physiology, 101(2):690-691.

Parati, G., Saul, J. P., Di Rienzo, M., \& Mancia, G. (1995). Spectral analysis of blood pressure and heart rate variability in evaluating cardiovascular regulation. A critical appraisal. Hypertension, 25(June 1995):1276-1286.

Perini, R. \& Veicsteinas, A. (2003). Heart rate variability and autonomic activity at rest and during exercise in various physiological conditions. European Journal of Applied Physiology, 90(3-4):317-325.

Platisa, M. M. \& Gal, V. (2006). Reflection of heart rate regulation on linear and nonlinear heart rate variability measures. Physiological measurement, 27(2):145-154.

R Core Team (2013). R: A Language and Environment for Statistical Computing.

Rassias, A. J., Holzberger, P. T., Givan, A. L., Fahrner, S. L., \& Yeager, M. P. (2005). Decreased physiologic variability as a generalized response to human endotoxemia. Critical care medicine, 33(3):512-519.

Sandercock, G. R. H. \& Brodie, D. a. (2006). The use of heart rate variability measures to assess autonomic control during exercise. Scandinavian Journal of Medicine and Science in Sports, 16(5):302-313.

Stein, P. K., Domitrovich, P. P., Huikuri, H. V., \& Kleiger, R. E. (2005). Traditional and nonlinear heart rate variability are each independently associated with mortality after myocardial infarction. Journal of Cardiovascular Electrophysiology, 16(1):13-20.

Task Force of the European Society of Cardiology and the North American Society of Pacing and Electrophysiology (Task Force) (1996). Heart rate variability: standards of measurement, physiological interpretation and clinical use. Task Force of the European 
Society of Cardiology and the North American Society of Pacing and Electrophysiology. Circulation, 93(5):1043-1065. 


\section{Capítulo 6}

\section{Conclusões}

Essa tese investigou a influência de alterações associadas com a corrida no controle cardíaco e possibilitou as seguintes conclusões.

A a1ApEn é uma ferramenta robusta, consistente e com um tempo computacional adequado, sendo uma abordagem adequada para caracterizar séries temporais. Adicionalmente, a complexidade cardíaca obtida com essa forma de análise é capaz de identificar estados fisiológicos de maneira mais consistente que ferramentas no domínio da frequência.

Em relação ao efeito agudo da corrida na variabilidade cardíaca (VC) e na complexidade cardíaca (CC), temos que: 1) as inconsistências encontradas na literatura estão associadas às diferenças nos protocolos experimentais e analíticos; 2) a VC e a CC se correlacionam, de maneira geral, positivamente com a frequência cardíaca; 3) O protocolo com velocidades crescentes soma os efeitos da velocidade e do tempo nos estimadores e, assim, é o mais adequado ao estudo dessa correlação; 4) Em tal protocolo, uma correlação negativa entre a1ApEn-CC e frequência cardíaca está associada com sedentarismo; 5) Dessa maneira, a inclinação da regressão linear entre complexidade cardíaca e frequência cardíaca é uma abordagem eficaz para diferenciar estados fisiológicos.

O estudo da correlação dos estimadores de controle cardíaco com a frequência cardíaca 
em maratonistas permitiu concluir que complexidade cardíaca obtida via a1ApEn é capaz de discernir maratonistas em função do tempo de treinamento para provas de longa duração.

Finalmente, para os casos nos quais os experimentos eram realizados em velocidade constante, existe um componente oscilatório nos resultados tanto de HF-VC quanto de CC. Esse componente é mais proeminente para CC e está, potencialmente, associado com fatores termorregulatórios.

Em relação à tese como um todo, temos que as abordagens propostas foram capazes de não apenas trazer diversas informações novas sobre as alterações associadas com a corrida no controle cardíaco mas, também, introduzir metologias com grande potencial em outros contextos. 
Apêndice A

Area Apen, and pApEn for 19

time-series 


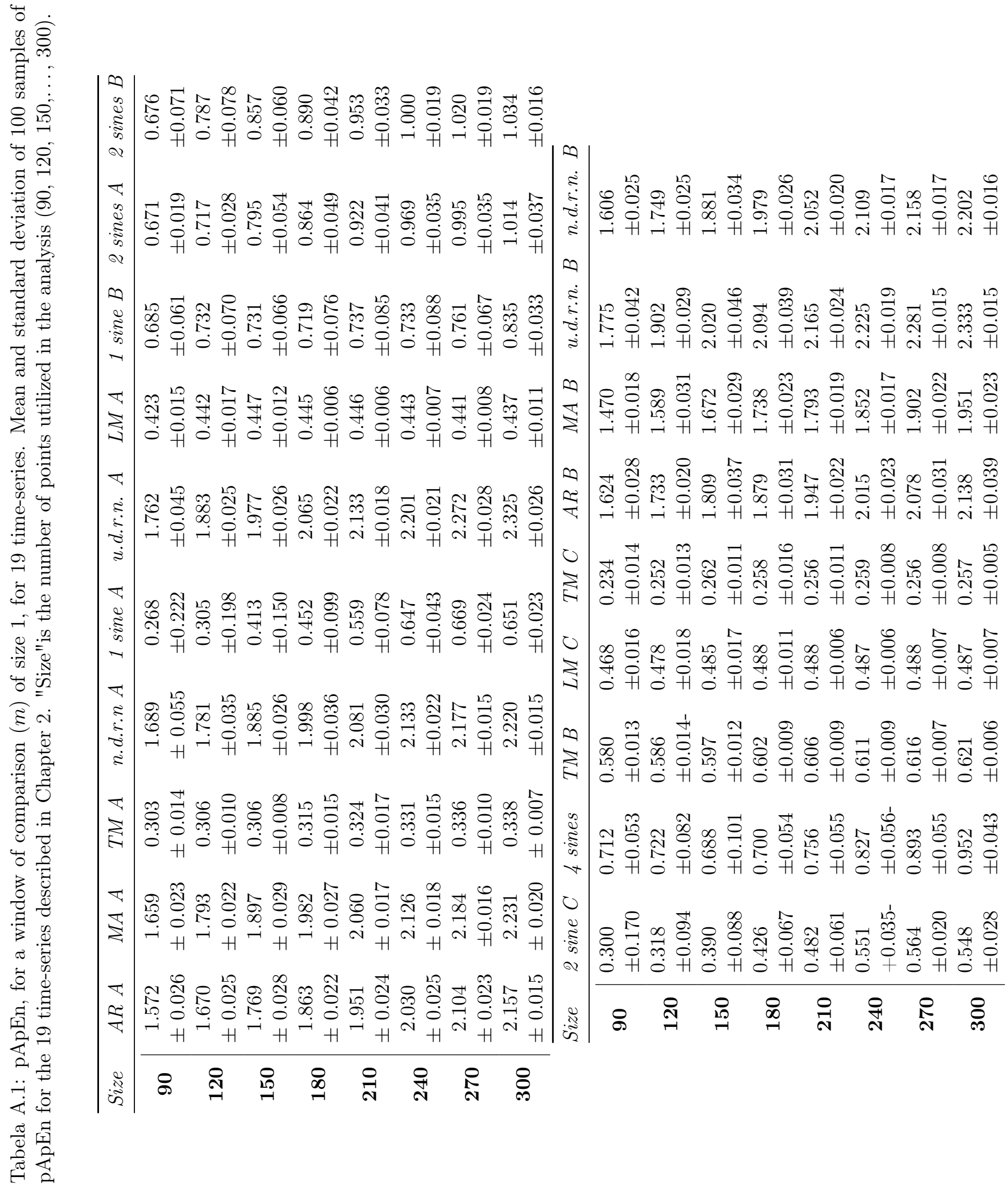


Apêndice A. Area Apen, and pApEn for 19 time-series

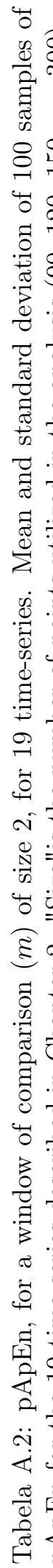

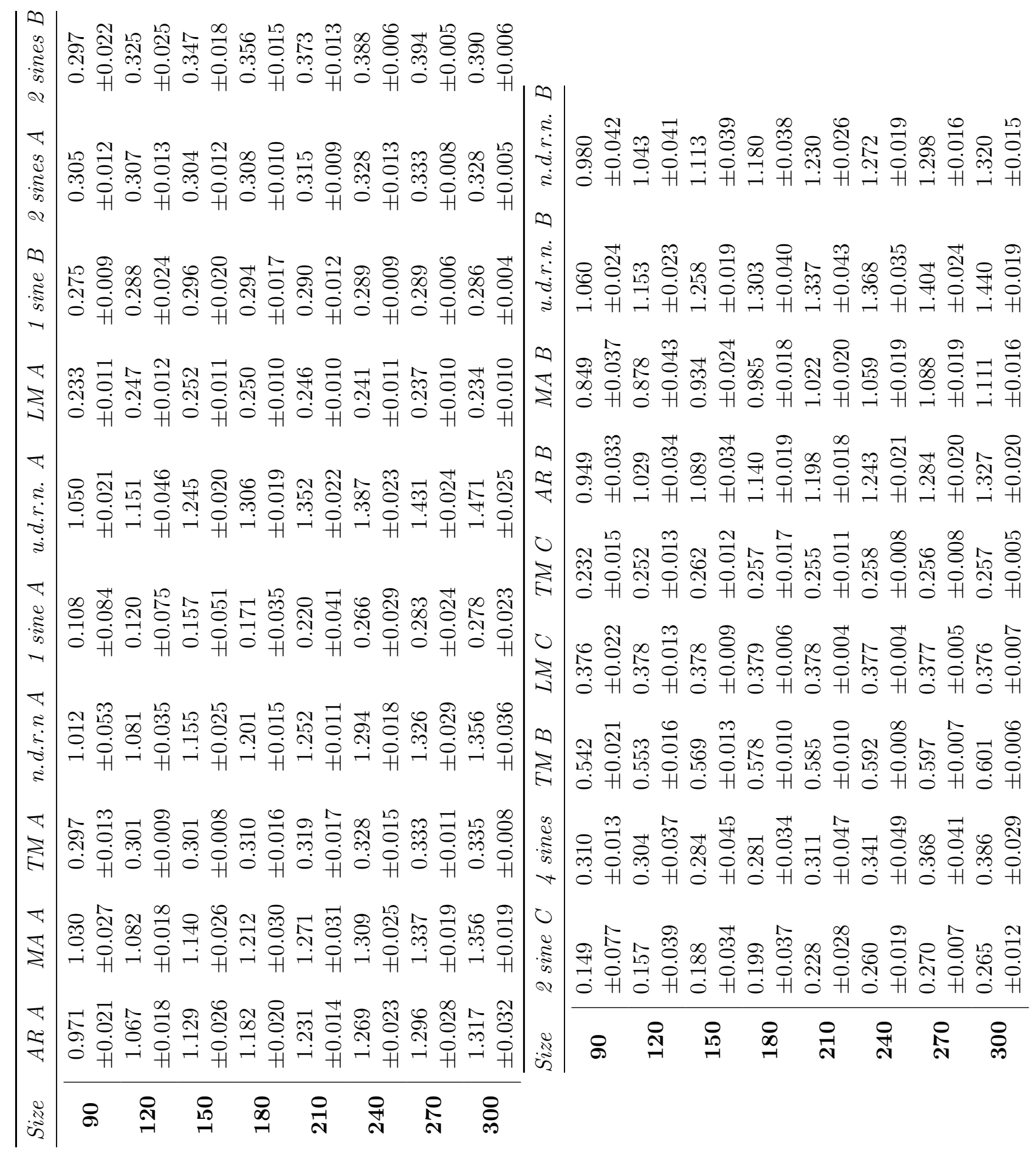




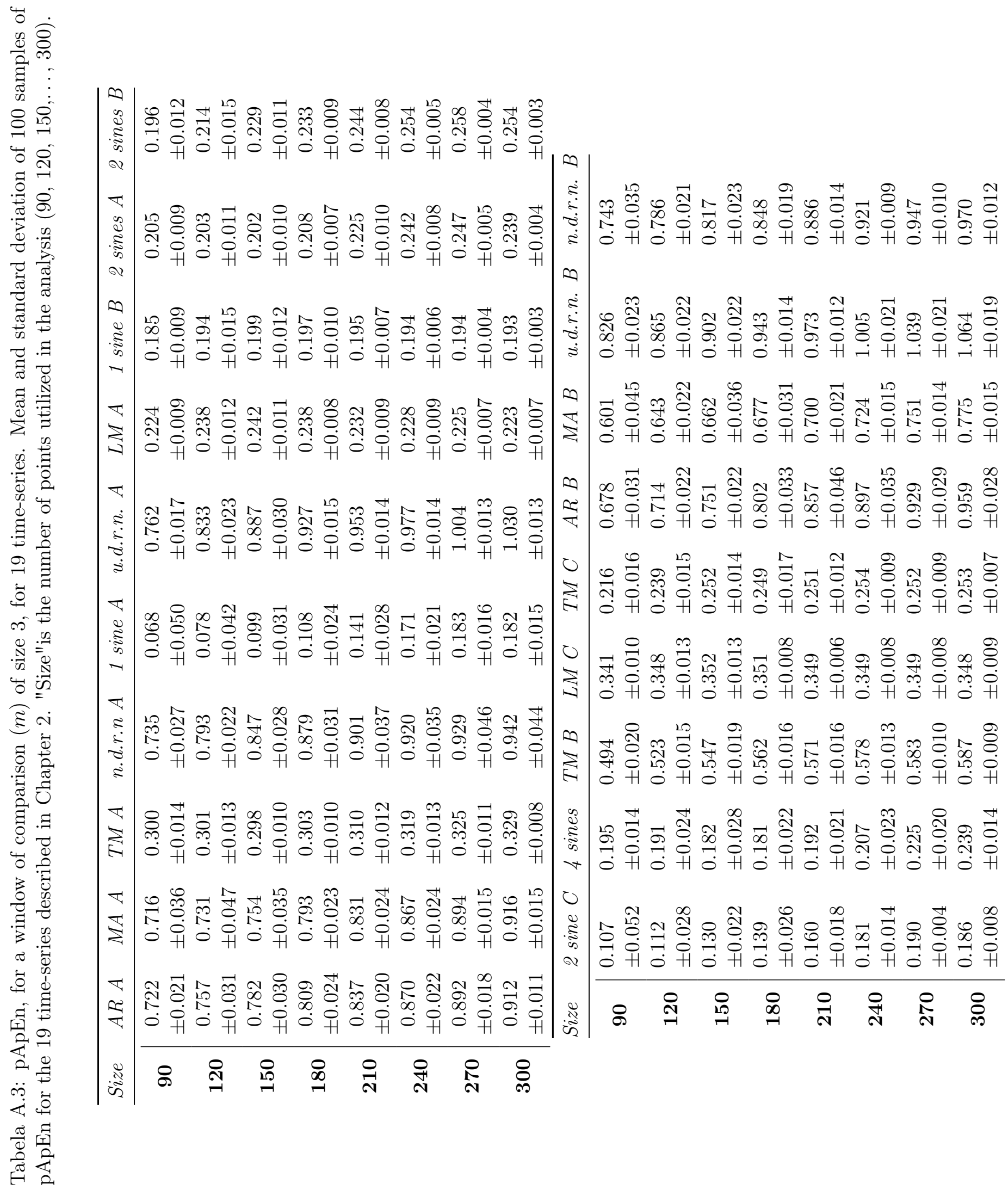


Apêndice A. Area Apen, and pApEn for 19 time-series

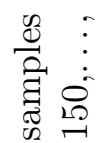

○

पै

ㅎㅇ

$\cdot \frac{\pi}{0.0}$

胥

䒕

刍

证

ชี

:

$\sum^{\mathbb{E}}$

मे

है

$\frac{\pi}{0}$

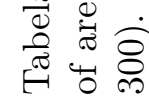




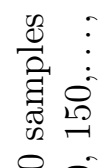

ᄋ

पै

a

.

気

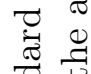

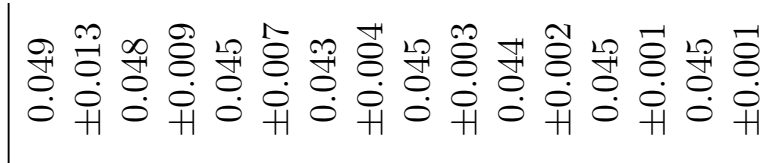

용

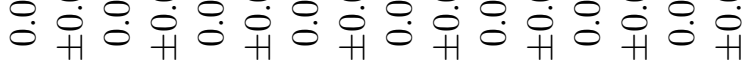

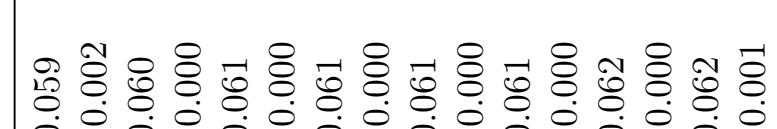

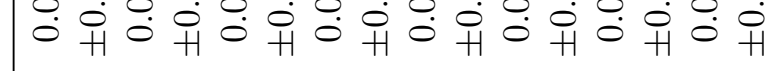

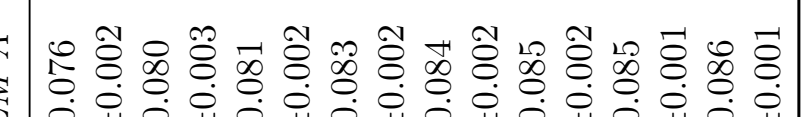
$\rightarrow$

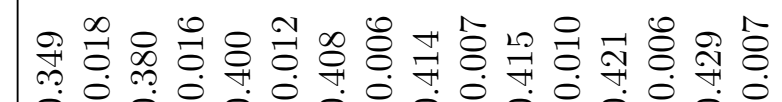

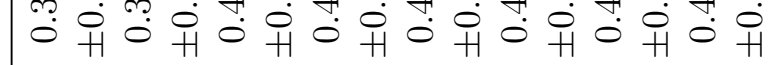

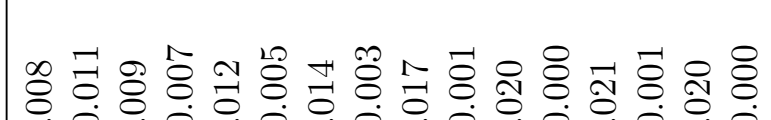

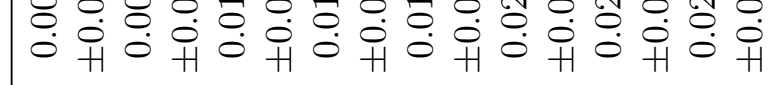

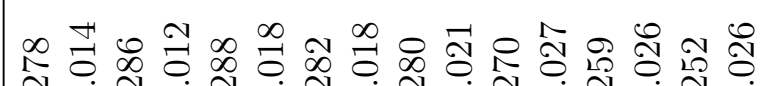
永

స

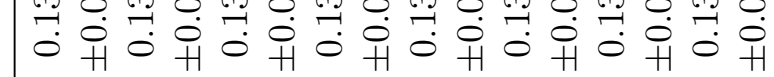

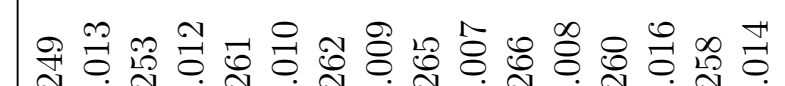

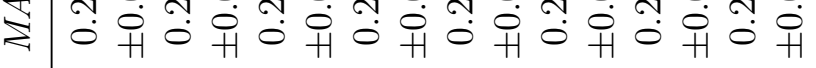

『

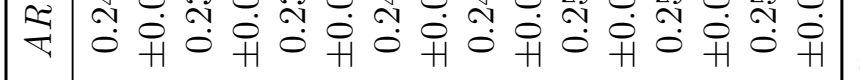

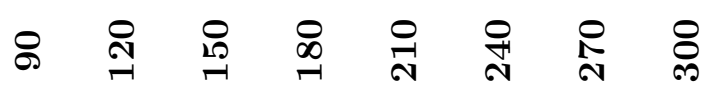

幽

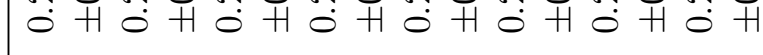

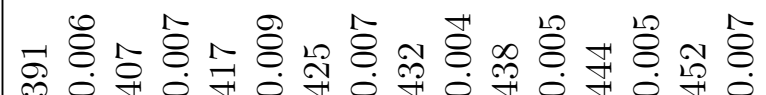
品

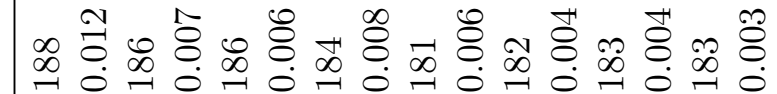
0 H $\dot{0}$ H $\dot{0}$ H $\dot{0}$ H $\dot{0}$ H $\dot{0}$ H $\dot{0}$ H

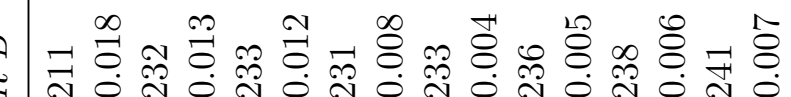

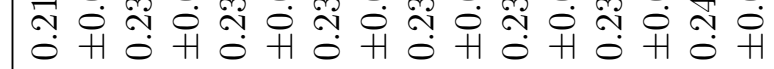

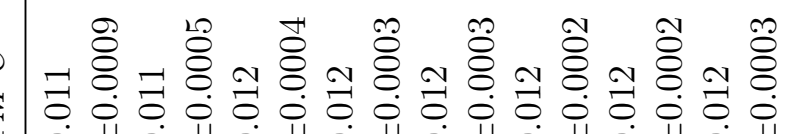

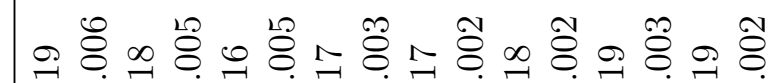

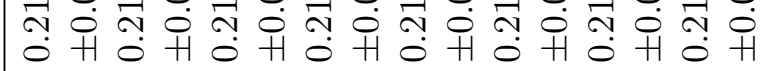

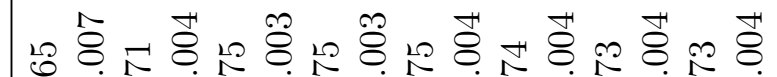
峲

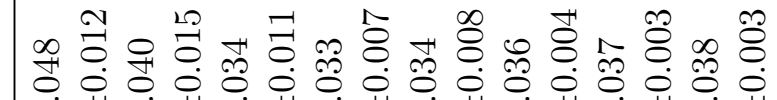

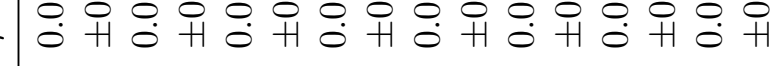

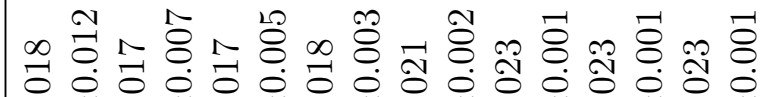
完 $\begin{aligned} & 0 \\ & 0\end{aligned}$

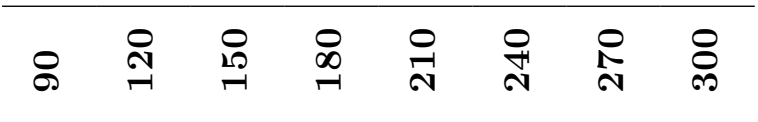


Apêndice A. Area Apen, and pApEn for 19 time-series

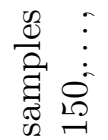

○

पै

๐

䨔

昰

䒕

胥

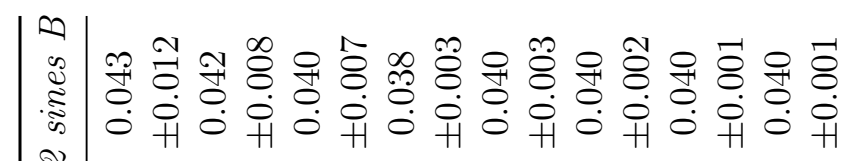

है:

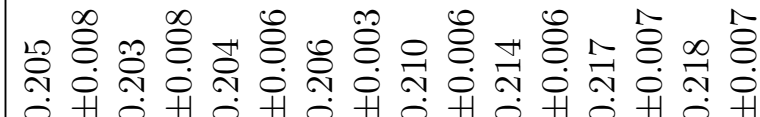

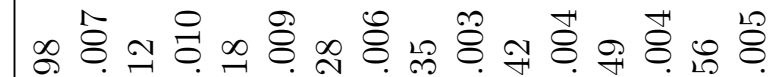

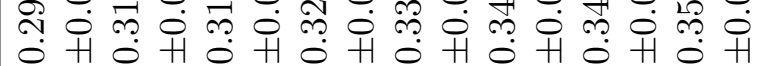

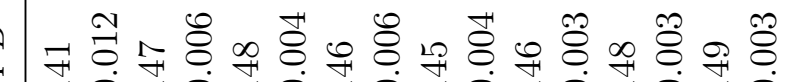

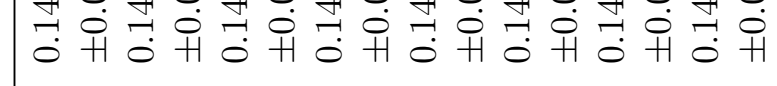

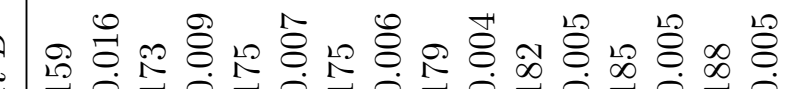

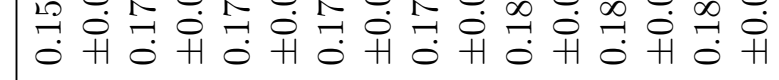

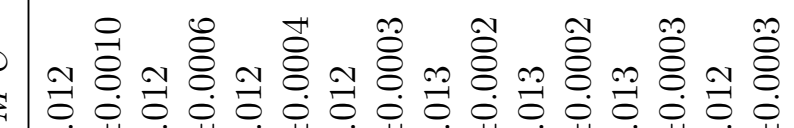

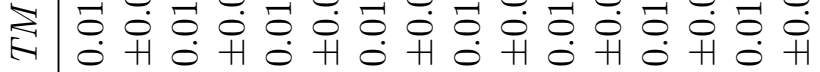

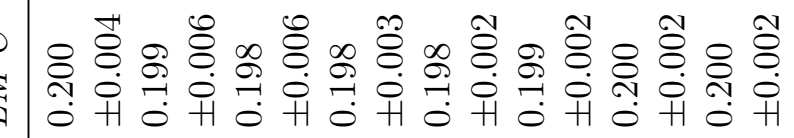

$\approx \pi$

离离 